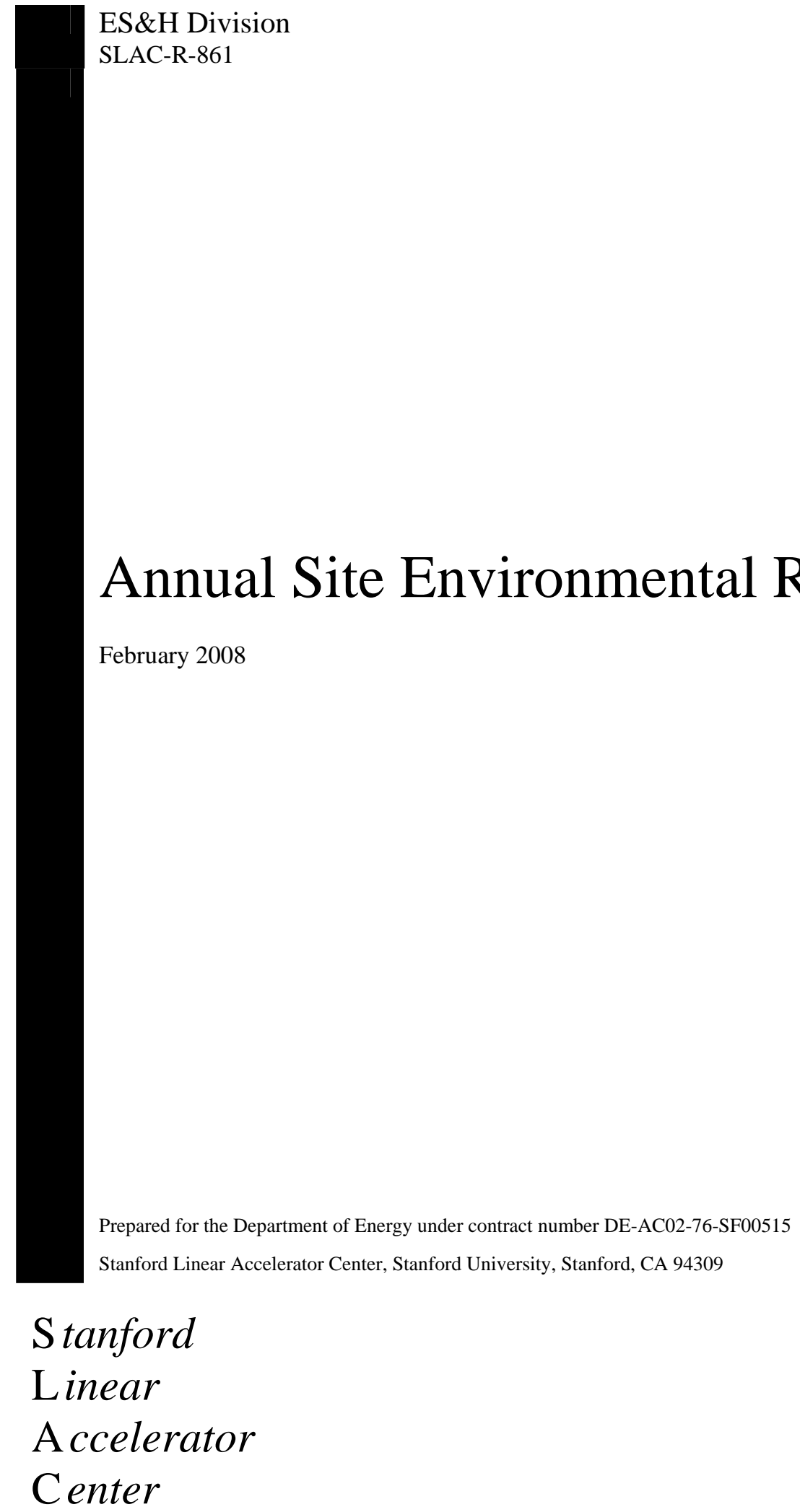

ES\&H Division

SLAC-R-861

\title{
Annual Site Environmental Report: 2006
}

February 2008

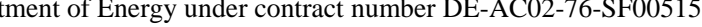




\section{Disclaimer}

This document, and the material and data contained therein, was developed under sponsorship of the United States Government. Neither the United States nor the Department of Energy, nor the Leland Stanford Junior University, nor their employees, makes any warranty, express or implied, or assumes any liability or responsibility for accuracy, completeness, or usefulness of any information, apparatus, product, or process disclosed, or represents that its use will not infringe privately owned rights. Mention of any product, its manufacturer, or suppliers will not, nor is it intended to, imply approval, disapproval, or fitness for any particular use. A royalty-free, non-exclusive right to use and disseminate same, for any purpose whatsoever, is expressly reserved to the United States and the university.

\section{Publication Data}

This document was designed and published by Environmental Safety \& Health (ES\&H) Division Publishing

Document Title: Annual Site Environmental Report: 2006

Original Publication Date: February 2008

Original Source: ES\&H Division

Document Number: SLAC-R-861

Prepared for the United States Department of Energy (DOE) under contract DE-AC02-76-SF00515

This report is available on line at http://www.slac.stanford.edu/pubs/slacreports/slac-r-861.html. Printed copies can be obtained by DOE employees and contractors from the Office of Scientific and Technical Information, PO Box 62, Oak Ridge, TN 37831 and by the public from the National Technical Information Service, US Department of Commerce, 5285 Port Royal Road, Springfield, VA 22161.

Comments on the report may be sent to

ES\&H Publishing Coordinator

eshpubs@slac.stanford.edu

Mailstop 84

Stanford Linear Accelerator Center

2575 Sand Hill Road

Menlo Park, CA 94025

Additional information about Stanford Linear Accelerator Center is available at http://www.slac.stanford.edu/ 


\section{U.S. Department of Energy \\ Office of Science \\ Stanford Site Office \\ 2575 Sand Hill Road, MS-8A \\ Menlo Park, CA 94025}

October 10, 2007

SUBJECT: 2006 Annual Site Environmental Report (ASER) for the Stanford Linear

Accelerator Center (SLAC)

This report, prepared by SLAC for the U.S. Department of Energy, Stanford Site Office (SSO), provides a comprehensive summary of the environmental program activities at SLAC for calendar year 2006. Annual Site Environmental Reports (ASERs) are prepared for all DOE sites with significant environmental activities, and distributed to relevant external regulatory agencies and other interested organizations or individuals.

To the best of my knowledge, this report accurately summarizes the results of the 2006 environmental monitoring, compliance, and restoration programs at SLAC. This assurance can be made based on SSO and SLAC review of the ASER, and quality assurance protocols applied to monitoring and data analyses at SLAC.

Any questions or comments regarding this report may be directed to Dave Osugi of the SSO at (650) 926-3305, or by mail to the address above.

Sincerely,

Paul M. Golan

Site Manager

Stanford Site Office 


\section{Certification of Accuracy}

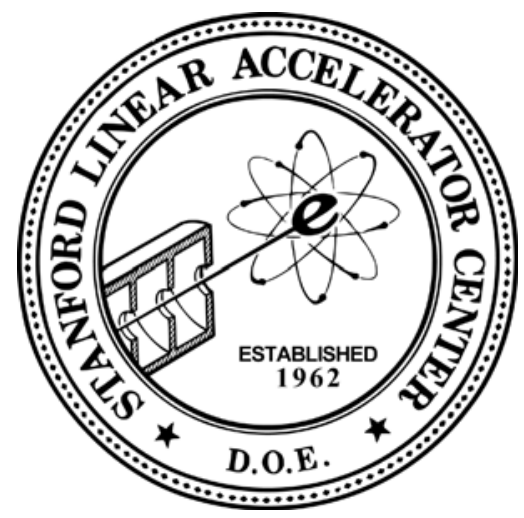

Annual Site Environmental Report

January - December 2006

SLAC-R-861

Stanford Linear Accelerator Center

I certify that the information submitted herein is current for the reporting period, accurate, and complete, based on my familiarity with the information and my inquiry of those individuals immediately responsible for obtaining the information.

Sayed Rokni

Date $\underline{9 / 26 / 2007}$

Acting Associate Director

Environment, Safety, and Health Division 


\section{Contents}

Disclaimer

Publication Data

Contents

Figures

Tables

vi

Appendices

vii

Preface

viii

Organization

viii

Contributors

ix

Primary Coordinators and Authors

ix

Additional Authors

ix

Editing and Publishing

Acronyms

$\mathrm{x}$

Executive Summary

ES-1

1 Site Overview

1-1

1.1 Introduction

1-1

1.1.1 SLAC Mission

1-1

1.1.2 Research Program

$1-1$

1.2 Location

1-3

1.3 Geology

$1-3$

$1.4 \quad$ Climate

$1-4$

1.5 Land Use

1-4

1.6 Water Supply

$1-5$

1.7 Demographics

$1-5$

2 Environmental Compliance

2-1

2.1 Introduction

2-1

2.2 Regulatory Framework

2-1

2.3 Environmental Permits and Notifications

$2-1$

2.4 Environmental Incidents

$2-2$

2.4.1 Non-radiological Incidents

$2-2$

2.4.2 Radiological Incidents

$2-2$ 
2.5 Assessments, Inspections and Quality Assurance 2-2

2.5.1 Assessments 2-2

2.5.2 Inspections $2-3$

2.5.3 Quality Assurance 2-3

2.6 Environmental Performance Measures 2-4

3 Management Systems 3-1

3.1 Introduction 3-1

3.2 SLAC Organization 3-1

3.3 ES\&H Division Organization 3-1

3.3.1 Environmental Protection 3-1

3.3.2 Fire Department 3-1

3.3.3 Radiation Protection $3-2$

3.3.4 Chemical and General Safety 3-2

3.3.5 Medical Department 3-2

3.3.6 Knowledge Management 3-2

3.4 Integrated Safety and Environmental Management System $\quad 3-2$

3.4.1 Safety and Environmental Management System 3-2

3.4.2 Work Smart Standards 3-3

3.4.3 Environmental Performance Measures 3-3

3.4.4 Training 3-3

3.5 Environmental Management System 3-3

4 Environmental Non-radiological Programs $4-1$

4.1 Introduction 4-1

4.2 Air Quality Management Program 4-2

4.2.1 Regulatory Framework 4-2

4.2.2 Program Status 4-2

4.2.3 Summary and Future Plans $\quad$ 4-6

4.3 Industrial and Sanitary Wastewater Management Program 4-6

4.3.1 Regulatory Framework 4-7

4.3.2 Program Status 4-8

4.3.3 Summary and Future Plans $\quad$ 4-11

4.4 Surface Water Management Program 4-11

4.4.1 Regulatory Framework 4-11

4.4.2 Program Status $\quad$ 4-12

4.4.3 Summary and Future Plans $\quad$ 4-14 
4.5 Hazardous Materials Management 4-14

4.5.1 Regulatory Framework $\quad$ 4-15

4.5.2 Program Status 4-15

4.5.3 Hazardous Materials Business Plan Program 4-16

4.5.4 Toxics Release Inventory Program 4-16

4.5.5 California Accidental Release Prevention Program 4-17

4.5.6 Aboveground Storage Tank Program 4-17

4.5.7 Toxic Substances Control Act Program 4-18

4.5.8 Chemical Management System 4-18

4.6 Waste Minimization and Management 4-19

4.6.1 Waste Minimization Accomplishments 4-19

4.6.2 Hazardous Waste Management 4-23

4.6.3 Non-hazardous Waste Management 4-25

4.6.4 Other Waste Management Activities 4-26

4.7 Environmental Planning 4-27

4.7.1 SLAC Long Range Development Plan 4-27

4.7.2 National Environmental Policy Act 4-27

5 Environmental Radiological Program 5-1

5.1 Introduction 5-1

$5.2 \quad$ Sources of Radiation and Radioactivity 5-1

5.3 Monitoring for Direct Radiation 5-2

5.4 Assessment of Airborne Radioactivity 5-2

5.5 Assessment of Radioactivity in Water 5-3

5.5.1 Industrial Water 5-3

5.5.2 Stormwater 5-5

5.5.3 Groundwater 5-5

5.6 Assessment of Radioactivity in Soil $\quad$ 5-6

5.7 Release of Property Containing Residual Radioactive Material 5-6

5.8 Potential Dose to the Public 5-7

5.9 Biota Dose 5-7

5.9.1 Dose to Biota from Direct Radiation 5-8

5.9.2 Dose to Biota from Activation Products $\quad 5-8$

5.10 Low-level Radioactive Waste Management $\quad$ 5-9

6 Groundwater Protection and Environmental Restoration 6-1

6.1 Introduction 6-1 
6.2 Background Conditions 6-1

6.3 Areas with Potential Impact from Chemicals 6-1

6.4 Strategies for Controlling Potential Sources of Chemicals 6-2

6.5 Restoration Activities 6-2

6.5.1 Regulatory Framework 6-3

6.6 Groundwater Characterization Monitoring Network 6-3

6.7 Site Descriptions and Results 6-8

6.7.1 Former Solvent Underground Storage Tank 6-8

6.7.2 Former Hazardous Waste Storage Area 6-8

6.7.3 Plating Shop 6-9

6.7.4 Test Lab and Central Lab 6-10

6.7.5 Beam Dump East 6-10

$\begin{array}{lll}\text { 6.7.6 Lower Salvage Yard } & 6.10\end{array}$

6.7.7 IR-6 and IR-8 Drainage Channels $\quad$ 6-10

6.7.8 Excavation Clearance Program 6-11 


\section{Figures}

Figure 1-1 SLAC Site Location $\quad$ 1-2

Figure 1-2 Site Area General Geographic and Geologic Setting 1-4

Figure 4-1 Industrial and Sanitary Wastewater Monitoring Locations $\quad$ 4-8

Figure 4-2 Water Quality at the Sand Hill Road Station 4-9

Figure 4-3 Surface Water Monitoring Locations $\quad$ 4-12

Figure 4-4 Hazardous Waste Generation, 1996-2006 4-20

Figure 4-5 Municipal Solid Waste Recycling, 1996-2006 4-21

Figure 4-6 TSCA-Regulated Hazardous Waste, 1996-2006 4-24

Figure 4-7 Municipal Solid Waste Recycling and Disposal, 1996-2006 4-26

Figure 6-1 Groundwater Characterization Monitoring Network 6-4

Figure 6-2 Westside Groundwater Network and Impacted Areas 6-5

Figure 6-3 Eastside Groundwater Network and Impacted Areas 6-5 


\section{Tables}

Table 1-1 Populations of Communities near SLAC 1-6

Table 2-1 General Permits Held by SLAC 2-1

Table 2-2 Environmental Audits and Inspections $\quad$ 2-3

Table 4-1 Recent Environmental Awards $\quad$ 4-1

Table 4-2 Halogenated Solvent Cleaning Sources Subject to NESHAPs 4-5

Table 4-3 Water Quality at the Sand Hill Road Station 4-9

Table 4-4 Water Quality at the Metal Finishing Pre-treatment Facility 4-10

Table 4-5 Water Quality Results and Comparison to Parameter Benchmark Values 4-14

Table 4-6 Aboveground Petroleum Tanks 4-17

Table 4-7 Waste Minimization and Pollution Prevention Projects 4-22

Table 4-8 Hazardous Waste Treatment Units Subject to Tiered Permitting 4-25

Table 4-9 NEPA Documentation Prepared during $2006 \quad$ 4-28

Table 5-1 Activation Products in Water or Air 5-2

Table 5-2 Airborne Radioactivity Released in $2006 \quad$ 5-3

Table 5-3 Radioactivity in Wastewater Released in $2006 \quad 5-4$

Table 5-4 Summary of Radioactivity in SLAC Wastewater, 1996-2006 5-5

Table 5-5 Summary of Tritium $\left({ }^{3} \mathrm{H}\right)$ Concentrations Measured in Monitoring Wells in 2006 5-6

Table 5-6 Summary of Potential Annual Doses due to SLAC Operations in $2006 \quad$ 5-7

Table 5-7 Potential Dose (mrem) to Maximally Exposed Individual, 1997-2006 5-8

Table 6-1 Monitoring Locations and Number of Wells $\quad$ 6-7 


\section{Appendices}

A Distribution List 


\section{Preface}

To satisfy the requirements of the United States Department of Energy Order 231.1, "Environment, Safety and Health Reporting", the Environment, Safety, and Health Division of the Stanford Linear Accelerator Center prepares an annual report describing its environmental programs and activities.

This Annual Site Environmental Report:2006 summarizes the Stanford Linear Accelerator compliance with standards and requirements, describes the management and monitoring systems in place, and highlights significant accomplishments for the year.

\section{Organization}

The report is published in a single volume, organized into the following chapters:

- Chapter 1, "Site Overview", describes the environmental setting of the Stanford Linear Accelerator Center and the activities conducted at the site

- Chapter 2, "Environmental Compliance”, gives an account of the regulatory framework and results concerning the site's environmental programs

- Chapter 3, "Management Systems", outlines the organizational structure, methods, and responsibilities relevant to environmental programs

- Chapters 4, 5, and 6, respectively "Environmental Non-radiological Programs”, "Environmental Radiological Programs", and "Groundwater Protection and Environmental Restoration", give more detailed accounts of the programs and their results for the year

An executive summary provides an overview of the report. 


\section{Contributors}

This report was prepared under the direction of Helen Nuckolls, ES\&H Division, Environmental Protection Department.

\section{Primary Coordinators and Authors}

- Rich Cellamare (Chapter 4)

- Judy Fulton (Chapter 4)

- Steve Frey (Chapter 3)

- Darrin Gambelin (Chapter 4)

- Mike Hug (Chapter 4)

- Adam Ng (Chapter 6)

- Dellilah Sabba (executive summary, Chapters 1, 2 and 6)

- Kirk Stoddard (Chapter 4)

- Henry Tran (Chapter 5)

\section{Additional Authors}

- Elizabeth Dahlen

- Helen Nuckolls

- Susan Witebsky

\section{Editing and Publishing}

ES\&H Division Publishing edited and published this report; SLAC Technical Publications provided electronic publishing and printing support. 


\begin{tabular}{|c|c|}
\hline ASER & annual site environmental report \\
\hline AST & aboveground storage tank \\
\hline BAAQMD & Bay Area Air Quality Management District \\
\hline BaBar & SLAC B Factory detector \\
\hline $\mathrm{BDE}$ & beam dump east \\
\hline BMP & best management practice \\
\hline CalARP & California Accidental Release Prevention Program \\
\hline CEF & Conventional and Experimental Facilities Department \\
\hline CERCLA & Comprehensive Environmental Response, Compensation, and Liability Act \\
\hline CFR & Code of Federal Regulations \\
\hline $\mathrm{Ci}$ & curie \\
\hline CMS & chemical management system \\
\hline CUPA & certified unified program agency \\
\hline CWA & Clean Water Act \\
\hline $\mathrm{CX}$ & categorical exclusion \\
\hline CY & calendar year \\
\hline DOE & United States Department of Energy \\
\hline DPE & dual phase extraction \\
\hline DTSC & California Department of Toxic Substances Control \\
\hline DWS & drinking water standard \\
\hline EA & environmental assessment \\
\hline EBR & Environmental Baseline Report \\
\hline EIS & environmental impact statement \\
\hline EMS & environmental management system \\
\hline EPCRA & Emergency Planning and Community-Right-to-Know Act \\
\hline EP & Environmental Protection Department \\
\hline ES\&H & environment, safety, and health \\
\hline ESHAC & ES\&H Advisory Committee \\
\hline FFTB & Final Focus Test Beam \\
\hline FHWSA & Former Hazardous Waste Storage Area \\
\hline
\end{tabular}




\begin{tabular}{|c|c|}
\hline FMS & flow metering station \\
\hline FSUST & Former Solvent Underground Storage Tank Area \\
\hline FY & fiscal year \\
\hline GDF & gasoline dispensing facility \\
\hline GHG & greenhouse gas \\
\hline GLAST & Gamma Ray Large Area Space Telescope \\
\hline gpd & gallons per day \\
\hline GSA & United States General Services Administration \\
\hline H-134a & tetrafluoroethane \\
\hline HAPs & hazardous air pollutants \\
\hline Haas & Haas tcm \\
\hline HMBP & hazardous materials business plan \\
\hline HVAC & heating, ventilation, and air conditioning \\
\hline IDPE & interim dual phase extraction \\
\hline IR & interaction region \\
\hline ILC & International Linear Collider \\
\hline INL & Idaho National Laboratory \\
\hline ISEMS & integrated safety and environmental management system \\
\hline ISM & integrated safety management \\
\hline JRBP & Jasper Ridge Biological Preserve \\
\hline $\mathrm{km}$ & kilometer \\
\hline $\mathrm{L}$ & liter \\
\hline lbs & pounds \\
\hline linac & linear accelerator \\
\hline LCLS & Linac Coherent Light Source \\
\hline LLRW & low-level radioactive waste \\
\hline LRDP & long-range development plan \\
\hline LSTs & limited streamer tubes \\
\hline LSY & lower salvage yard \\
\hline $\mathrm{m}$ & meter \\
\hline $\mathrm{M} \& \mathrm{O}$ & management and operating \\
\hline MEI & maximally exposed individual \\
\hline MFPF & metal finishing pre-treatment facility \\
\hline $\mathrm{mg} / \mathrm{L}$ & milligrams per liter \\
\hline
\end{tabular}




\begin{tabular}{|c|c|}
\hline MGE & Main Gate East Channel \\
\hline MPMWD & Menlo Park Municipal Water Department \\
\hline MRA & maintenance removal action \\
\hline mrem & millirem \\
\hline $\mathrm{mSv}$ & milli Sievert \\
\hline NAE & North Adit East Channel \\
\hline NEPA & National Environmental Policy Act \\
\hline NESHAPs & National Emission Standards for Hazardous Air Pollutants \\
\hline NOV & notice of violation \\
\hline ODS & ozone-depleting substance \\
\hline $\mathrm{OIO}$ & Office of Independent Oversight \\
\hline PBR & permit by rule \\
\hline PBV & parameter benchmark value \\
\hline PCB & polychlorinated biphenyl \\
\hline $\mathrm{pCi}$ & picoCuries \\
\hline $\mathrm{pCi} / \mathrm{L}$ & picoCuries per liter \\
\hline PEP & Positron-Electron Project \\
\hline ppd & pounds per day \\
\hline ppm & parts per million \\
\hline PPOA & pollution prevention opportunity assessments \\
\hline QA & quality assurance \\
\hline QC & quality control \\
\hline RCA & reportable compliance activities \\
\hline RCRA & Resource Conservation and Recovery Act \\
\hline RI & remedial investigation \\
\hline RMP & risk management plan \\
\hline $\mathrm{RP}$ & Radiation Protection Department \\
\hline RWQCB & regional water quality control board \\
\hline SARA & Superfund Amendments and Reauthorization Act \\
\hline SBSA & South Bayside System Authority \\
\hline $\mathrm{SF}_{6}$ & sulfur hexafluoride \\
\hline SLAC & Stanford Linear Accelerator Center \\
\hline SMOP & synthetic minor operating permit \\
\hline SMP & self-monitoring program \\
\hline
\end{tabular}




$\begin{array}{ll}\text { SPCC } & \text { spill prevention control and countermeasures } \\ \text { SPEAR } & \text { Stanford Positron-Electron Asymmetric Ring } \\ \text { SSO } & \text { DOE Stanford Site Office } \\ \text { SSRL } & \text { Stanford Synchrotron Radiation Laboratory } \\ \text { SVOCs } & \text { semi-volatile organic compounds } \\ \text { SWMP } & \text { stormwater monitoring program } \\ \text { SWPPP } & \text { stormwater pollution prevention plan } \\ \text { SWRCB } & \text { State Water Resources Control Board } \\ \text { TCA } & 1,1,1-\text { trichloroethane } \\ \text { TDS } & \text { total dissolved solids } \\ \text { TL/CL } & \text { Test Lab and Central Lab Area } \\ \text { TPH } & \text { total petroleum hydrocarbons } \\ \text { TRI } & \text { toxics release inventory } \\ \text { TSCA } & \text { Toxic Substances Control Act } \\ \text { TSS } & \text { total suspended solids } \\ \text { Unidocs } & \text { Uniform documents } \\ \text { USEPA } & \text { United States Environmental Protection Agency } \\ \text { UST } & \text { Wolatile organic compounds } \\ \text { VOCs } & \text { West Bay Sanitary District } \\ \text { WBSD } & \text { Waste Management Group } \\ \text { WSS } & \text { Work Smart Standard } \\ \text { WTing system }\end{array}$




\section{Executive Summary}

This report provides information about environmental programs during the calendar year (CY) of 2006 at the Stanford Linear Accelerator Center (SLAC), Menlo Park, California. Activities that span the calendar year; i.e., stormwater monitoring covering the winter season of 2006/2007 (October 2006 through May 2007), are also included.

Production of an annual site environmental report (ASER) is a requirement established by the United States Department of Energy (DOE) for all management and operating (M\&O) contractors throughout the DOE complex. SLAC is a federally-funded research and development center with Stanford University as the $\mathrm{M} \& \mathrm{O}$ contractor.

SLAC continued to follow the path to self-declare an environmental management system under DOE Order 450.1, "Environmental Protection Program" and effectively applied environmental management in meeting the site's integrated safety and environmental management system goals. For normal daily activities, all SLAC managers and supervisors are responsible for ensuring that proper procedures are followed so that

- Worker safety and health are protected

- The environment is protected

- Compliance is ensured

Throughout 2006, SLAC focused on these activities through the SLAC management systems. These systems were also the way SLAC approached implementing "greening of the government" initiatives such as Executive Order 13148. The management systems at SLAC are effective, supporting compliance with all relevant statutory and regulatory requirements. The SLAC Office of Assurance was created during 2006 in response to DOE Order 226.1.

During 2006, there were no reportable releases to the environment from SLAC operations, and there were no Notice of Violations issued to SLAC from any of the regulatory agencies that oversee SLAC. In addition, many improvements in waste minimization, recycling, stormwater drain system, groundwater restoration, and SLAC's chemical management system (CMS) were continued during 2006 to better manage chemical use. Program-specific details are discussed below.

SLAC operates its air quality management program in compliance with its established permit conditions. The Bay Area Air Quality Management District (BAAQMD) did not conduct a facility inspection of SLAC during 2006, though it did visit the site on four different occasions. The BAAQMD did compliment SLAC for the overall configuration of SLAC's gasoline dispensing facility and of SLAC's asbestos/demolition notification program during two of the visits.

DOE awarded SLAC the 2006 Best in Class for Pollution Prevention and Environmental Stewardship Accomplishment in recognition of SLAC's CMS program which manages the procurement and use of chemicals. As an example of the efficiency of the CMS, SLAC reviewed its use of gasses and associated tanks and phased out numerous gas tanks that were no longer needed or were not acceptable for long-term storage, in turn, reducing SLAC’s on-site chemical inventory. 
As part of SLAC's waste minimization and management efforts, more than one thousand tons of municipal solid waste was recycled by SLAC during 2006.

SLAC operates its industrial and sanitary wastewater management program in compliance with established permit conditions. During 2006, SLAC obtained a new facility-wide wastewater discharge permit which replaced four separate permits that were previously issued to SLAC.

In 2006, no radiological incidents occurred that increased radiation levels or released radioactivity to the environment. In addition to managing its radioactive wastes safely and responsibly, SLAC worked to reduce the amount of waste generated. SLAC has implemented programs and systems to ensure compliance with all radiological requirements related to the environment.

The Environmental Restoration Program continued work on site characterization and evaluation of remedial alternatives at four sites with volatile organic compounds in groundwater and several areas with polychlorinated biphenyls and low concentrations of lead in soil. SLAC is regulated under a site cleanup requirements order (board order) issued by the California Regional Water Quality Control Board, San Francisco Bay Region (RWQCB) for the investigation and remediation of impacted soil and groundwater at SLAC. The new board order lists specific tasks and deadlines for groundwater and soil remedial investigation. All 2006 submittals to the board were completed on time. 


\section{Site Overview}

This chapter describes the environmental setting of SLAC and the activities conducted at the site.

For an overview of site environmental planning, including descriptions of environmental resources, see the long-range development plan (LRDP) prepared in 2002 (revised June 2003). ${ }^{1}$

\subsection{Introduction}

SLAC is a national research laboratory operated by Stanford University under contract to the DOE. SLAC is located on the San Francisco Peninsula, about halfway between San Francisco and San Jose, California (see Figure 1-1). Current research and scientific user facilities are in areas of photon science, particle physics, and particle astrophysics. Six scientists have been awarded the Nobel Prize for work carried out at SLAC and there are 10 members of its faculty in the National Academies.

The majority of SLAC funding comes from DOE Office of Science, with smaller contributions from National Aeronautics and Space Administration, National Institute of Health, and other federal and nonfederal sources.

\subsubsection{SLAC Mission}

\section{Photon Science Discoveries}

- To make discoveries in photon science at the frontiers of the ultrasmall and ultrafast in a wide spectrum of physical and life sciences

Particle and Particle Astrophysics Discoveries

- To make discoveries in particle and astroparticle physics to redefine humanity's understanding of what the universe is made of and the forces that control it

Operate Safely; Train the Best

- To operate a safe laboratory that employs and trains the best and brightest, helping to ensure the future economic strength and security of the nation

\subsubsection{Research Program}

SLAC has three major research areas. The first, in photon science, is to develop and support innovative research instrumentation for $\mathrm{x}$-ray based studies of matter on length scales down to the nano- to atomiclevel and on time scales from milli- down to femto-seconds. Photon science research includes complex,

1 Stanford University Architect/Planning Office, Stanford Linear Accelerator Center Long Range Development Plan (December 2002, revised June 2003), http://wwwgroup.slac.stanford.edu/bsd/SLAC_LRDP_final.pdf 
correlated and magnetic materials science, molecular environmental science, and structural biology; there is a rapidly developing new area of excellence in ultrafast x-ray science.

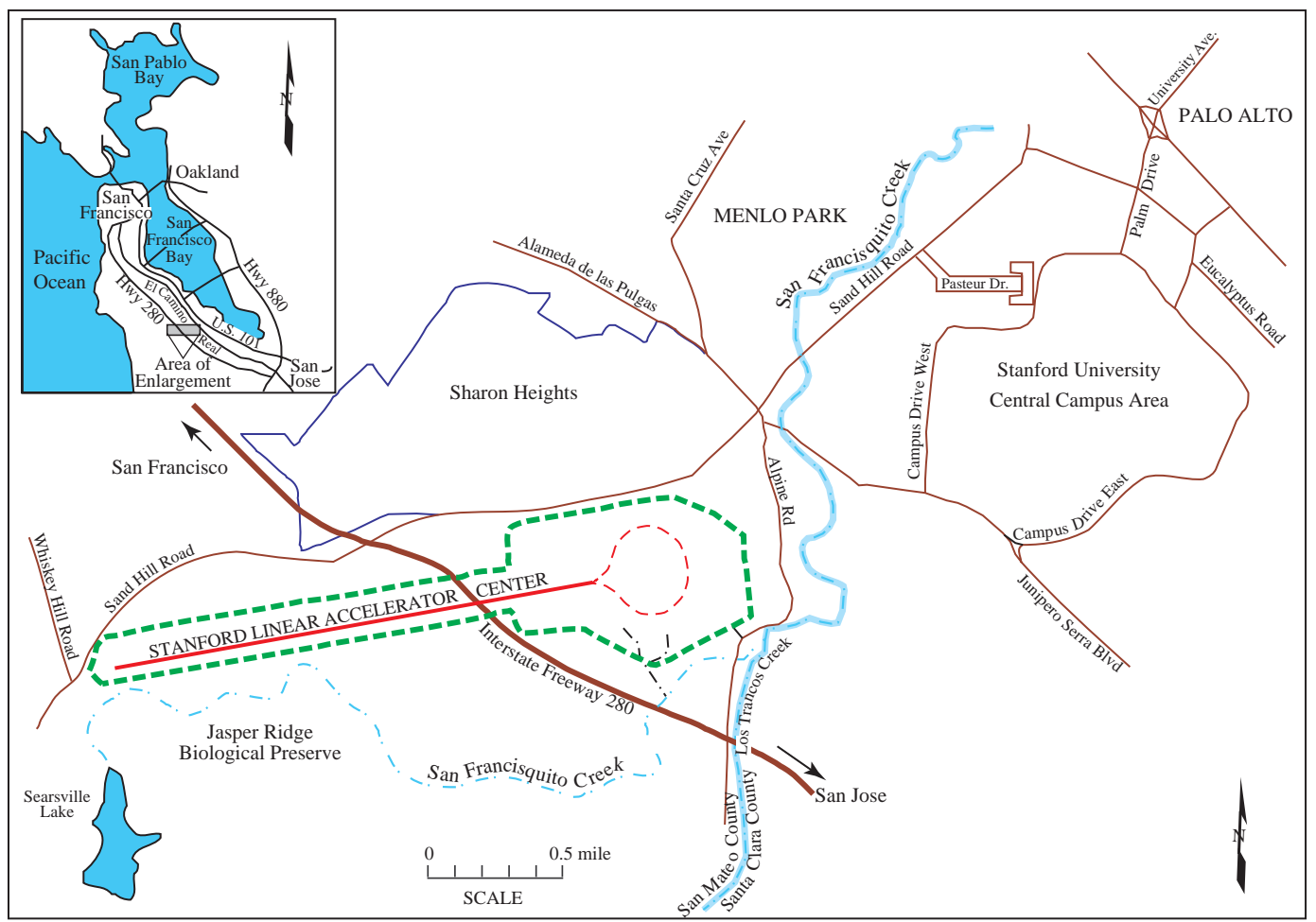

Figure 1-1 SLAC Site Location

Another research area is the use of particle accelerators and observatories in space and on the ground to understand what our universe is made of at its most basic and fundamental level. The principal areas of particle physics are the electron energy frontier using a linear collider, theoretical investigations of the quantum universe and, at the Kavli Institute for Particle Astrophysics and Cosmology, non-accelerator tests of the Standard Cosmology Model through investigations of dark matter and dark energy.

Continuing over the next two years, a third research area at SLAC is the construction of the Linac Coherent Light Source (LCLS), the world's first $x$-ray-free electron laser. SLAC is committed to the on-time and onbudget construction and rapid commissioning of this major new facility that will open revolutionary frontiers for photon science in the coming decades.

Also at SLAC is the 2-mile linear accelerator (linac), which generates high intensity beams of electrons and positrons up to 50 giga-electron volts. The linac is also used for injecting electrons and positrons into colliding-beam storage rings for particle physics research.

The Positron-Electron Project (PEP) storage ring is about 875 yards in diameter. While the original PEP program was completed in 1990, the storage ring has since been upgraded to serve as an asymmetric $\mathrm{B}$ factory (known as PEP-II) to study the B meson. PEP-II continued its program with the SLAC B Factory (BaBar) detector throughout 2006. 
A smaller storage ring, the Stanford Positron-Electron Asymmetric Ring (SPEAR), contains a separate, shorter linac and a booster ring for injecting accelerated beams of electrons. SPEAR is fully dedicated to synchrotron radiation research. The synchrotron light generated by the SPEAR storage ring is used by the Stanford Synchrotron Radiation Laboratory (SSRL), a division of SLAC, to perform experiments.

SLAC is committed to continuing its leadership in advocating and working on the design of the International Linear Collider (ILC) machine and the detector. The laboratory has the strongest electron accelerator group in the United States, if not the world, and in collaboration with our international partners will contribute to both the design and testing of major ILC subsystems as well as to the overall design.

\subsection{Location}

SLAC is located in a belt of low, rolling foothills between the alluvial plain bordering San Francisco Bay to the east and the Santa Cruz Mountains to the west. The site varies in elevation from 175 to 380 feet above sea level. The alluvial plain to the east around the bay lies less than 151 feet above sea level; the mountains to the west rise abruptly to over 2000 feet.

The site occupies 426 acres of land owned by Stanford University. The property was leased in 1962 for purposes of research into the basic properties of matter. The DOE now owns the original 50-year lease to the Atomic Energy Commission. The land is part of Stanford's academic reserve and is located west of the university and the city of Palo Alto in an unincorporated portion of San Mateo County.

The site lies between Sand Hill Road and Alpine Road, bisected by Highway 280, on an elongated parcel roughly 2.75 miles long, running in an east-west direction. The parcel widens to about 0.65 mile at the target (east) end to allow space for buildings and experimental facilities. The south side of much of the western end of the parcel is bordered by Stanford University's Jasper Ridge Biological Preserve (JRBP), which includes part of the San Francisquito Creek riparian channel, the last channel of its kind between San Jose and San Francisco still in its natural state.

\subsection{Geology}

The SLAC site is underlain by sandstone, with some basalt at the far eastern end. In general, the bedrock on which the western half of the SLAC linac rests is the Whiskey Hill Formation (Eocene age), and the bedrock under the eastern half is the Ladera Sandstone (Miocene age). On top of this bedrock at various places along the accelerator alignment is the Santa Clara Formation (Pleistocene age), where alluvial deposits of sand and gravel are found. At the surface is a soil overburden of non-consolidated earth material averaging from 0.3 to 3 feet in depth. Figure 1-2 shows the general geographic and geologic setting of the area. 


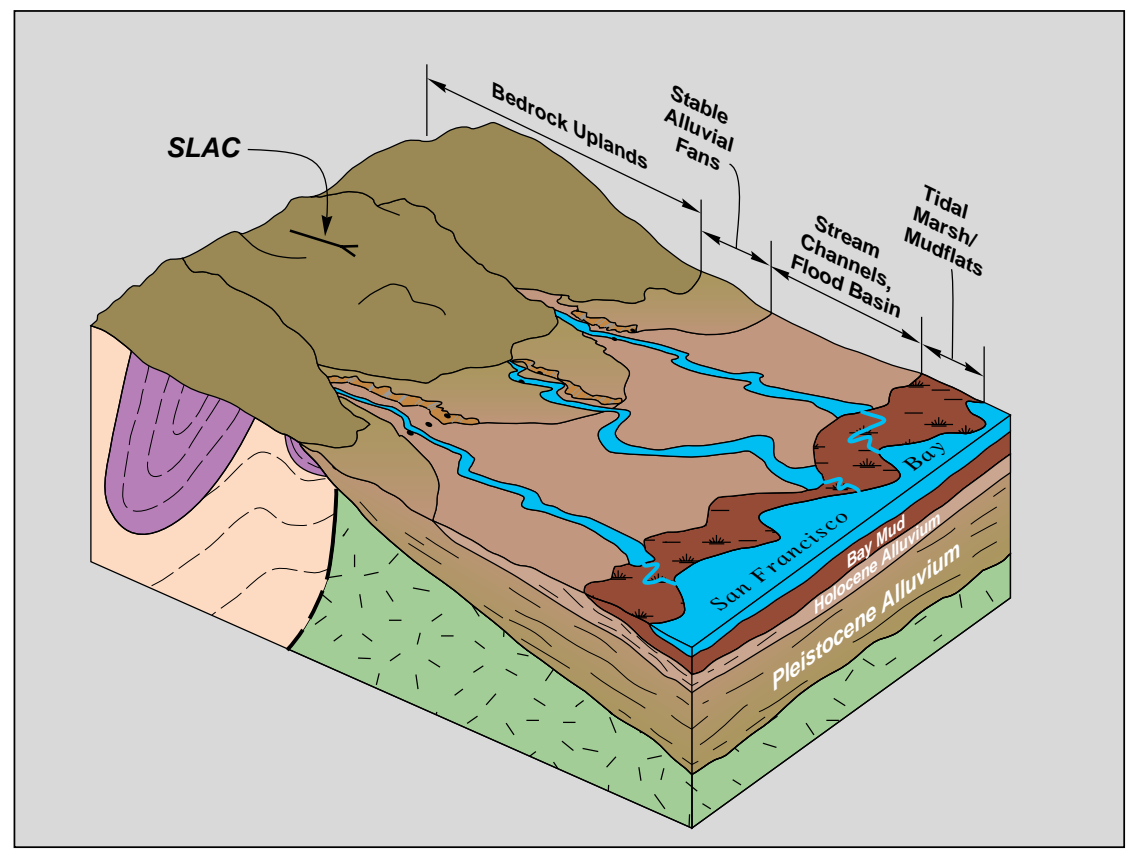

Figure 1-2 Site Area General Geographic and Geologic Setting

\subsection{Climate}

The climate in the SLAC area is Mediterranean. Winters are cool and moist, and summers are mostly warm and dry. Daily mean temperatures are seldom below 32 degrees Fahrenheit or above 86 degrees Fahrenheit.

Rainfall averages about 22 inches per year. The distribution of precipitation is highly seasonal. About 75 percent of the precipitation, including most of the major storms, occurs during the four-month period from December through March. Most winter storm periods are from two days to a week in duration. The storm centers are usually characterized by relatively heavy rainfall and high winds. The combination of topography and air movement produces substantial fluctuations in intensity, which can best be characterized as a series of storm cells following one another that produce heavy precipitation for periods of five to 15 minutes with lulls in between bursts.

\subsection{Land Use}

The SLAC site is in an unincorporated portion of San Mateo County and is zoned in the San Mateo County General Plan as a residential estate. Approximately 34 percent of the property is developed with buildings and pavement, mostly in the core campus area.

Land use to the immediate west is commercial, and farther west is agricultural and the JRBP. Land use to the north is mostly commercial, residential, and recreational (a golf course), with a school and convalescent hospital north of the central campus. Land use to the east is residential, recreational (another golf course), and educational (the Stanford campus). Land use to the south is agricultural (including a horse boarding and training facility), reserved open space, and residential. 


\subsection{Water Supply}

SLAC domestic water is furnished via the Menlo Park Municipal Water Department (MPMWD), the source of which is the City of San Francisco-operated Hetch Hetchy aqueduct system, fed from reservoirs in the Sierra Nevada. SLAC and the neighboring Sharon Heights development (to the north), including the Stanford shopping center, receive water service from an independent system (called Zone 3) within the MPMWD. This separate system taps the Hetch Hetchy aqueduct and pumps water up to a 268,391-cubicfeet reservoir in Atherton north of Sand Hill Road, approximately 1.5 miles from central SLAC.

The Zone 3 system was constructed in 1962 under special agreements between the City of Menlo Park, the Sharon Heights developer, Stanford University, and the DOE. The cost of construction, including reservoir, pump station, and transmission lines, was shared among the various parties, so each party has a vested interest in the system, and is entitled to certain capacity rights in accordance with these agreements.

Drinking and process water are both transported throughout SLAC by a distribution system protected by backflow prevention devices. SLAC has no drinking-water supply wells. The drinking-water supply well nearest to SLAC is about 1,500 feet from the SLAC boundary.

Use of water at SLAC is about equally divided between water used to cool equipment (such as the linac) and domestic uses (such as landscape irrigation and drinking water). The average water consumption by SLAC in 2006 was 36,031 cubic feet per day, or 13,151,500 cubic feet total.

\subsection{Demographics}

SLAC's primary customers are the approximately 3,000 students, postdoctoral students, and scientists from around the world who make use of its accelerator-based instrumentation and techniques for their research. SLAC has a working population of about 1,500, of which about 279 are PhD physicists. Approximately 681 staff members are professional, including physicists, engineers, programmers, and other scientificrelated personnel. The balance of the staff comprises support personnel, including technicians, crafts personnel, laboratory assistants, and administrative assistants. In addition to the regular population, at any given time SLAC hosts between 900 and 1,000 visiting scientists.

The populated area around SLAC is a mix of offices, schools, single-family housing, apartments, condominiums, and Stanford University. Approximately 3,500 people live within a one-mile radius of central SLAC. SLAC is mainly surrounded by five communities: the city of Menlo Park; the towns of Atherton, Portola Valley, and Woodside; and the unincorporated community of Stanford University, which is in Santa Clara County. Nearby unincorporated communities in San Mateo County include Ladera and two neighborhoods in western Menlo Park.

Table 1-1 provides a summary of populations in the communities around SLAC. Within one mile of SLAC's perimeter are two public and two private schools with elementary and/or middle school students. 
Table 1-1 Populations of Communities near SLAC

\begin{tabular}{lllr} 
Type & Community & County & Population \\
\hline Incorporated town or city & Atherton & San Mateo & 7,194 \\
& Menlo Park & San Mateo & 30,785 \\
& Palo Alto & Santa Clara & 58,598 \\
& Portola Valley & San Mateo & 4,462 \\
& Woodside & San Mateo & 5,352 \\
& Ladera & San Mateo & 1,492 \\
Unincorporated community & Stanford & Santa Clara & 13,200 \\
& West Menlo Park & San Mateo & 3,629 \\
& Weekend Acres & San Mateo & 268 \\
& & & 124,980 \\
Total & & \\
Sources: & & \\
1 Census 2000 data from the San Mateo County web site and from US Census Bureau site & \\
2 Stanford population from Stanford University Planning Department estimates & \\
Note: Population in unincorporated areas outside the defined communities is not included &
\end{tabular}




\section{Environmental Compliance}

\subsection{Introduction}

This chapter provides a summary of the regulatory framework within which the environmental programs of SLAC operate, and compliance with those regulations for 2006.

\subsection{Regulatory Framework}

The SLAC Work Smart Standards (WSS) identify environmental protection and safety requirements and standards that are applicable to facilities and facility operations. ${ }^{2}$

\subsection{Environmental Permits and Notifications}

The permits held by SLAC in 2006 are shown in Table 2-1.

Table 2-1 General Permits Held by SLAC

\begin{tabular}{lllr} 
Issuing Agency & Permit Type & Description & Number \\
\hline Bay Area Air Quality & Air quality & $\begin{array}{l}\text { Synthetic minor operating permit, issued per Title V } \\
\text { of the Clean Air Act }\end{array}$ & 1 \\
& & \\
Management District & operation of various types of equipment & 58 \\
& & Unit 1A - Building 025, permit by rule (PBR) for & 1 \\
\hline California Department of & $\begin{array}{l}\text { Hazardous waste } \\
\text { Toxic Substance Control } \\
\text { treatment }\end{array}$ & $\begin{array}{l}\text { Unit 1B - Building 038, PBR for metal finishing } \\
\text { pretreatment facility }\end{array}$ & 1 \\
& Unit 1C - Building 038, PBR for batch hazardous \\
& waste treatment tank & 1 \\
& Unit 2 - Building 038, PBR for sludge dryer & 1 \\
& Unit 4 - Building 035, conditional authorization permit & 1 \\
& for Former Solvent Underground Storage Tank \\
& (FSUST) groundwater treatment system & 1 \\
& Unit 5 - Former Hazardous Waste Storage Area \\
& (FHWSA), PBR for groundwater treatment system & 1
\end{tabular}

2 Stanford Linear Accelerator Center, "Work Smart Standards”, http://wwwgroup.slac.stanford.edu/esh/general/isems/wss/wssweb.htm 


\begin{tabular}{lllr} 
Issuing Agency & Permit Type & Description & Number \\
\hline $\begin{array}{l}\text { South Bayside System } \\
\text { Authority and West Bay } \\
\text { Sanitary District }\end{array}$ & $\begin{array}{l}\text { Wastewater } \\
\text { discharge }\end{array}$ & Mandatory Wastewater Discharge Permit & 1 \\
\hline $\begin{array}{l}\text { Regional Water Quality } \\
\text { Control Board }\end{array}$ & Stormwater & Industrial activities stormwater general permit & 1 \\
\hline $\begin{array}{l}\text { US Environmental Protection } \\
\text { Agency }\end{array}$ & Hazardous waste & Hazardous waste generator permit & 1
\end{tabular}

\subsection{Environmental Incidents}

\subsubsection{Non-radiological Incidents}

SLAC was in compliance with all non-radiological requirements related to the environment throughout 2006. There were no reportable spills during 2006.

\subsubsection{Radiological Incidents}

In 2006, no radiological incidents occurred that increased radiation levels or released radioactivity to the environment. As detailed in Chapter 5, "Environmental Radiological Program”, SLAC was in compliance with all radiological requirements related to the environment throughout 2006.

\subsection{Assessments, Inspections, and Quality Assurance}

As described in Chapter 3, "Management Systems", the environmental programs at SLAC are subject to a number of assessments, inspections, and quality assurance measures. Those conducted during 2006 are reported here.

\subsubsection{Assessments}

\subsubsection{External}

External assessments conducted by regulators are conducted periodically and include quarterly radiation monitoring of the SLAC perimeter by California Department of Health Services.

\subsubsection{Independent Assessments}

Members of DOE's Office of Independent Oversight (OIO) evaluated various aspects of SLAC's operations during parts of October and November 2006. One aspect of their evaluation was a review of SLAC's Environmental Management System (EMS). This entailed review of pertinent documents and performing a field audit of EMS aspects of operations at SLAC. No EMS findings were identified.

The DOE reviewed several aspects of SLAC's operations, including the Integrated Safety and Environmental Management System (ISEMS), between June 26 and 30, 2006. This was a precursor to the OIO evaluation. No findings were identified.

The Environmental Safety and Health Advisory Committee (ESHAC) is an external committee that works in conjunction with the SLAC Policy Committee which advises the president of Stanford University on all 
aspects of SLAC operations. The goals of the ESHAC are to review the SLAC ES\&H vision, mission, strategy, plans, progress against plans, and performance. The ESHAC met with SLAC in March, July and October of 2006 to review the LCLS project. Their review included some EMS aspects of the project. At the conclusion of the March 2006 meeting, the ESHAC commended SLAC on the progress of SLAC's EMS program.

\subsubsection{Inspections}

Periodic inspections of the environmental programs are performed at SLAC by environmental regulatory agencies. Table 2-2 lists the inspections conducted in 2006 by these agencies.

Table 2-2 Environmental Audits and Inspections

\begin{tabular}{|c|c|c|c|}
\hline Regulatory Agency & Inspection Title & Date & Violations \\
\hline South Bayside System Authority & Annual Wastewater Discharge Inspection & December 8 & 0 \\
\hline $\begin{array}{l}\text { Bay Area Air Quality Management } \\
\text { District }\end{array}$ & Various activities with emissions to air & $\begin{array}{l}\text { Visited SLAC four } \\
\text { times during 2006; } \\
\text { however, routine } \\
\text { inspection not } \\
\text { performed }\end{array}$ & 0 \\
\hline $\begin{array}{l}\text { San Mateo County Department of } \\
\text { Health Services }\end{array}$ & $\begin{array}{l}\text { Hazardous waste generation program, } \\
\text { tiered permitting, and hazardous materials } \\
\text { business plan }\end{array}$ & October 25 and 26 & 0 \\
\hline
\end{tabular}

\subsubsection{Quality Assurance}

The SLAC site-wide quality assurance (QA) program is consistent with the requirements of DOE Order 414.1C, ${ }^{3}$ and has roles, responsibilities, and authorities for implementing the ten criteria from the DOE order are included in the SLAC Institutional QA Program Plan.

The Office of Assurance (established shortly after the start of 2006) is responsible for:

- Auditing quality assurance for line work as well as ES\&H programs

- Maintaining the SLAC Institutional Quality Assurance Program Plan

- Providing direction for implementation of the ten criteria from DOE Order 414.1C

\subsubsection{Environmental Non-radiological Program}

The Environmental Restoration Program uses the Quality Assurance Project Plan for the Environmental

Restoration Program ${ }^{4}$ for soil and groundwater contamination investigations. This document has most

3 United States Department of Energy, DOE Order 414.1C, “Quality Assurance”, http://www.directives.doe.gov/pdfs/doe/doetext/neword/414/o4141c.html

4 Stanford Linear Accelerator Center, Environment, Safety, and Health Division, Environmental Protection and Restoration Department, Quality Assurance Project Plan for the Environmental Restoration Program (SLAC-I-750-2A17M-003 R003, May 2006) 
components required of quality assurance project plans according to the United States Environmental Protection Agency (USEPA); the Comprehensive Environmental Response, Compensation, and Liability Act (CERCLA, or Superfund); and DOE guidance documents. The components include defining required laboratory and field QA and quality control (QC) procedures and corrective actions, and data validation and reporting.

\subsubsection{Environmental Radiological Program}

Twice a year SLAC participates in the Mixed Analyte Performance Evaluation Program held by DOE Idaho National Laboratory (INL). Under this program, the INL provided the SLAC Radioanalysis Laboratory with samples that contained unknown gamma- and beta-emitting radionuclides. The lab used these samples to test and improve its gamma counting and liquid scintillation counting capabilities. This ensures that the lab’s counting system performs accurate measurements.

\subsection{Environmental Performance Measures}

At the institutional level, a program of performance measures in environmental protection, waste minimization, pollution prevention and EMS have been established. ${ }^{5}$ Review of performance to these measures by senior management is part of the overall planned program assessment activities.

5 Stanford Linear Accelerator Center, Environment, Safety, and Health Division, “ISEMS: Performance Measures” (FY07), http://www-group.slac.stanford.edu/esh/general/isems/perfmeas/ 


\section{Management Systems}

\subsection{Introduction}

This chapter provides an overview of the ES\&H Division's management systems, including organizational structure, management approach, and EMS implementation. The results for the various measures and reviews discussed below are contained in Chapter 2, "Environmental Compliance".

\subsection{SLAC Organization}

In May of 2005, an extensive reorganization of the SLAC Directorates took place in anticipation of a change in program at SLAC from DOE High Energy Physics funded activities to DOE Basic Energy Sciences funded activities by the end of fiscal year (FY) 2008. The previous organization of the SLAC directorates had been in place for many years: Director’s Office, Business Services Division, ES\&H Division, Research Division, SSRL Division, and Technical Division. After the reorganization, elements of the old directorates were reassigned to Director's Office, Operations Directorate, Photon Sciences Directorate, Particle and Particle Astrophysics Directorate, and LCLS Construction Directorate. Specifically, the Business Services and ES\&H Divisions were reassigned to the Operations Directorate while the SSRL Division was reassigned to the Photon Sciences Directorate. Additionally, plans were made for the formation of a new Office of Assurance, which would be responsible for the SLAC Quality Assurance program. Shortly after the start of CY06, the SLAC Office of Assurance was formed in response to DOE Order 226.1. The purpose of SLAC's assurance program is to ensure products and services meet or exceed customer's expectations. SLAC's customers include the DOE, the many users who participate in experiments at SLAC using the laboratory's unique experimental facilities, and the sponsors of work done under work-for-others program.

\subsection{ES\&H Division Organization}

The ES\&H Division consists of six departments (see below) and a division office. The division office is tasked with overall strategic planning and management. The shared goal is to ensure SLAC operates in compliance with federal, state, and local regulations, as well as DOE requirements.

\subsubsection{Environmental Protection}

The Environmental Protection (EP) Department has three technical groups. The EP Group provides oversight of stormwater and industrial wastewater, toxic substance control, and groundwater protection. The Environmental Restoration Group oversees work to restore property impacted with chemicals. The Waste Management (WM) Group develops and implements waste minimization and pollution prevention plans, and coordinates the disposal of regulated waste.

\subsubsection{Fire Department}

During 2006, the Fire Department, staffed by fire personnel from the Palo Alto Fire Department, continues to report to the ES\&H division office. Fire protection services are provided to the site on a 24 hour-a-day, seven days-a-week basis. 


\subsubsection{Radiation Protection}

The Radiation Protection Department (RP) has four technical groups. The Radiation Physics Group provides expertise in shielding design for new experiments and facilities, and provides oversight for safe operation of beam lines to protect workers, members of the general public and the environment. The Field Operations Group oversees radiological monitoring and control. The Dosimetry and Radiological Environmental Group provides dosimetric services and environmental impact monitoring and assessment. The Radioactive Waste and Material Accountability Group oversees radioactive waste management at SLAC.

\subsubsection{Chemical and General Safety}

The Chemical and General Safety Department manages the overall safety and health programs, as well as hazardous materials management, the CMS and the non-radiological air quality program.

\subsubsection{Medical Department}

During 2006, the Medical Department, staffed by contract professional medical personnel, continued to report to the ES\&H Division office. The Medical Department provides a full range of occupational medicine services.

\subsubsection{Knowledge Management}

The Knowledge Management Department provides training, publishing, and web services, and manages the ES\&H Division budget.

\subsection{Integrated Safety and Environmental Management System}

The ES\&H Division has been designed to ensure SLAC operates in a safe, environmentally responsible manner and complies with applicable laws, regulations, and standards. The program is based on integrating these into the mission and everyday operations of the site, and as such embodied the ISEMS approach even before this idea was made a DOE requirement and incorporated into the operating contract of the site. The revisions to the ISEMS program at SLAC were guided by an integrated safety management (ISM) steering committee with representatives from all the directorates at SLAC, including the ES\&H Division.

\subsubsection{Safety and Environmental Management System}

The "plan, do, check, and improve" approach of ISEMS ${ }^{6}$ has been formally adopted by SLAC, and is the foundation of the site's ISEMS ${ }^{7}$ and the ES\&H program. The approach consists of the following five core functions:

1. Define the scope of work

2. Analyze the hazards

6 Stanford Linear Accelerator Center, Environment, Safety, and Health Division, “Integrated Safety and Environmental Management Systems”, http://www-group.slac.stanford.edu/esh/general/isems/

7 Stanford Linear Accelerator Center, Environment, Safety, and Health Division, SLAC Integrated Safety and Environmental Management System Description (SLAC-I-720-0A00B-001), http://wwwgroup.slac.stanford.edu/esh/general/isems/sms.pdf 
3. Develop and implement hazard controls

4. Perform work within controls

5. Provide feedback and continuous improvement

\subsubsection{Work Smart Standards}

To ensure that SLAC complies with safety and environmental standards, the laws and regulations that specify the environment, safety, and health requirements of the laboratory have been identified and incorporated into the SLAC management and operating contract. These requirements, known as the SLAC WSS, are reviewed annually, and are based on and respond to potential hazards and environmental impacts identified by those who work at SLAC ${ }^{8}$.

\subsubsection{Environmental Performance Measures}

In addition to adopting WSS, SLAC evaluates its activities against performance measures. The environmentally relevant measures are:

- Environmental violations and releases

- Environmental restoration goals

- Waste minimization/pollution prevention goals

- Hazardous and radioactive waste

Specific performance measures are adopted and reported in a fiscal-year structure ${ }^{9}$.

\subsubsection{Training}

To ensure every employee is both aware and capable of fulfilling his or her responsibilities, the ES\&H Division operates an extensive program of classroom- and computer-based training. For example, personnel who handle hazardous chemicals and waste are instructed in chemical and waste management, waste minimization, pollution prevention, stormwater protection, on-site transportation of hazardous chemicals and waste, and spill and emergency response. Details on the ES\&H training program are available on line ${ }^{10}$.

\subsection{Environmental Management System}

Stanford University provides the land for the SLAC site to the DOE at no cost, charging no rent and exacting no fee. SLAC, as a Department of the University, manages the land with future generations in mind, thus ensuring proper stewardship and the eventual return of the land to unrestricted use. This stewardship goal is embodied in the safety management system described above, which already

8 Stanford Linear Accelerator Center, “Work Smart Standards Set”, http://wwwgroup.slac.stanford.edu/esh/general/isems/wss/.

9 The measures for fiscal years 1997 through 2006 can be found on line at http://wwwgroup.slac.stanford.edu/esh/general/isems/perfmeas/.

10 Stanford Linear Accelerator Center, Environment, Safety, and Health Division, “Training”, http://wwwgroup.slac.stanford.edu/esh/training/ 
incorporates many of the characteristics and requirements of an EMS as defined in Executive Order 13148, "Greening the Government through Leadership in Environmental Management", including the roles and responsibilities for an EMS.

Requirements for an EMS are contained in the order, DOE Order 450.1, "Environmental Protection Program"11. SLAC continued to follow the path to self-declare an EMS. Objectives and Targets were developed and implemented for significant environmental aspects identified at SLAC. In October 2006, a review of the EMS was conducted by SLAC senior management.

11 United States Department of Energy, DOE Order 450.1, “Environmental Protection Program”, http://www.directives.doe.gov/pdfs/doe/doetext/neword/450/o4501c2.html 


\section{Environmental Non-radiological Programs}

\subsection{Introduction}

During the course of providing accelerators, detectors, instrumentation, and support for national and international research programs, SLAC manufactures and maintains one-of-a-kind research equipment, which requires the use and management of industrial chemicals, gases, and metals. In addition, SLAC has the potential to impact the environment due to storage and handling of chemicals and the large quantities of electricity and cooling water that are used in the operation of the accelerator. Finally, SLAC has environmental management issues relevant for any employer with more than 1,500 full-time staff, 3,000 scientific users per year, more than 230 vehicles, hundreds of buildings, and 426 acres of land situated in an environmentally sensitive location.

SLAC expends considerable effort to minimize waste and emissions. If possible, SLAC avoids creating waste and emissions in the first place. When unavoidable, SLAC minimizes the amount it does produce and then carefully manages the impacts that may occur as a result of waste generation. Recent recognition of SLAC's environmental performance accomplishments is provided in Table 4-1.

Table 4-1 Recent Environmental Awards

\begin{tabular}{|c|c|c|c|}
\hline Year & Organization & Award/Recognition Program & Description \\
\hline 2002 & USEPA & Champion of Green Government Award & $\begin{array}{l}\text { Identifying/developing alternatives to ozone } \\
\text { depleting solvents }\end{array}$ \\
\hline 2003 & USEPA & Champion of Green Government Award & $\begin{array}{l}\text { Reuse and reclamation of hazardous } \\
\text { materials, and reduction of hazardous } \\
\text { waste generation }\end{array}$ \\
\hline 2004 & DOE & Pollution Prevention Award & $\begin{array}{l}\text { Development of a site-wide chemical } \\
\text { management system }\end{array}$ \\
\hline 2004 & USEPA & Champion of Green Government Award & $\begin{array}{l}\text { By upgrading lighting in Klystron Gallery } \\
\text { will save } \$ 236,000 \text { annually }\end{array}$ \\
\hline 2006 & DOE & $\begin{array}{l}\text { Pollution Prevention and Environmental } \\
\text { Stewardship Accomplishment - } \\
\text { Noteworthy Practice }\end{array}$ & $\begin{array}{l}\text { Resource conservation achieved by } \\
\text { building experimental facilities with reused } \\
\text { materials }\end{array}$ \\
\hline 2006 & DOE & $\begin{array}{l}\text { Pollution Prevention and Environmental } \\
\text { Stewardship Accomplishment - Best in } \\
\text { Class }\end{array}$ & $\begin{array}{l}\text { Instituted the Chemical Management } \\
\text { Services which manages chemicals } \\
\text { procurement and use }\end{array}$ \\
\hline
\end{tabular}

Additionally, SLAC continually strives to increase its environmental performance, per the objectives of Executive Order 13148, “Greening the Government through Leadership in Environmental Management”, and its own EMS (see Chapter 3).

This chapter provides an overview of the non-radiological environmental programs SLAC implements to protect air and water quality, to manage hazardous materials safely, and to minimize the generation of hazardous, non-hazardous, and solid waste. The chapter sections are organized by protection program and describe the regulatory framework, program status for 2006, and relevant performance trends. The 
radiological environmental program is discussed in Chapter 5, and programs covering the monitoring and remediation of groundwater, soil, and sediment are discussed in Chapter 6.

\subsection{Air Quality Management Programs}

SLAC operates various sources of air pollution, including a plating shop, a paint shop, several machine shops, a magnet shop, boilers, solvent degreasers, and a vehicle fueling station. In addition, high-energy physics experiments can emit volatile organic compounds (VOCs) due to the nature of the gas atmospheres required for use in particle detectors. This section describes the regulatory framework to which SLAC is subject for the purpose of air quality protection, and presents the status of SLAC's air quality protection programs in 2006.

\subsubsection{Regulatory Framework}

In the San Francisco Bay Area, most federal and state air regulatory programs are implemented through the rules and regulations of the BAAQMD. Included in the BAAQMD roles and responsibilities are implementation of Title V of the Clean Air Act. As a result of this implementation, SLAC became subject to the Title $\mathrm{V}$ permitting program and applied for a synthetic minor operating permit (SMOP). SLAC's Title V SMOP permit was issued by the BAAQMD on July 26, 2002. The Title V SMOP placed caps on facility-wide emissions of VOCs, total hazardous air pollutants (HAPs), and individual HAPs.

Other mechanisms by which BAAQMD regulates SLAC's air emissions include

1. Annual enforcement inspections

2. New source permit evaluations

3. Annual information updates for emissions of air toxics as identified by the California Air Resources Board in its toxic substances checklist

4. Annual information updates for adhesives usage as specified in BAAQMD Regulation 8-51-1502.2C

5. Asbestos and demolition project notification requirements

SLAC is also subject to the following two air quality programs:

- The National Emission Standards for Halogenated Solvent Cleaning, under Title 40, Code of Federal Regulations (CFR), Part 63.460, administered through the Air Division of USEPA Region 9

- The Protection of Stratospheric Ozone, under 40 CFR 82, likewise administered through the Air Division of USEPA Region 9

\subsubsection{Program Status}

\subsubsection{Annual Facility Enforcement Inspection}

No annual facility-wide inspection was performed by BAAQMD in 2006. However, BAAQMD inspectors were onsite several times during the calendar year. Most notably, a site visit occurred in August 2006 under the Reportable Compliance Activities program (RCA). Under this program, any operating anomaly or equipment malfunction is to be reported in a timely manner, whether or not an emissions exceedance is known to have occurred. An elevated VOC reading was measured at the soil-vapor extraction system at the Former Hazardous Waste Storage Area (see Section 6.7.2) on July 30, 2006. In accordance with the RCA program, the anomaly was reported within 24 hours, and a BAAQMD inspector came to SLAC the next 
day to follow up. Fortunately, the problem was traced to a faulty hand-held meter, so no exceedance occurred.

An unscheduled site visit occurred in June 2006, when a BAAQMD inspector visited SLAC to examine the SLAC gasoline dispensing facility (GDF). This was not an official visit, and no enforcement activity occurred. Instead, the inspector complimented the overall configuration of this source and made several recommendations to ensure future compliance and minimize or eliminate future problems. These recommendations were transmitted in writing to the SLAC Transportation Department, who acted on them promptly.

Another unscheduled site visit was made in July 2006 by BAAQMD personnel as a spot check of the asbestos/demolition notification program. The inspector was highly complimentary of both the field operations and SLAC's awareness and implementation of this program.

\subsubsection{New Source Permits}

SLAC submitted three permit applications to BAAQMD in 2006. The first was for the portable generator associated with the Gamma Ray Large Area Space Telescope (GLAST) project. The second application was for the SSRL paint shop, which is expected to be declared exempt from permitting requirements. The third application was for a trailer mounted portable generator. Under BAAQMD’s Accelerated Permit program, a proposed source can commence operation upon submittal of a complete permit application package. However, final approval is still pending for all three of these sources.

In January 2006, SLAC received approval for its full-scale dual-phase extraction system at the Former Hazardous Waste Storage Area (see Section 6.7.2), and the original source permit for the interim extraction system at that location was cancelled. As expected, process monitoring showed an initial spike in VOCs emissions, then a steady decrease to consistently low levels. As a result, the system was later approved for unabated emissions, as the VOCs concentrations were below all regulated thresholds.

In light of these changes, at the end of 2006 there was a net increase of three in the number of permitted and exempt emissions sources. Thus, SLAC had a total of 58 sources of air emissions listed in its facilitywide permit-to-operate, comprising 36 permitted and 22 exempt sources.

\subsubsection{Annual Update for Permit-to-Operate and Annual Title V SMOP Emissions Report}

SLAC submits two primary annual reports to the BAAQMD. One is the annual update that is prepared in response to the BAAQMD information update request for selected permitted sources, and covers the previous calendar year. The other is the Title $\mathrm{V}$ annual emissions report for all onsite sources for the SMOP and covers the period of July 1, 2005 through June 30, 2006. Following submittal of the former report, SLAC received the renewal of its permit-to-operate on June 28, 2006, effective through July 1, 2007. SLAC submitted the Title V annual emissions report on time in July 2006.

Currently, the largest source of air emissions at SLAC is its BaBar detector. SLAC has operated the detector within permit conditions at all times since its startup in 1999, using isobutane, which is the only significant Precursor Organic Compound used at SLAC. In 2005, BAAQMD modified and expanded the BaBar subsystem permits to create three individual permits, the drift chamber, the instrumented flux return/resistive plate chamber, and the testing facility for limited streamer tubes (LSTs). Each permit included a specific emissions threshold for isobutane. Throughout 2006, all three subsystems operated smoothly with no emissions exceedances. LSTs testing was completed by the end of 2006. 


\subsubsection{Annual Air Toxics Report}

Concurrent with BAAQMD's annual information request, facilities are also required to review the toxic substances checklist promulgated by BAAQMD to support the California Air Resources Board's Air Toxics program. If facilities emit more of a listed chemical than the applicable degree of accuracy threshold, regardless of whether the emissions originate from a permitted source, facilities have an obligation to report air toxics usage at the same time of their annual update.

SLAC submitted its annual air toxics information to BAAQMD on May 31, 2006, covering the 2005 reporting year. Air toxics emitted from permitted sources included the following:

- $\quad$ tetrafluoroethane (H-134a), a Freon compound used in one of the components of the BaBar detector: 9,300 pounds (lbs)

- Fluorinert-brand electronic liquid (a mixture of perfluorinated compounds), used in heat exchangers for one of the components of the BaBar detector: 366 gallons (about 5,120 lbs)

- $\quad$ Freon-22 and H-134a, used in SLAC heating, ventilation, and air conditioning (HVAC) equipment: 275 and $3 \mathrm{lbs}$, respectively

- 1,1,1-trichloroethane (TCA), a solvent used in the Plating Shop for degreasing parts: 1,570 lbs (the TCA degreaser was used as a backup while the primary near-zero emission degreaser was taken out of service for several months to perform maintenance)

As of 2006, the BAAQMD determined that the Annual Emissions Report required by the SMOP met the reporting requirements of the Air Toxics program as well. As a result, submittal of a separate annual Air Toxics report is no longer required.

\subsubsection{Annual Adhesives Usage Report}

SLAC submitted its annual adhesives usage report to BAAQMD to satisfy Regulation 8-51-502.2c on April 13, 2006 (covering the 2005 reporting year) and reported using a total of 43 adhesives.

\subsubsection{Asbestos and Demolition Project Notification Program}

For projects that involve the demolition of existing structures or the management of regulated asbestoscontaining material, SLAC is required to provide advance notice to BAAQMD. During 2006, approximately 38 construction projects were evaluated for the purpose of air quality protection. Based on the project scopes and the results of pre-work asbestos surveys, asbestos/demolition notifications were submitted to BAAQMD for four of these projects.

\subsubsection{National Emission Standards for Hazardous Air Pollutants}

SLAC operates four sources that are subject to 40 CFR 63, Subpart T, "National Emission Standards for Halogenated Solvent Cleaning”, part of the National Emission Standards for Hazardous Air Pollutants (NESHAPs) regulations, as shown in Table 4-2. Reporting comprises an annual performance report and two semi-annual exceedance reports.

No exceedances occurred during the covered reporting periods. The four NESHAPs units were operated in accordance with their NESHAPs emissions limits during the covered reporting periods. 
Table 4-2 Halogenated Solvent Cleaning Sources Subject to NESHAPs

\begin{tabular}{llll} 
Source & Source Description & Location & Halogenated Solvent Used \\
\hline S-4 & Batch vapor degreaser & Plating Shop & TCA \\
S-54 & Near-zero emission degreaser & Plating Shop & Tetrachloroethylene \\
S-58 & Batch cleaning tank & $\begin{array}{l}\text { Electron Gun } \\
\text { Testing/Maintenance }\end{array}$ & TCA \\
& Batch cleaning tank & Plating Shop & Methylene chloride
\end{tabular}

\subsubsection{Protection of Stratospheric Ozone}

No releases of stratospheric ozone-depleting substances (ODS) occurred during 2006 that were subject to the release reporting and corrective action requirements in the ODS regulations (40 CFR 82).

Per Executive Order 13148, “Greening the Government through Leadership in Environmental Management”, SLAC is subject to two DOE-mandated ODS-management objectives:

- By 2005, retrofit or replace 100 percent of chillers that have greater than 150 tons of cooling capacity, were manufactured prior to 1984, and that use Class 1 ODS (chillers with cooling capacities of 150 tons and less are not included)

- By 2010, eliminate the procurement of all Class 1 ODS

SLAC completed the activities to attain the first objective in 2002, three years ahead of schedule. The only major chiller left onsite that uses a Class I ODS is a 150-ton unit manufactured prior to 1984, which is slated for replacement with a non-ODS chiller in FY07.

SLAC has identified the following four projects that will be necessary to achieve the second objective.

- SSRL Building 118 Chiller Replacement - slated for replacement in FY07

- Halon Fire Systems Replacement (two systems) - under review of applicability

- Miscellaneous HVAC Equipment Replacement (approximately six small systems) - being evaluated to determine if they are subject to replacement or exempt under the 'de minimis' rule

- TCA Replacement Project, Conventional Experimental Facilities (CEF) Department - negotiate the transfer of ownership of this material from the CEF to the Plating Shop, and investigate options for offsite storage

\subsubsection{Vehicle Fleet Management}

SLAC operates and maintains a fleet of more than 230 cars, trucks, and specialized pieces of heavy equipment to support its daily operations. Vehicles are provided by one of two federal agencies: the DOE and the General Services Administration (GSA).

The GDF is regulated as a permitted emissions source by the BAAQMD. The GDF provides both gasoline and diesel for SLAC vehicles. Records of deliveries of both gasoline and diesel are tracked and reported annually to BAAQMD. Under the conditions of SLAC's site-wide air permit, the gasoline dispensing system obtained an annual source test to ensure proper functioning. In accordance with its individual permit, a source test was performed for the GDF in September 2006 and all results were within regulatory limits. The results were transmitted automatically to the BAAQMD. 
Secondary fuel distribution is achieved by portable diesel dispensing tanks. These tanks are also filled at the GDF and then transported throughout SLAC to refuel heavy equipment and stationary engines, such as emergency back-up generators.

At the beginning of the year, SLAC operated only six remaining DOE-owned vehicles that run on fossil fuels. The average age of these vehicles was 17 years. By the end of the year, SLAC had disposed of one of these aging vehicles, leaving only five DOE vehicles onsite. SLAC continued its efforts to replace and upgrade its vehicle fleet. In 2006, SLAC maintained a fleet of 115 electric vehicles.

Further reductions in the average age of SLAC's vehicle fleet are anticipated. As expected, each reduction brings about corresponding decreases in the associated air emissions.

\subsubsection{Greenhouse Gas Inventory and Baseline}

Sulfur hexafluoride $\left(\mathrm{SF}_{6}\right)$, the most potent greenhouse gas (GHG) known, is used at SLAC in both electrical equipment and experimental apparatus. In light of recent concerns about GHG and new California legislation (Assembly Bill 32), research proposals now routinely address the use of $\mathrm{SF}_{6}$, evaluate potential alternatives, and address the responsible management of this gas, even in minute quantities. It remains clear that $\mathrm{SF}_{6}$ is an extremely useful material, by far the most appropriate for some applications, and that research into acceptable substitutes has barely begun. The ES\&H Division continued its efforts to raise awareness of the need for rigorous management of $\mathrm{SF}_{6}$ throughout the facility.

\subsubsection{Summary and Future Plans}

SLAC emits pollutants to the atmosphere from its operation of one-of-a-kind research and manufacturing equipment, as well as from more conventional sources such as building maintenance and vehicle fleet operation. SLAC operates its air quality management program in compliance with its established permit conditions. SLAC maintains an active program to improve its environmental performance in the air quality arena. Recent years have witnessed the following accomplishments:

- Decrease of more than 90 percent in halogenated solvent emissions from SLAC's Plating Shop

- Replacement of three pre-1984, Class 1 ODS using chillers

- Decrease in the average age of SLAC's vehicle fleet

- Successful negotiations to obtain a Title V SMOP, which implements caps on facility-wide HAPs emissions

- Installation of new natural gas metering and instrumentation control systems at its main boilers

Future plans include the phasing out of all Class 1 ODS, continued work on the GHG baseline/inventory survey for the facility, development and implementation of a new air emissions data management system, and further transition to a newer, more alternatively-fueled vehicle transportation fleet.

\subsection{Industrial and Sanitary Wastewater Management Program}

SLAC discharges industrial pollutants and sanitary sewage to the sewage collection system operated by the West Bay Sanitary District (WBSD). The sewage is then conveyed via the WBSD's collection system to the wastewater treatment plant operated by the South Bayside System Authority (SBSA). Much of SLAC's industrial pollutants are removed prior to discharge at such facilities as the Metal Finishing Pre-treatment Facility (MFPF) and the contained water treatment system at Cooling Tower 1701. This section describes 
the regulatory framework under which SLAC operates for the purpose of water quality protection, and presents the status of SLAC's water quality protection programs in 2006.

\subsubsection{Regulatory Framework}

The Federal Water Pollution Control Act, also referred to as the Clean Water Act (CWA), was enacted in 1972 to halt the degradation of our nation's waters. The CWA established the National Pollutant Discharge Elimination System, which regulates discharges of wastewater from point sources such as a publicly owned treatment work and categorically regulated industrial facilities such as electroplating shops. In 1987, the CWA was amended to include non-point source discharges such as stormwater run-off from industrial, municipal, and construction activities. The CWA is the primary driver behind the SLAC water quality protection programs.

SLAC operates its industrial and sanitary wastewater programs under a mandatory wastewater discharge permit (WB 061216) which is negotiated jointly with the WBSD and SBSA. The permit was issued on December 16, 2006, and may be renewed annually until December 15, 2011. Previously, SLAC maintained four separate permits which covered discharges from the facility in general, the MFPF, the Former Underground Storage Tank treatment system (see Section 6.7.1), and the Former Hazardous Waste Storage Area treatment system (see Section 6.7.2). These four permits were combined into a single permit that covers the entire facility during the 2006 permit renewal. SLAC also has a contractual relationship with the WBSD, which specifies the total industrial and sanitary flow allowed to be discharged.

SLAC's industrial and sanitary monitoring locations are shown in Figure 4-1. SLAC's Sand Hill Road flow metering station (Sandhill flow meter station [FMS]) is located immediately upstream of SLAC's sewer system connection to WBSD's Sand Hill Road trunk line, just to the north of the SLAC main gate.

\section{Industrial and Sanitary Water Monitoring Locations}

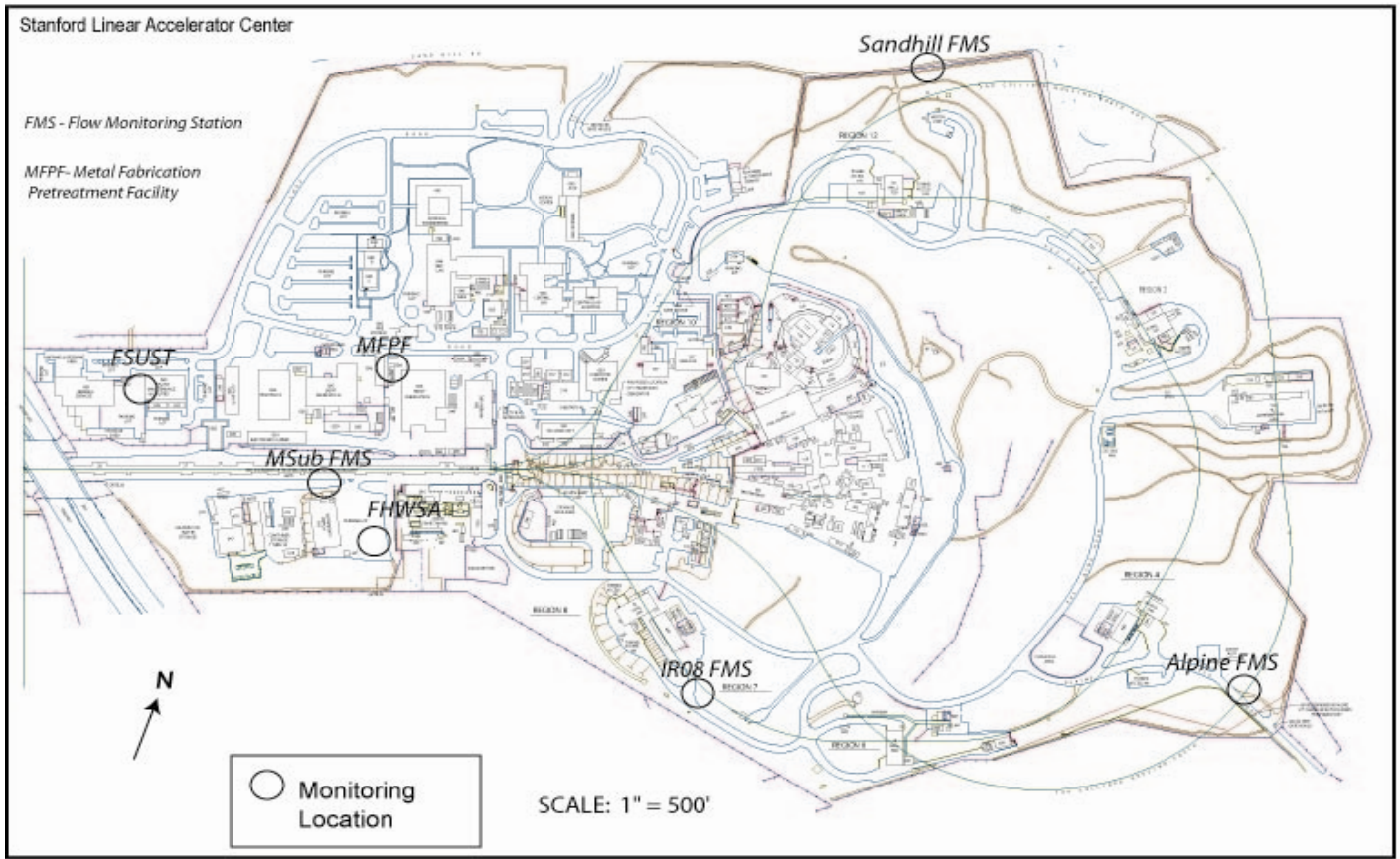

Figure 4-1 Industrial and Sanitary Wastewater Monitoring Locations 
SLAC also has three flow monitoring stations (MSub, Alpine, and IR08) on the south side of the facility, which collectively monitor the flow SLAC discharges to the WBSD's Alpine Road trunk line.

SLAC is required to submit a semi-annual self-monitoring report ${ }^{12}$ which includes the results of its monitoring of the MFPF, certification of a solvent management plan for approximately 100 solvents selected by the SBSA, and reports for discharges of treated groundwater ${ }^{13}$ and radioactivity in industrial wastewater (see Section 5.5.1).

\subsubsection{Program Status}

\subsubsection{Annual Facility Enforcement Inspection}

The SBSA conducted an annual inspection of SLAC on December 8, 2006. The inspection focused on the consolidation of the industrial wastewater permits from four to one. No notice of violation (NOV) was issued.

\subsubsection{Flow Monitoring Results}

Total industrial and sanitary wastewater discharged to the WBSD's regional collection system was approximately 22.4 million gallons, which equates to an average of approximately 61,400 gallons per day (gpd). SLAC was within its discharge entitlement of approximately 23.5 million gallons, or 64,400 gpd.

12 Stanford Linear Accelerator Center, Environment, Safety, and Health Division, Environmental Protection Department, Semiannual Self-Monitoring Report, Mandatory Wastewater Discharge Permit WB 020401-P (July 31, 2006, submitted to Norman Domingo, Technical Services Supervisor, SBSA)

- Semiannual Self-Monitoring Report, Mandatory Wastewater Discharge Permit WB 061216 (January 19, 2007, submitted to Norman Domingo, Technical Services Supervisor, SBSA)

13 Stanford Linear Accelerator Center, Environment, Safety, and Health Division, Environmental Protection Department, Groundwater Discharge Self Monitoring Report, 1st Quarter 2006, Discretionary Groundwater Discharge Permit No. GW WB041015 (April 12, 2006, submitted to SBSA)

- Groundwater Discharge Self Monitoring Report, $2^{\text {nd }}$ Quarter 2006, Discretionary Groundwater Discharge Permit No. GW WB041015 (July 11, 2006, submitted to SBSA)

—, Groundwater Discharge Self Monitoring Report, $3^{\text {rd }}$ Quarter 2006, Discretionary Groundwater Discharge Permit No. GW WB041015 (October 13, 2006, submitted to SBSA)

- Groundwater Discharge Self Monitoring Report, $4^{\text {th }}$ Quarter 2006, Discretionary Groundwater Discharge Permit No. GW WB041015 (January 12, 2007, submitted to SBSA)

Erler \& Kalinowski, Inc, Groundwater Discharge Self Monitoring Report, 1st Quarter 2006, Discretionary Groundwater Discharge Permit No. GW WB 082201 (April 14, 2006, submitted to SBSA)

—, Groundwater Discharge Self Monitoring Report, 2nd Quarter 2006, Discretionary Groundwater Discharge Permit No. GW WB 082201 (July 21, 2006, submitted to SBSA)

—, Groundwater Discharge Self Monitoring Report, 3rd Quarter 2006, Discretionary Groundwater Discharge Permit No. GW WB 082201 (October 13, 2006, submitted to SBSA)

- Groundwater Discharge Self Monitoring Report, 4th Quarter 2006, Discretionary Groundwater Discharge Permit No. GW WB 082201 (January 12, 2007, submitted to SBSA) 


\subsubsection{Water Quality Monitoring Results}

A summary of the water quality results for the Sand Hill Road station is presented in Table 4-3, along with the discharge limits set forth in SLAC's permits.

Table 4-3 Water Quality at the Sand Hill Road Station

\begin{tabular}{|l|l|l|l|l|l|}
\hline \multirow{2}{*}{ Parameter } & \multicolumn{4}{|c|}{ SBSA Calculated Results (ppd) } & Wastewater \\
\cline { 2 - 6 } & February 7, 2006 & April 24, 2006 & July 31, 2006 & October 25, 2006 & $\begin{array}{l}\text { Wischarge } \\
\text { Limits }{ }^{(p p d)}\end{array}$ \\
\hline Cadmium & $<0.010$ & $<0.010$ & $<0.004$ & $<0.004$ & 0.036 \\
\hline Chromium & $<0.020$ & $<0.020$ & $<0.030$ & $<0.030$ & 0.18 \\
\hline Copper & 0.120 & 0.100 & 0.120 & 0.070 & 0.13 \\
\hline Lead & 0.040 & $<0.040$ & $<0.040$ & $<0.040$ & 0.33 \\
\hline Nickel & $<0.030$ & $<0.0300$ & $<0.030$ & $<0.030$ & 0.042 \\
\hline Silver & $<0.003$ & 0.004 & $<0.006$ & $<0.006$ & 0.036 \\
\hline Zinc & 0.248 & 0.122 & 0.450 & 0.160 & 0.45 \\
\hline pH $^{* \star}$ & 8.20 & 8.20 & 8.80 & 8.20 & $6.0-12.5$ \\
\hline
\end{tabular}

ppd = pounds per day

* Compliance is determined by comparing the mass discharge limit with the average of the samples taken for the previous 12 months.

** $\mathrm{pH}$ is regulated as Daily Maximum rather than an Annual Average Limit

SLAC was in compliance with all seven heavy metal limits during 2006. On an annual basis, SLAC discharged less than 50 percent of its permitted discharge limits with the exception of nickel (50 percent) and copper (60 percent), as shown in Figure 4-2.

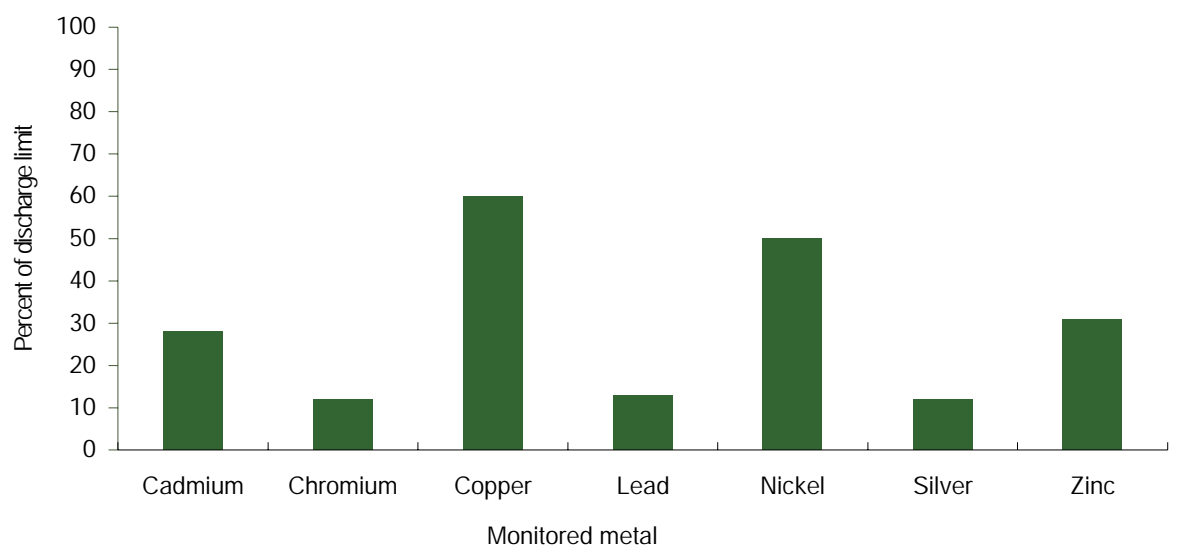

Annual average $=$ calculated average percent of discharge limit from quarterly sampling events

Figure 4-2 Water Quality at the Sand Hill Road Station

The analytical results and permit limits for water quality samples collected at the MFPF are presented in Table 4-4. SLAC was in compliance with all discharge limits on the three sampling dates. 
Table 4-4 Water Quality at the Metal Finishing Pre-treatment Facility

\begin{tabular}{|c|c|c|c|c|c|}
\hline \multirow[b]{3}{*}{ Analytical Parameter } & \multirow{2}{*}{\multicolumn{2}{|c|}{ Discharge Limits }} & \multirow{3}{*}{\begin{tabular}{|l}
$\begin{array}{l}\text { SBSA Annual } \\
\text { Sampling }\end{array}$ \\
November 9 \\
$\begin{array}{l}\text { SBSA Monitoring } \\
\text { Results (mg/L) }\end{array}$ \\
\end{tabular}} & \multicolumn{2}{|c|}{ SLAC Semi-Annual Sampling } \\
\hline & & & & March 26 & November 14 \\
\hline & $\begin{array}{l}\text { Federal Daily } \\
\text { Maximum (mg/L) }\end{array}$ & $\begin{array}{l}\text { Federal Monthly } \\
\text { Average (mg/L) }\end{array}$ & & $\begin{array}{l}\text { SLAC Monitoring } \\
\text { Results (mg/L) }\end{array}$ & $\begin{array}{l}\text { SLAC Monitoring } \\
\text { Results (mg/L) }\end{array}$ \\
\hline \multicolumn{6}{|l|}{ Metals } \\
\hline Cadmium & 0.11 & 0.07 & $<0.004$ & $<0.01$ & $<0.00008$ \\
\hline Chromium & 2.77 & 1.71 & $<0.03$ & $<0.04$ & 0.013 \\
\hline Copper & 3.38 & 2.07 & 0.47 & 0.37 & 0.28 \\
\hline Lead & 0.69 & 0.43 & $<0.04$ & $<0.04$ & 0.001 \\
\hline Nickel & 3.98 & 2.38 & 0.09 & 0.037 & 0.035 \\
\hline Silver & 0.43 & 0.24 & $<0.006$ & $<0.0136$ & 0.038 \\
\hline Zinc & 2.61 & 1.48 & 0.29 & $<0.03$ & 0.016 \\
\hline \multicolumn{6}{|l|}{ Non-metals } \\
\hline Cyanide & 1.20 & 0.65 & $<0.003$ & 0.024 & $<0.006$ \\
\hline pH (unitless) & $6.0-12.5$ & NA & 9.50 & 9.89 & 8.51 \\
\hline
\end{tabular}

1 All monitoring results, except for $\mathrm{pH}$, are expressed in units of milligrams per liter (mg/L).

$2 \mathrm{NA}=$ not applicable

\subsubsection{Best Management Practices Implementation Results}

The Industrial Wastewater Program started initiating best management practices (BMPs) in 2004 to reduce discharge of constituents of concern to the sanitary sewer. The following were accomplished in 2006 as part of this effort:

- A new BMP was developed and implemented to reduce the amount of copper discharged to the sanitary sewer. When practicable, water from the flushing of copper pipes will be collected and treated at the MFPF to remove metals prior to discharge to the sanitary sewer.

- $\quad$ ES\&H Manual Chapter 43, Industrial Wastewater, was updated and published. SLAC employees and contractors may refer to the chapter for guidance, contacts, and BMPs for the wastewater program.

\subsubsection{Summary and Future Plans}

SLAC discharges industrial and sanitary wastewater to the WBSD regional sewer collection system. These discharges originate from manufacturing locations such as SLAC's Plating Shop, heat exchange systems such as SLAC's six major cooling tower installations, and employee toilets and sinks throughout the facility. 
SLAC operates its industrial and sanitary wastewater management program in compliance with established permit conditions. In 2006, SLAC operated the program for the tenth consecutive year without receiving an NOV from program regulators.

The four existing industrial wastewater permits were combined into one site-wide permit. This permit consolidation allows SLAC to better manage its discharge and reporting requirements. SLAC plans to install an additional flow meter to track flow from the Interaction Region 6 (IR-6) area before discharging to the Alpine trunk line.

\subsection{Surface Water Management Program}

Stormwater leaves the 426-acre SLAC site through 25 drainage channels. In certain portions of the site, stormwater has the potential to come into contact with industrial activities or facilities. Such activities or facilities include metal working, outdoor storage, cooling towers, electrical equipment operation, and secondary containments. Many of the channels drain areas where the stormwater has little or no potential of exposure to industrial activities. SLAC has identified seven monitoring locations which are representative of stormwater discharges associated with industrial activities. These are listed below and shown in Figure 4-3.

- $\quad$ IR-8 Channel (IR-8)

- $\quad$ IR-6 Channel (IR-6)

- North Adit East Channel (NAE)

- $\quad$ Main Gate East Channel (MGE)

- $\quad$ IR-2 North Channel (IR-2)

- Building 81 North Channel (B81)

- Building 15 and Building 18 combined flow (B015/B018)

\subsubsection{Regulatory Framework}

Federal regulations allow authorized states to issue general permits to regulate industrial stormwater or non-point source discharges. California is an authorized state; and in 1991, the State Water Resources Control Board (SWRCB) adopted the industrial activities stormwater general permit, with the goal of reducing water pollution by regulating stormwater discharges associated with industrial activities. SLAC filed a notice of intent to comply with the general permit.

California's general permit was re-issued in 1997. SLAC adheres to the requirements of the general permit, through its development and implementation of a stormwater pollution prevention plan (SWPPP). ${ }^{14}$ The SWPPP has two main components: a stormwater monitoring program (SWMP) and a BMP program. ${ }^{15}$ The SWMP presents the rationale for sampling, lists the sampling locations, and specifies the analyses to be

14 Stanford Linear Accelerator Center, Environment, Safety, and Health Division, Environmental Protection and Restoration Department, SLAC Stormwater Pollution Prevention Plan (SLAC-I-7500A16M-002)

15 Stanford Linear Accelerator Center, Environment, Safety, and Health Division, Environmental Protection Department, "Stormwater", http://wwwgroup.slac.stanford.edu/esh/groups/ep/water/stormwater/ 
performed. The BMPs present a list of 17 generic and site-specific practices that serve to minimize the impact on stormwater from SLAC’s industrial activities (see Section 4.4.2.2).

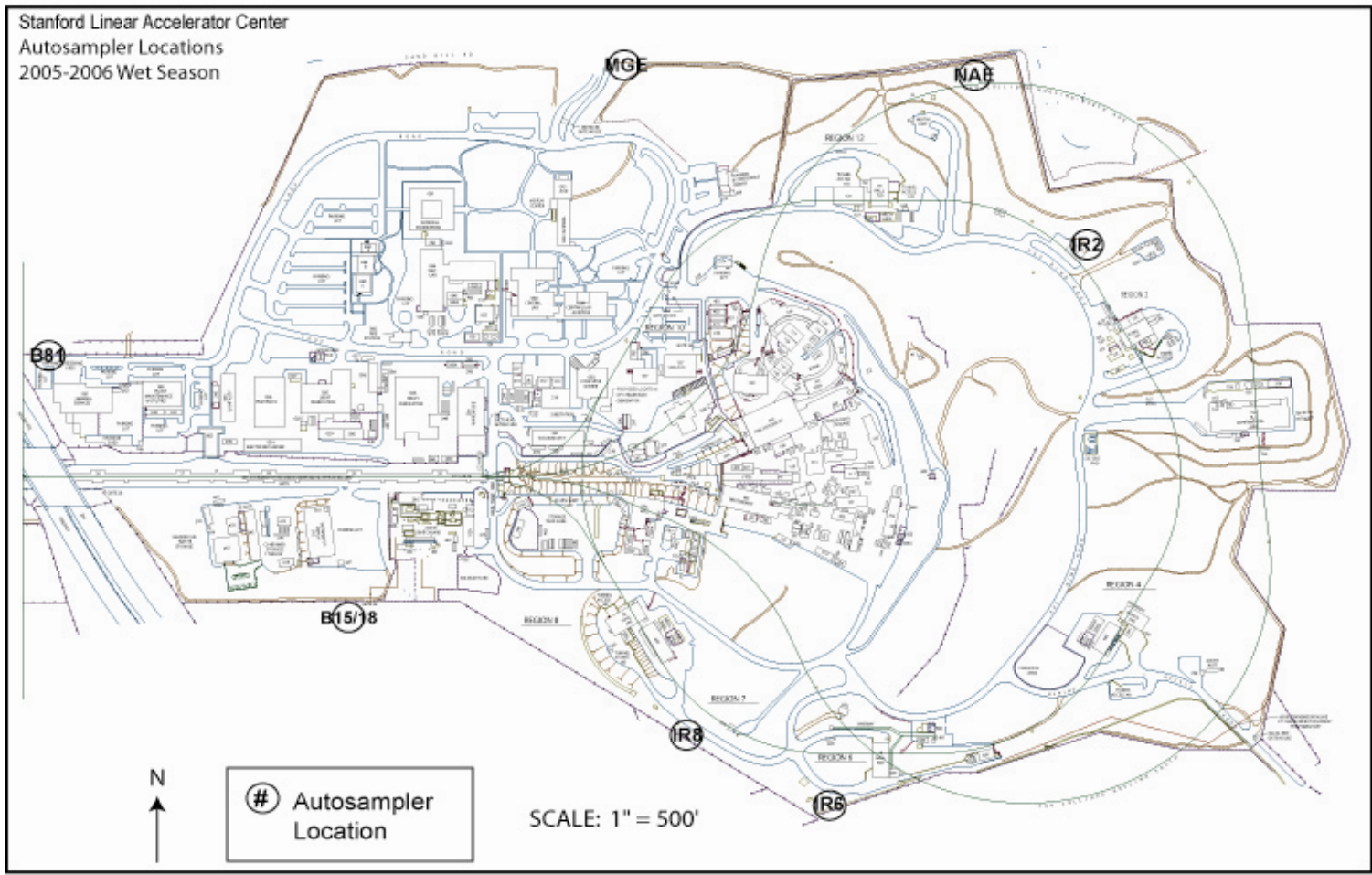

Figure 4-3 Surface Water Monitoring Locations

\subsubsection{Program Status}

\subsubsection{Water Quality Monitoring Results}

SLAC's SWMP incorporates all general permit sampling and analysis requirements, such as frequency (samples collected from first storm of season and one additional storm), locations (samples collected from locations where stormwater comes into contact with industrial activities), analytes (SLAC analyzes for five metal and nine non-metal analytes), and sampling methodologies.

The general permit's definition of wet season runs from October 1 through May 30. This reflects SLAC's climatological conditions, as rain rarely falls during June through September. Since the general permit's definition of wet season spans two calendar years, the 2006 water quality monitoring results published in the ASER are for the 2006-2007 wet season (October 2006 through May 2007). 
The general permit requires submission of an annual report on stormwater activities by July 1 , following the May 30 close of the wet season. ${ }^{16}$ SLAC met all sampling and analysis requirements in its SWMP and delivered its annual report, which included all water quality monitoring results, to the RWQCB.

Automated samplers are located at each of the stormwater monitoring sites. The samplers are triggered by rain gauges and level sensors. Samples are collected during the first storm event at each location and one other event during the rainy season. During the 2006-2007 wet season, 14 samples (two samples per location) were collected during four storm events.

Stormwater samples were analyzed for 14 parameters. Many of the parameters that SLAC monitors have parameter benchmark values (PBVs) established by the SWRCB ${ }^{17}$ Note that PBVs represent a threshold at which BMPs should be re-evaluated for effectiveness, not numerical discharge limits.

Table 4-5 summarizes the results and compares them to the PBVs. The majority of the analytical results (77 percent) were below the PBVs. Analytes that exceeded the PBVs were primarily specific conductance, aluminum, iron, zinc and total suspended solids (TSS). In an effort to reduce the metals and TSS levels, prior to the 2006/07 wet season, SLAC increased the preventive maintenance, including annual site-wide street cleaning, as discussed in the next section.

\subsubsection{Stormwater Management Improvements}

BMPs are implemented at SLAC to reduce the potential for stormwater to come into contact with industrial activities. The BMPs are one component of an environmental management system that includes planning, implementing, checking, and improving performance.

BMP and surface water program-related accomplishments during 2006 included the following:

- The stormwater awareness training frequency has been increased and will now be required once every three years for affected employees

- Increased preventive maintenance schedule for stormwater protection activities including annual sitewide street cleaning has continued

- Infrastructure improvement projects: End Station A/End Station B project to remove potential unauthorized connections to the stormdrain system continued in 2006

- EP staff worked closely with LCLS staff to provide guidance on the development of the construction SWPPP and oversight for stormwater protection activities

- ES\&H Manual Chapter 26, Stormwater was updated and published. The chapter includes guidance, contact information, and BMPs for the stormwater program.

16 Stanford Linear Accelerator Center, Environment, Safety, and Health Division, Environmental Protection Department, 2005-2006 Annual Stormwater Report (30 June 2007, submitted to Rico Duazo, San Francisco Bay RWQCB)

17 State of California, State Water Resources Control Board, Sampling and Analysis Reduction Certification (no date), http://www.swrcb.ca.gov/stormwtr/docs/smanlrdc.doc 
Table 4-5 Water Quality Results and Comparison to Parameter Benchmark Values

\begin{tabular}{|l|l|l|l|l|l|r|}
\hline Analyte & Units & $\begin{array}{l}\text { Number } \\
\text { of } \\
\text { Results }\end{array}$ & $\begin{array}{l}\text { Number } \\
\text { of } \\
\text { Detects }\end{array}$ & $\begin{array}{l}\text { Maximum } \\
\text { Conc. } \\
\text { Detected }\end{array}$ & $\begin{array}{l}\text { SWRCB } \\
\text { PBV (1) }\end{array}$ & $\begin{array}{l}\text { Number of } \\
\text { Results } \\
\text { >PBV }\end{array}$ \\
\hline Metals & & & & & & 10 \\
\hline Aluminum & $\mathrm{mg} / \mathrm{L}$ & 14 & 14 & 18 & 0.75 & 2 \\
\hline Copper & $\mathrm{mg} / \mathrm{L}$ & 14 & 14 & 0.19 & $0.0636(\mathrm{H})$ & 10 \\
\hline Iron & $\mathrm{mg} / \mathrm{L}$ & 14 & 14 & 27 & 1 & 6 \\
\hline Lead & $\mathrm{mg} / \mathrm{L}$ & 14 & 14 & 0.11 & $0.0816(\mathrm{H})$ & \\
\hline Zinc & $\mathrm{mg} / \mathrm{L}$ & 14 & 14 & 0.97 & $0.117(\mathrm{H})$ & 5 \\
\hline Non-Metals & & & & & & 0 \\
\hline Total Suspended Solids & $\mathrm{mg} / \mathrm{L}$ & 14 & 14 & 900 & 100 & $\mathrm{NA}$ \\
\hline Total Organic Carbon & $\mathrm{mg} / \mathrm{L}$ & 14 & 14 & 43 & 110 & 11 \\
\hline pH & $\mathrm{SU}$ & 14 & 14 & 8.39 & $6-9$ & 0 \\
\hline Turbidity & $\mathrm{NTU}$ & 14 & 14 & 150 & $\mathrm{NA}$ & $\mathrm{NA}$ \\
\hline Specific Conductance & $\mu \mathrm{s}$ & 14 & 14 & 3700 & 200 & 45 \\
\hline Polychlorinated Biphenyls & $\mathrm{mg} / \mathrm{L}$ & 14 & 0 & $\mathrm{ND}(2)$ & 0.000477 & \\
\hline Radioactivity & $\mathrm{pCi} / \mathrm{L}$ & 14 & 0 & $\mathrm{ND}(2)$ & $\mathrm{NA}$ & \\
\hline Total & & 168 & 140 & & & \\
\hline
\end{tabular}

Notes:

1 SWRCB parameter benchmark values are available at www.swrcb.ca.gov/stormwtr/docs/smanlrdc.doc. Metal PBVs shown are on a total metal basis. $(\mathrm{H})$ signifies that this is a hardness dependant benchmark. The PBV shown for polychlorinated biphenyls (PCBs) is for Aroclor-1260. SWRCB PBVs have not been set for chromium, molybdenum, radioactivity (tritium, gamma), or turbidity. SLAC may choose to develop benchmarks for site specific conditions.

2 The analyte was not detected in any of the samples for which it was analyzed.

$N A=$ Not available

$\mathrm{ND}=$ Not detected

\subsubsection{Summary and Future Plans}

SLAC discharges stormwater with the potential to come into contact with industrial activities. An extensive monitoring program is in place at the seven discharge locations where past sampling results indicate the greatest potential exists for industrial contact. During the 2006-2007 wet season, SLAC met all requirements of its surface water monitoring plan.

In 2006, SLAC operated its surface water program for the fourteenth consecutive year without receiving NOVs from regulatory agencies. When analytical results from the 2006-2007 wet season were compared with the PBVs, more than seventy percent of all the parameter results were below the benchmarks. SLAC continued to actively pursue several BMP-related performance improvements during the year.

\subsection{Hazardous Materials Management}

SLAC uses hazardous materials as part of its experimental programs in high-energy physics and synchrotron radiation. For instance, isobutane and the refrigerant H-134a are used to create detector atmospheres with the appropriate physical and chemical properties to aid in detecting subatomic particles. In addition, SLAC uses hazardous materials in the manufacturing and maintenance of accelerator devices. Examples of hazardous materials managed at SLAC include 
- Cryogens

- Flammable gases

- Compressed gases

- Acids and bases

- Solvents

- Adhesives

- Paints and epoxies

- Metals

Hazardous materials management spans numerous programs; but the purpose remains the same: to ensure the safe handling of hazardous materials in order to protect workers, the community, and the environment.

\subsubsection{Regulatory Framework}

The regulatory framework for hazardous materials regulations, especially in California, has historically been a complex and overlapping web of statutes and regulations. Some of the most important regulatory drivers at the federal level include Title III of the Superfund Amendments and Reauthorization Act of 1986 (SARA) also referred to as the Emergency Planning and Community Right-to-Know Act (EPCRA) which focuses on community safety, the Occupational Safety and Health Act (1970) addressing worker safety, the Hazardous Materials Transportation Act whose purpose is to ensure the safe transport of hazardous materials in commerce and the Toxic Substances Control Act (TSCA).

Important drivers at the state level generally date back to the mid-1980s and include hazardous materials business plans (HMBP), the California Accidental Release Prevention Program (CalARP), the underground and aboveground storage tank programs, and the pollution prevention and waste minimization program.

In general, the implementing agency for hazardous materials regulation in California is the California certified unified permitting agency (CUPA). The Environmental Health Division of the San Mateo County Health Services Agency is the CUPA responsible for overseeing hazardous materials and waste management at SLAC. A CUPA has broad enforcement responsibilities in the following six hazardous material subject areas:

- Aboveground storage tanks/spill prevention control and countermeasures (AST/SPCC programs)

- Hazardous Materials Business Plan (HMBP)

- California Accidental Release Prevention (CalARP)

- Uniform Fire Code hazardous materials issues

- $\quad$ Underground storage tanks (USTs)

- $\quad$ Pollution prevention and waste minimization

\subsubsection{Program Status}

Discussed in the following sections are the status of SLAC's current programs related to hazardous materials management, including its hazardous materials business plan, toxics release inventory (TRI), and CalARP programs. Also discussed are SLAC's above ground storage tanks program and its polychlorinated biphenyls (PCBs) management program under the TSCA. 


\subsubsection{Annual Facility Enforcement Inspection}

The CUPA did not perform inspections of SLAC during 2006.

\subsubsection{Hazardous Materials Business Plan Program}

The EPCRA was passed in 1986 as Title III of the SARA, which established requirements for emergency planning, notification, and reporting. In California, the requirements of SARA Title III are incorporated into the state's Hazardous Materials Release Response Plan and Inventory Law, more commonly referred to as the HMBP program.

For the 2006 reporting year, SLAC updated its HMBP and electronically submitted it through the Uniform documents (Unidocs) web tool to the CUPA on April 1, 2007. The HMBP includes a list of all hazardous materials present at SLAC in amounts exceeding the state's aggregate threshold quantities (55 gallons for liquids, 500 lbs for solids, and 200 cubic feet for compressed gases) on a building-by-building basis. The inventory includes hazardous materials and waste. The hazardous materials inventory is based on procurement data generated through the CMS. The hazardous waste inventory is based on the database maintained by the Waste Management group. The CMS maps are used to indicate storage area locations. The plan also includes the SLAC Consolidated Chemical Contingency Plan. ${ }^{18}$ This plan combines the emergency response requirements for the following programs:

- Hazardous materials business plan

- Hazardous waste contingency plan

- Spill prevention control and countermeasure plan

- Risk management plan

This was the second year that the HMBP was submitted electronically through the Unidocs system utilizing the maps and chemical information developed as part of the CMS. Information generated by chemical storage asset custodians, will be used to help maintain the accuracy of the CMS maps. The plans for the future include the Unidocs functionality for determining control area quantities and defined in the fire code for hazardous material storage.

\subsubsection{Toxics Release Inventory Program}

Under Executive Order 13148, “Greening the Government through Leadership in Environmental Management", the DOE requires its facilities to comply with the Toxic Chemical Release Reporting and Community Right-to-Know requirements (40 CFR 312), more commonly referred to as the TRI program. SLAC annually provides the appropriate information to meet these program requirements to the DOE. Submittals go to the DOE Stanford Site Office (SSO) which provides the information to DOE Headquarters. The information from all DOE facilities is then rolled up and reported to the USEPA.

Of the more than 400 listed TRI chemicals, only two, lead and copper, are reported at SLAC in excess of their respective regulatory threshold criteria. As a result, SLAC prepared release inventory forms for lead and copper and submitted them to the DOE SSO on June 26, 2006, in advance of the July 1, 2006, deadline.

18 SLAC Consolidated Chemical Contingency Plan (SLAC-I-730-3A86H-008) 


\subsubsection{California Accidental Release Prevention Program}

In August 2004, SLAC received a letter from the CUPA instructing SLAC to update its chemical inventory information to determine whether SLAC had any regulated chemicals in excess of the CalARP thresholds. Only one chemical was found: potassium cyanide, which is used only in the Plating Shop complex. Accordingly, the CUPA determined that a risk management plan (RMP) would be necessary.

After extensive investigation and discussion, it was determined that, because the worst-case scenario for a release of potassium cyanide did not generate offsite consequences, more detailed process hazard assessment and consequence analysis was not required. The final Program 1 RMP for SLAC was submitted to the CUPA on September 1, 2006, and received 100 percent certification from the CUPA. A follow-up site visit is scheduled in 2007, primarily to observe operations in the Plating Shop and verify the information provided in the RMP.

\subsubsection{Aboveground Storage Tank Program}

ASTs are regulated under the authority of the CWA and California's Aboveground Petroleum Storage Act. A listing of ASTs containing petroleum at SLAC during 2006 is presented in Table 4-6. All of the petroleum tanks at SLAC are constructed of steel. Each tank is either double-walled, or has a cinder-block or poured-concrete containment basin surrounding the tank base.

Table 4-6 Aboveground Petroleum Tanks

\begin{tabular}{lllr} 
Petroleum Product & Property Control Number & Location & Capacity (gallons) \\
\hline Diesel & 20501 & B023 Central Utility & 10,000 \\
Diesel & 19683 & B112 Master Substation & 2,000 \\
Gas/Diesel & 21443 & B035 Vehicle Refueling Station & $1,500 / 500$ \\
*Vacuum Oil & 19596 & B020 North Damping Ring & 516 \\
Diesel & NA & B082 Fire Station & 500 \\
Diesel & NA & B505A Generator Fueling & 500 \\
Diesel & NA & B007 MCC Generator Fueling & 500 \\
*Vacuum Oil & 19595 & B021 South Damping Ring & 260 \\
X-ray Oil & 15192 & B044 Klystron Test Lab & 900 \\
X-ray Oil & 15192 & B044 Klystron Test Lab & 400 \\
Compressor Oil & NA & B127 Cryogenics & 200 \\
Compressor Oil & 18562 & B127 Cryogenics & 200 \\
Diesel & NA & B756 SLD Generator Fueling & 500 \\
* These tanks are used only for short-term storage & &
\end{tabular}

An SPCC plan is required by 40 CFR 112 for all petroleum-containing ASTs greater than 660 gallons in size. The SLAC SPCC plan remains up to date and is available on line. ${ }^{19}$

19 Stanford Linear Accelerator Center, Environment, Safety, and Health Division, Environmental Protection Department, Spill Prevention, Control, and Countermeasures Plan (SLAC-I-750-0A16M001), https://www-internal.slac.stanford.edu/esh/documents internal/SPCC.pdf 
SLAC did not have any USTs in operation during 2006. All USTs previously in operation have been removed.

\subsubsection{Toxic Substances Control Act Program}

The objective of TSCA is to minimize the exposure of humans and the environment to chemicals introduced by the manufacturing, processing, and commercial distribution sectors. One portion of TSCA regulates equipment filled with oil or other dielectric fluids that contain PCBs.

TSCA regulations are administered by the USEPA. No USEPA inspections regarding TSCA were conducted at SLAC during 2006.

At the end of 2006, 99 transformers were in service at SLAC. Transformers with PCB concentrations equal to or greater than 50 parts per million (ppm) but less than 500 ppm are defined by TSCA as PCBcontaminated transformers. Of the 99 transformers in service at SLAC, only 16 are PCB-contaminated. SLAC has no PCB transformers (transformers with concentrations of PCB equal to or greater than 500 $\mathrm{ppm}$ ). The total quantity of PCBs contained in the 99 transformers currently in service is approximately 24 lbs.

A project related to TSCA that was performed during 2006 was the lining of three cracked secondary containments where oil-filled transformers are located. The transformers in all three secondary containments are defined by TSCA as non-PCB (transformers with concentrations of PCBs less than 50 ppm).

\subsubsection{Chemical Management System}

SLAC has officially been purchasing chemicals solely through Haas tcm (Haas) since August 2005 under its CMS. Haas provides all sourcing, purchasing, expediting, and vendor management support for all nonradioactive chemicals and gases used by SLAC.

The key objectives of the CMS program at SLAC are to:

- Reduce SLAC's chemical and gas cost through vendor leveraged buying power

- Reduce SLAC's risk and space requirements associated with storing, managing and handling chemicals

- Reduce time spent by SLAC researchers and other personnel on sourcing, ordering and tracking chemicals

By the end of calendar year 2006, the program has achieved the following:

- 1774 active chemicals were set up in the catalogue

- Over \$52,000 in vendor-owned inventory stocked for just-in-time delivery

- There were 309 users of the CMS system

- Purchase order cycle time is less than 1 business day on average

- Total savings on indexed baseline prices for gain sharable items was \$59,661 


\subsection{Waste Minimization and Management}

During the course of its research operations, SLAC generates a variety of waste streams, including hazardous waste, non-hazardous industrial waste, municipal solid waste, and scrap metal.

Whenever practicable, SLAC actively practices the pollution prevention hierarchy with respect to each of these waste streams:

- First, reduce waste and prevent pollution at the source through process changes, substitutions, and work practices

- Second, reduce waste and prevent pollution by reusing or recycling materials

- Third, reduce waste and prevent pollution by using appropriate control technologies

- Finally, after exhausting the first three approaches, exercise proper disposal

The following performance measures in the operating contract between the DOE and Stanford University reflect the importance that both parties place on waste minimization: ${ }^{20}$

- SLAC will reduce its generation of hazardous waste from routine operations by 69 percent by the year 2006 using 1993 as the baseline year

- SLAC will recycle 53 percent of its municipal solid waste by the year 2006

\subsubsection{Waste Minimization Accomplishments}

SLAC has achieved both of its waste minimization goals since the year 2000.

SLAC continues to make progress in reducing hazardous waste generated from routine operations, as shown in Figure 4-4. For 2006, SLAC reduced generation of hazardous waste from routine operations by 71 percent from the 1993 baseline. The goal for FY06 was to achieve a 69 percent reduction in routine hazardous waste relative to the 1993 baseline. The percent reduction that has been achieved over the last four years indicates that waste generation and reduction has been relatively stable for routine hazardous waste. Part of the reason for the stability is because larger waste reductions were easier to achieve in the past. Additional measures, that may be more focused and more difficult to implement, are needed to address hazardous wastes from smaller but more numerous hazardous waste generators. Additional measures to reduce hazardous waste may be taken in the future by helping smaller generators increase their awareness of waste reduction opportunities and helping them learn to develop for themselves more focused waste reduction measures for their work areas.

20 Stanford Linear Accelerator Center, Environment, Safety, and Health Division, “ISEMS: Performance Measures”, http://www-group.slac.stanford.edu/esh/general/isems/perfmeas/ 


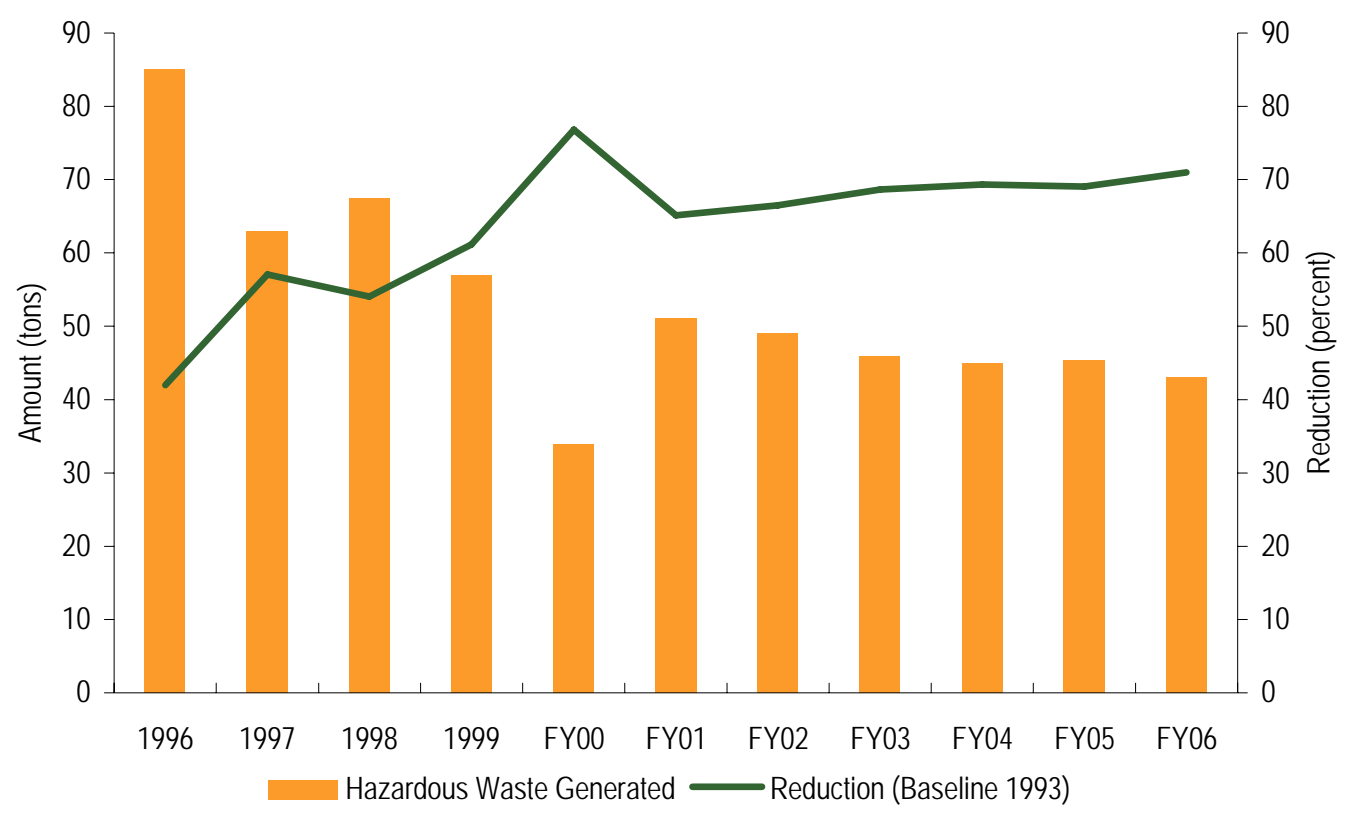

Figure 4-4 Hazardous Waste Generation, 1996-2006

SLAC's progress in recycling its municipal solid waste is shown in Figure 4-5. For 2006, SLAC recycled 71 percent of its municipal solid waste. The goal for FY06 was to achieve 53 percent recycling.

The term municipal solid waste refers to the following waste streams generated at SLAC:

- Beverage containers (glass, aluminum, plastic)

- Paper (white paper, mixed paper)

- Cardboard

- Wood

- Scrap metal

- Garden/landscaping waste

- Construction debris (asphalt, concrete, and soils)

- Universal (fluorescent light bulbs and mercury-containing equipment) and electronic wastes

- Batteries (automotive and common (AA, AAA, C, D, nickel-cadmium, other) batteries)

- Office materials (toner and inkjet cartridges)

- Trash not otherwise sorted at the source and placed into dumpsters 


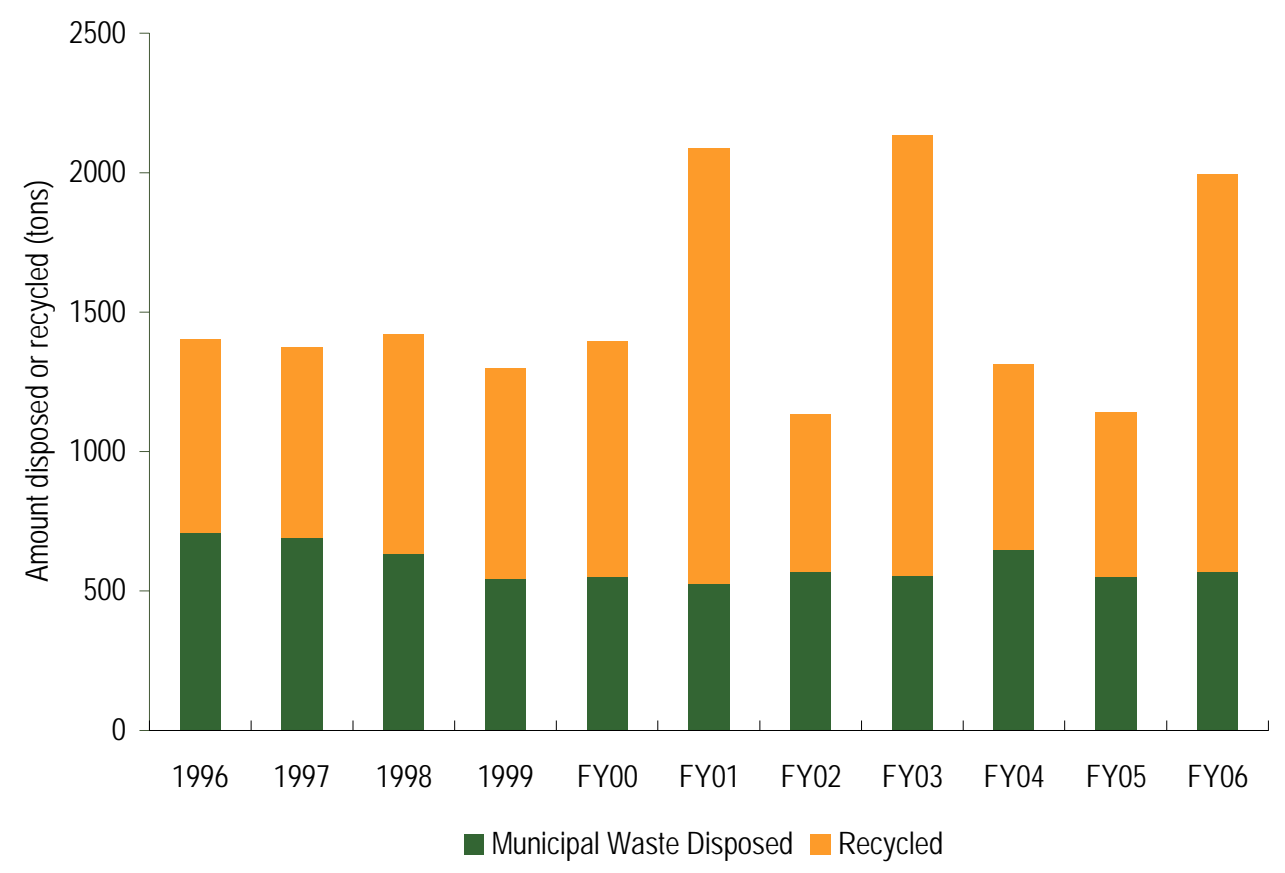

Figure 4-5 Municipal Solid Waste Recycling, 1996-2006

Waste minimization and pollution prevention projects initiated during the last ten years and continuing during 2006 are listed in Table 4-7.

In addition to the projects below, SLAC has been continuing to perform process waste assessments or pollution prevention opportunity assessments (PPOAs) and pollution prevention projects to reduce the use of toxic materials, to conserve resources, and to prevent pollution in a technically and economically feasible manner for the future. Assessments and projects are in the following areas:

- As a PPOA, SLAC investigated the feasibility of taking waste concrete blocks and creating rubble for reuse in road bed construction projects. When concrete is not associated with radiological control areas, on-site or off-site reuse of concrete rubble for road bed is an attractive option to off-site disposal because of the potential to reduce off-site transportation costs. As a result of this PPOA, 262 tons of concrete were recycled in 2006 by sending this material to a local recycling firm for reuse as road bed rubble.

- Reviewed SLAC's inventory and generation of electronic waste and investigated options for improved reuse and recycling of waste materials as a measure to ensure there is no misuse of hazardous materials in overseas markets.

- Performed PPOAs that reviewed the use of trichloroethylene as a chemical cleaner for electron gun cathodes and the use of hexavalent chromium in plating operations. No alternative for trichloroethylene in this application is readily available at this time without substantial research. Based on review of alternatives to hexavalent chromium usage and regulations which encourage elimination of hexavalent chromium, SLAC Mechanical Fabrication Department, Metal Finishing Operations, will be replacing hexavalent chromium with less toxic alternatives in FY07. 
Table 4-7 Waste Minimization and Pollution Prevention Projects

\begin{tabular}{lll} 
Name/Description & $\begin{array}{l}\text { Year } \\
\text { Initiated }\end{array}$ & Waste Reduction/Pollution Prevention Result \\
\hline $\begin{array}{l}\text { Reduction of ferric chloride } \\
\text { and filter cake in the }\end{array}$ & 2002 & $\begin{array}{l}\text { As of 2004, SLAC reduced generation of hazardous waste (filter } \\
\text { cake) by an average of 49 percent over a three year period relative } \\
\text { treatment of rinse waters }\end{array}$ \\
$\begin{array}{l}\text { from metal finishing } \\
\text { to 1998 and per gallon of rinse water treated }\end{array}$
\end{tabular}

operations

Off-site recycling program for laser printer and ink jet cartridges

Transportation pollution prevention program

Reduction of equipment using class I ozonedepleting substances (Class I ODS)

Two-mile klystron gallery lighting upgrade

Chemical Management Service (CMS)

Water Conservation

Development of EMS Objectives and Targets

Incorporating pollution prevention initiatives into the Linear Coherent Light Source Project

Revision of the Hazardous Waste Chapter and the Waste Minimization and Pollution Prevention Chapter in SLAC ES\&H Manual

Phase out of old gas tanks
2002

SLAC completed a two phase project to reduce energy usage and pollution by replacing lower-efficiency lighting system with a highefficiency one in the 2-mile linear accelerator saving over 4.4 million kilowatt-hours of electricity per year, reducing greenhouse gases generated from electricity generation, and reducing mercury usage.

for off-site recycling of spent laser printer and ink jet cartridges - recycled 342 cartridges in FY05 and vendor contributed $\$ 1$ per recycled cartridge to charity

SLAC became the first DOE Office of Science facility to order and dispense only Bio-diesel 20 for all its diesel applications. Also, 25 electric powered vehicles are in use. Three old DOE-owned motor vehicles were replaced with GSA alternative fuel vehicles.

Phased out 3 chillers (pre-1984, over 150 ton cooling capacity each) that used Class I ODS

The CMS program is fully implemented. Through streamlining the chemical supply chain has removed the need to order excess chemicals.

A pilot project is in progress to conserve water through the use of waterless urinals.

EMS Objectives and Targets were developed to help further integrate pollution prevention into SLAC day-to-day activities

A number of environmental initiatives have been included in the LCLS Project while it is in the design and construction phase procurement of recycled material content products, soil reuse, radioactive materials reuse, pollution prevention measures to prevent soil and water contamination from lead, construction measures to prevent soil erosion and stormwater pollution

Developed improved procedures and guidance for management of hazardous waste by employees and for the implementation of waste minimization and pollution prevention (WM/P2). SLAC achievements in WM/P2 are presented site-wide through a SLACimplemented recognition program for employees.

Using the CMS, SLAC reviewed its use of gasses and associated tanks and phased out numerous gas tanks that were no longer needed or were not acceptable for long-term storage, in turn, reducing SLAC's on-site chemical inventory. 


\subsubsection{Hazardous Waste Management}

SLAC is a 90-day hazardous waste generator. SLAC does not have a Resource Conservation and Recovery Act (RCRA) Part B permit that would allow it to treat hazardous waste, store it on site, and/or dispose of it on site (that is, a treatment, storage, and disposal facility permit) under the federal-level RCRA regulations. SLAC does have permits to treat a few RCRA-exempt and non-RCRA (that is, California-only) hazardous waste streams (see Section 4.6.2.3 regarding the state-level tiered permit program).

\subsubsection{Regulatory Framework}

The RCRA provided cradle-to-grave authority to regulate hazardous wastes, from their generation to their ultimate disposal. Regulation is through a system of recordkeeping, permitting, monitoring, and reporting.

The primary objective of RCRA was to protect human health and the environment. A secondary objective was to conserve valuable material and energy resources by promoting beneficial solid waste management, resource recovery, and resource conservation systems.

The USEPA has delegated authority to the state of California for implementing the federal RCRA program. In turn, the state has delegated its authority for certain aspects of hazardous waste program oversight to CUPAs; the San Mateo County Health Services Agency, Environmental Health Division serves as the CUPA tasked with overseeing SLAC’s hazardous waste management.

\subsubsection{Annual Facility Enforcement Inspection}

The CUPA did not inspect the hazardous waste generation program in 2006.

\subsubsection{Hazardous Waste Generation and Tracking}

SLAC utilizes a self-developed, site-specific computerized hazardous waste tracking system (WTS). Hazardous waste containers are tracked from the time they are issued to the generator to eventual disposal off-site. The WTS includes fields that generate information for the biennial SARA Title III, TRI, and TSCA PCBs annual reports.

SLAC categorizes the hazardous wastes it generates into the following categories:

- Hazardous wastes from routine laboratory operations

- Hazardous wastes considered to be TSCA-regulated waste

- Hazardous wastes resulting from remediation and/or cleanup/stabilization projects

Hazardous wastes regulated by the TSCA at SLAC result from two sources: removal of old electrical equipment containing PCBs and construction projects containing asbestos. TSCA wastes result from the phasing-out of these chemicals from use at SLAC. SLAC's progress in reducing the quantities of TSCA waste from these sources is shown in Figure 4-6. Specifically, during FY05, SLAC achieved a 99 percent reduction in its TSCA waste generation compared with a 1990 baseline. SLAC has no changes to report for reducing this waste since none of the small percentage of transformers containing PCBs were retrofilled or taken out of service during 2006. 


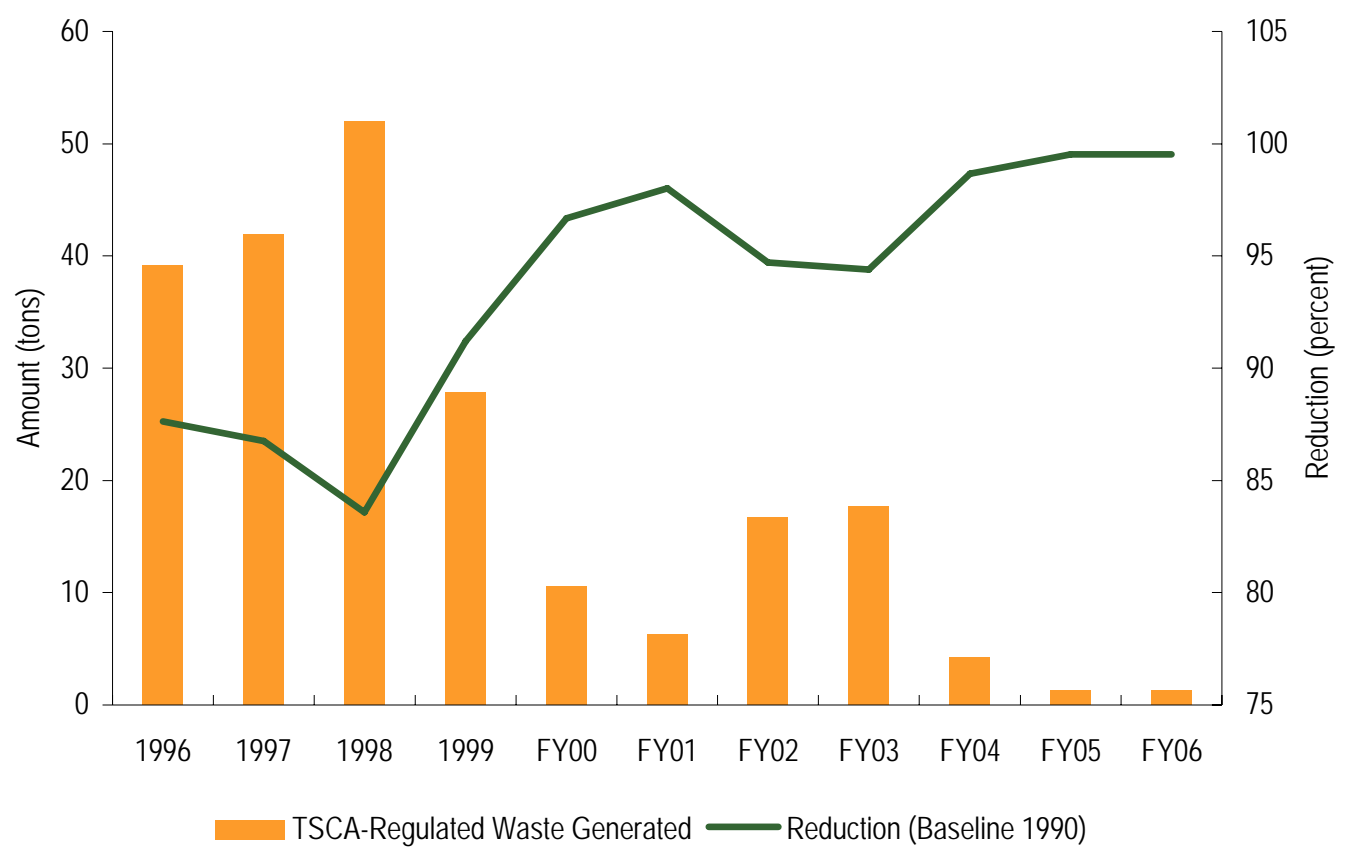

Figure 4-6 TSCA-Regulated Hazardous Waste, 1996-2006

Remediation wastes result from cleanup of soil and groundwater contaminated by historical management practices or accidental spills. Common remediation wastes at SLAC include metal- and PCB-contaminated soils, and volatile and semi-volatile organics in groundwater. Annual quantities of remedial waste generated vary based on projects scheduled for any given year. For a discussion of SLAC's environmental restoration programs that result in the generation of remediation wastes, see Chapter 6 .

SLAC's hazardous waste generation rates have been reduced through a combination of waste minimization and pollution prevention techniques, including the following:

- Reducing generation of excess chemicals through CMS

- Converting empty metal containers and drums to scrap metal

- Exchanging chemicals with other users

- Reclassifying waste streams to reduce hazardous waste volumes

- Reusing chemicals

- Returning unused material back to the vendor or manufacturer

- Sending electrical equipment off site for reuse by other organizations

SLAC expects to continue to make progress in reducing the generation of hazardous waste from routine laboratory operations, although in much smaller increments than was previously the case. Additionally, the generation of TSCA and remediation wastes will decrease as SLAC continues to phase out its use of PCBs, removes soils impacted with PCBs, and removes asbestos-containing materials. 


\subsubsection{Hazardous Waste Treatment: Tiered Permitting Program}

The five tiers of California hazardous waste permits, presented in order of decreasing regulation, are called full permit, standard permit, permit by rule, conditional authorization, and conditional exemption. SLAC operates a total of six hazardous waste treatment units, five under permit by rule and one under conditional authorization. These units are authorized to treat listed or characteristic hazardous wastes. The various units and tiered permit level are summarized in Table 4-8.

The CUPA did not inspect the tiered permitting program in 2006.

Table 4-8 Hazardous Waste Treatment Units Subject to Tiered Permitting

\begin{tabular}{lll} 
Tiered Permit Level & Unit Number & Location/Description \\
\hline Permit by rule & Unit 1A & Cyanide Treatment Tanks \\
Permit by rule & Unit 1B & Metal Finishing Pre-treatment Facility \\
Permit by rule & Unit 1C & Batch Hazardous Waste Treatment Tank \\
Permit by rule & Unit 2 & Metal Finishing Pre-treatment Facility - Sludge Dryer \\
Conditional authorization & Unit 4 & Groundwater Treatment System at the FSUST \\
Permit by rule & Unit 5 & Groundwater Treatment System at the FHWSA
\end{tabular}

Based on correspondence with the California Department of Toxic Substances Control (DTSC), the original MFPF (Unit 1) was not fully authorized because of the cyanide treatment operations, which SLAC had included in the original MFPF permit. As a result, SLAC split out the original MFPF into the above units $(1 \mathrm{~A}, 1 \mathrm{~B}$, and $1 \mathrm{C})$ to more clearly demark the treatment operations of the MFPF. SLAC continues to await inspection of these units by the DTSC to affirm that Tiered Permit requirements are being met for the cyanide treatment tanks (Unit 1A).

\subsubsection{Non-hazardous Waste Management}

Non-hazardous waste can be grouped into non-hazardous industrial waste and municipal solid waste.

\subsubsection{Non-hazardous Industrial Waste Management}

In addition to its hazardous waste management program, SLAC also operates various projects that involve disposal of non-hazardous waste called here non-hazardous industrial or regulated waste. SLAC's WM Group manages industrial waste resulting from SLAC's laboratory operations and remediation operations that, while not classified as hazardous, is not sufficiently "clean” to be disposed of in a municipal or sanitary solid waste landfill. Examples of industrial wastes include soils contaminated with low levels of petroleum hydrocarbons, PCBs or metals such that qualify as non-hazardous but are not acceptable to municipal landfills. In California, industrial wastes are generally termed Class 2 wastes, since they are specifically required to be sent to what are known as Class 2 landfills (these provide an intermediate level of protection to the environment between Class 1, hazardous waste landfills and Class 3, municipal solid waste landfills).

\subsubsection{Municipal Solid Waste Management}

SLAC's CEF Department operates a municipal solid waste program that collects a variety of recyclable materials as well as regular dumpster refuse. SLAC’s Property Control Department operates a salvage 
operation that sells metal and other industrial recyclables (construction materials, for example, concrete, clean soils, asphalt, wood) and equipment for their cash value. SLAC integrates the results of its metal salvage operations when reporting data about its municipal solid waste program. For FY06, SLAC also started including electronic waste collected under salvage operation as a recyclable material.

A site-wide program that recycles white paper, mixed paper, beverage containers (glass, aluminum, and plastic), cardboard, and scrap wood has been fully operational for more than 10 years. Collection stations are strategically distributed around the site with each station incorporating anywhere from one to a dozen green containers. Dumpsters for cardboard collection are strategically place around the site and a specific location is provided for waste wood. Scrap metal and electronic waste is collected and construction materials from building demolition and rehabilitation projects are also recycled. The contributions of the various waste streams being recycled are shown in Figure 4-7.

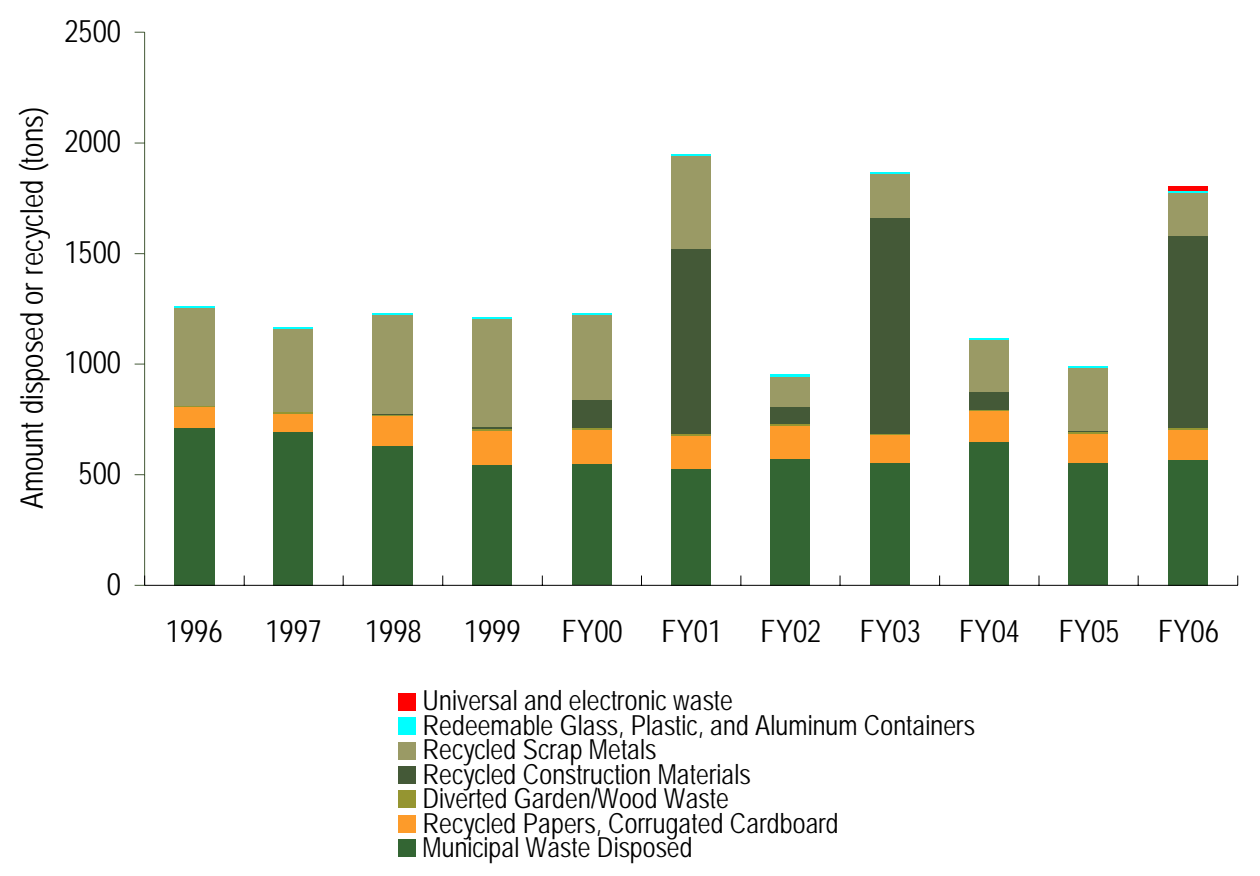

Figure 4-7 Municipal Solid Waste Recycling and Disposal, 1996-2006

\subsubsection{Other Waste Management Activities}

SLAC generates a small quantity of low-level radioactive waste every year; this waste stream is discussed in Chapter 5.

SLAC generates a small quantity of medical waste generated by the on-site Medical Department. In California, the state Medical Waste Management Act requires proper storage, treatment, and disposal of medical waste. The state program is administered by the California Department of Health Services.

Note: Batteries and office materials, although recycled, are not reported because quantities are small relative to the above. 


\subsection{Environmental Planning}

SLAC's scientific and support facilities were constructed under a clearly conceived planning framework established in the site's original general development plan (1961) and master plan (1966). For nearly four decades, SLAC facilities expanded within this original framework, but over the years, many small support and storage buildings and more parking demands have crowded the core research areas and obscured the original circulation plan. To meet the challenges of constructing major new projects in this constricted and environmentally sensitive location, SLAC employs two primary tools: National Environmental Policy Act (NEPA) analyses on a project-by-project basis, and conformance with SLAC's LRDP. ${ }^{21}$

\subsubsection{SLAC Long Range Development Plan}

In December 2002, SLAC published its LRDP, the result of both SLAC's LRDP Working Committee and the professional land use, environmental, and campus planners from the Stanford University Architect and Planning Office. The LRDP was revised in June 2003.

The LRDP encourages the gradual replacement of small, outdated structures with more efficient and wellplanned development. The plan includes a series of diagrams that overlay planned structures and circulation systems with environmental constraints to intelligently guide the location of future projects. Environmental factors considered in developing the plan include the following:

- Geology and seismicity

- Topography

- Sedimentation and erosion potential

- Hazardous materials

- Considerations of site locations relative to sensitive receptors

- Flooding and wetlands

- Habitat and species protection

- Visual character of SLAC

\subsubsection{National Environmental Policy Act}

SLAC developed its NEPA program in 1992. It is administered by SLAC's Operations Directorate, with staff from the EP Department providing environmental resources input and document review as requested. Under this program, proposed projects and actions are reviewed to evaluate whether NEPA documentation is required. If it is, the Operations Directorate works in conjunction with DOE to determine which of the following three categories of NEPA documentation, presented in increasing order of complexity, is required:

- Categorical exclusion (CX)

- Environmental assessment (EA)

- Environmental impact statement (EIS)

21 Stanford University Architect/Planning Office, Stanford Linear Accelerator Center Long Range Development Plan (December 2002, revised June 2003), http://wwwgroup.slac.stanford.edu/bsd/SLAC_LRDP_final.pdf 
Aspects that must be considered when scoping and preparing NEPA documentation commonly include potential increases in air emissions or hazardous materials usage; impacts on wetlands, sensitive species, and critical habitats; and increases in water consumption and wastewater discharge.

SLAC prepared and reviewed NEPA documentation for twenty eight projects during 2006, listed in Table 4-9. The projects were relatively minor in scope and environmental impact. The projects were either captured under an existing EA or were given a CX reference number. Completed NEPA documents are forwarded to the DOE/SSO for review and approval.

Table 4-9 NEPA Documentation Prepared during 2006

\begin{tabular}{|c|c|c|c|}
\hline Project Name & Project ID & Document ID & Date \\
\hline BL5-4 Upgrade & 360103 & DOE/EA-0882 & $01 / 06$ \\
\hline GLAST Data Handling Computer & 365401 & SS-SC-0601 & $02 / 06$ \\
\hline 12kv Feeder from Guest House ROB/Kavli & 5640 & SS-ER-9608 & $02 / 06$ \\
\hline Replace and Upgrade K10 Switchgear & 5645 & DOE/EA-1426 & $02 / 06$ \\
\hline Building 081 Underground Natural Gas Replacement & 030130 & SS-SC-0302 & $02 / 06$ \\
\hline IR-4 Chiller Replacement & 140130 & SS-ER-9608 & $02 / 06$ \\
\hline Ultra-fast Chemical Dynamics Laser System & 360202 & SS-SC-0211 & $03 / 06$ \\
\hline $\begin{array}{l}\text { Building } 50 \text { 1st Floor Infrastructure for Water Cooled } \\
\text { Racks }\end{array}$ & 5650 & SS-SC-0201 & $03 / 06$ \\
\hline Building 283-Replace Metrology Trailer & 140150 & SS-SC-0606 & $04 / 06$ \\
\hline Building 20 HVAC Replacement & 5660 & HVAC-0692 & $04 / 06$ \\
\hline Research Yard Bathroom & 5670 & SS-SC-0607 & $05 / 06$ \\
\hline Building 118 HVAC Replacement & 5655 & HVAC-0692 & $05 / 06$ \\
\hline Building 120 Fire Alarm Upgrade & 5665 & SS-ER-9608 & $05 / 06$ \\
\hline Beam line 14 & $742122-23$ & DOE/EA-0882 & $06 / 06$ \\
\hline RA-2 and RA-4 Substation Switchgear Replacement & 5675 & SS-SC-0202 & $06 / 06$ \\
\hline Building 015 HVAC Upgrade & 5685 & HVAC-0692 & $07 / 06$ \\
\hline Building 005 MCC HVAC Upgrade & 5680 & HVAC-0692 & $07 / 06$ \\
\hline Water Cooled Racks & 355501 & SS-SC-0201 & $08 / 06$ \\
\hline Building 028 Space Upgrade & 5690 & SS-SC-0608 & $09 / 06$ \\
\hline Gallery \& Accelerator Smoke Detection Upgrade & 5697 & SS-ER-9608 & $09 / 06$ \\
\hline Replace K5 Switchgear & 5695 & DOE/EA-1426 & $09 / 06$ \\
\hline ESA/ESB Storm Drain Connections & 5530 & SS-ER-9807 & $09 / 06$ \\
\hline
\end{tabular}




\begin{tabular}{llll} 
Project Name & Project ID & Document ID & Date \\
\hline Library Archive Storage & 3657 & SS-SC-0608 & $10 / 06$ \\
Pulse Compression System & 370000 & SS-SC-0609 & $10 / 06$ \\
CPC Solar Farm & $5700 T$ & SS-SC-0608 & $11 / 06$ \\
Electrical Distribution Upgrade for IR-2 \& CEH & 5633 & DOE/EA-1426 & $11 / 06$ \\
Differential Scanning Calorimeter & 370100 & HQ-SC/OAK & $12 / 06$ \\
Electron Beam Power Supply & 370200 & HQ-SC/OAK & $12 / 06$
\end{tabular}




\section{Environmental Radiological Program}

\subsection{Introduction}

All members of the public receive radiation doses from natural background radiation and from an assortment of human activities. This chapter describes sources of radiation and radioactivity at SLAC and provides an overview of how SLAC's Environmental Radiological Program assesses direct radiation and radioactivity in water, air, and soil for the purpose of determining the potential radiation dose to the public and impacts to the environment.

The dose that members of the public receive due to SLAC operations is a small fraction of the dose received from natural background radiation. As in past years, in 2006, the potential radiation dose to the public and the radiation-related impacts to the environment from SLAC operations were significantly below all regulatory limits.

\subsection{Sources of Radiation and Radioactivity}

The linear accelerator at SLAC is encased in a concrete tunnel 25 feet beneath the surface of the ground. Through this underground tunnel, particles are accelerated to nearly the speed of light.

Some particles strike accelerator components during the acceleration process. When that happens, the decelerating particles may emit secondary radiation in the form of high-energy photons and neutrons. At SLAC, direct radiation is the radiation that is present whenever particles are accelerated, but that ceases as soon as power to the accelerator is terminated. Direct radiation is mainly due to the secondary photon and neutron radiation emitted when high-energy particles are decelerated.

Both the particles being accelerated and secondary radiation may also make the substances they strike become radioactive. Table 5-1 lists the predominant radioactive elements produced in water or air and their half-lives.

Facilities at SLAC are designed to meet all applicable safety and environmental requirements. Nearly all the direct radiation is stopped by the combined shielding on the accelerator structure and the ground that surrounds the accelerator tunnel. SLAC monitors the small fraction of photons and neutrons that pass through the accelerator components, through the surrounding earth, to reach areas outside of the accelerator. This monitoring is described in Section 5.3.

SLAC also assesses, measures, and reports on radioactivity as required by its policies and by state or federal regulations. Sections 5.4 through 5.6 and 5.9 describe SLAC's programs to assess and control radioactivity that can be released into the environment. All known releases of radioactive materials are included in the tables in those sections. 
Table 5-1 Activation Products in Water or Air

\begin{tabular}{lll} 
Radioactive Element & Half-life & Primarily Produced In \\
\hline Oxygen $\left({ }^{15} \mathrm{O}\right)$ & 123.0 seconds & Water or air \\
Nitrogen $\left({ }^{13} \mathrm{~N}\right)$ & 10.0 minutes & Air \\
Carbon $\left.{ }^{11} \mathrm{C}\right)$ & 20.3 minutes & Water or air \\
Argon $\left({ }^{41} \mathrm{Ar}\right)$ & 1.8 hours & Air \\
Beryllium $\left({ }^{7} \mathrm{Be}\right)$ & 53.6 days & Water \\
Hydrogen $\left({ }^{3} \mathrm{H}\right)$ & 12.3 years & Water
\end{tabular}

\subsection{Monitoring for Direct Radiation}

DOE standards (10 CFR 835) require SLAC to demonstrate that radiation and radioactivity from SLAC did not cause any member of the public to receive a radiation dose greater than 100 millirems (mrem, a unit used to quantify radiation dose to humans) during the year. ${ }^{22}$ In 2006, the maximum dose that could have been received by a member of the public due to direct radiation from SLAC was approximately less than 0.4 mrem ( $4.0 \times 10^{-3}$ milli Sievert (mSv)), or 0.4 percent of the 100 mrem regulatory limit. This maximally exposed individual (MEI) is located near Sand Hill Road, approximately 650 meters (m) (2,133 feet) northeast of the intersection of Sand Hill and Whiskey Hill Road.

During 2006, SLAC measured direct radiation at 39 locations to determine the potential radiation dose to a member of the public. Readings from dosimeters used to measure radiation were recorded each calendar quarter. Landauer Incorporated, accredited by the DOE's Laboratory Accreditation Program and National Voluntary Laboratory Accreditation Program as a dosimeter supplier, provided and processed the dosimeters. Results from these dosimeters were also used to calculate the collective dose to the population (about 5 million) that lives within 80 kilometers $(\mathrm{km})$ (50 miles) of SLAC.

Section 5.8 and Table 5-6 summarize annual doses from both direct radiation and airborne radioactivity and show how those doses compare with those from natural background radiation.

\subsection{Assessment of Airborne Radioactivity}

USEPA regulations (40 CFR 61) enacted under the Clean Air Act and DOE Order 5400.5 require SLAC to demonstrate that airborne radioactivity released did not cause any member of the public to receive a dose greater than 10 mrem during the year. In 2006, the maximum dose that could have been received by a member of the public (business offices in the Portola Valley Training Center on the south east side of SLAC) due to airborne radioactivity from SLAC was $0.12 \mathrm{mrem}\left(1.2 \times 10^{-3} \mathrm{mSv}\right)$, or about one percent of the 10 mrem regulatory limit.

SLAC files an annual report that describes the possible sources, types, and quantities of airborne radioactivity released into the atmosphere. ${ }^{23}$ As detailed in that report, the released airborne radioactivity was calculated, based on conservative information about accelerator operations in 2006. Table 5-2

22 United States Department of Energy, DOE Order 5400.5, "Radiation Protection of the Public and the Environment”, http://www.directives.doe.gov/pdfs/doe/doetext/oldord/5400/054005c2.html

23 Stanford Linear Accelerator Center, Environment, Safety, and Health Division. Radiation Protection Department, Radionuclide Air Emissions Annual Report - CY2006 (May 2007) 
summarizes the released radioactivity, showing the quantities in curies (Ci). Potential doses to members of the public due to the released radioactivity were determined using USEPA software (CAP88). In addition to providing information on maximum individual doses, SLAC also assessed and reported the collective dose to the population that lives within $80 \mathrm{~km}$ (50 miles) of SLAC.

Table 5-2 and Table 5-6, as well as Section 5.8, provide a summary of the results and information on how the maximum possible doses compare with natural background radiation.

Table 5-2 Airborne Radioactivity Released in 2006

\begin{tabular}{llr} 
Category & Radioactive Element & Activity $(\mathrm{Ci})$ \\
\hline Tritium & Hydrogen $\left({ }^{3} \mathrm{H}\right)$ & $\mathrm{n} / \mathrm{a}$ \\
Krypton-85 & Krypton $\left({ }^{85} \mathrm{Kr}\right)$ & $\mathrm{n} / \mathrm{a}$ \\
Noble gases $\left(\mathrm{T}_{1 / 2}<40\right.$ days $)$ & Argon $\left({ }^{41} \mathrm{Ar}\right)$ & 2.6 \\
Short-lived activation products $\left(\mathrm{T}_{1 / 2}<3 \mathrm{hr}\right)$ & Oxygen $\left({ }^{15} \mathrm{O}\right)$ & 54.2 \\
& Nitrogen $\left({ }^{13} \mathrm{~N}\right)$ & 101.0 \\
& Carbon $\left({ }^{11} \mathrm{C}\right)$ & 10.8 \\
Other activation products $\left(\mathrm{T}_{1 / 2}>3 \mathrm{hr}\right)$ & $\mathrm{n} / \mathrm{a}$ & $\mathrm{n} / \mathrm{a}$ \\
Total radioiodine & $\mathrm{n} / \mathrm{a}$ & $\mathrm{n} / \mathrm{a}$ \\
Total radiostrontium & $\mathrm{n} / \mathrm{a}$ & $\mathrm{n} / \mathrm{a}$ \\
Total uranium & $\mathrm{n} / \mathrm{a}$ & $\mathrm{n} / \mathrm{a}$ \\
Plutonium & $\mathrm{n} / \mathrm{a}$ & $\mathrm{n} / \mathrm{a}$ \\
Other actinides & $\mathrm{n} / \mathrm{a}$ & $\mathrm{n} / \mathrm{a}$ \\
Total & & 169 \\
$\mathrm{n} / \mathrm{a}-$ not applicable & & \\
$\mathrm{T}_{1 / 2}-$ half life & &
\end{tabular}

\subsection{Assessment of Radioactivity in Water}

Three types of water are monitored for radioactivity at SLAC: industrial wastewater, stormwater, and groundwater. This section summarizes the 2006 monitoring and results for each water type.

\subsubsection{Industrial Wastewater}

Federal and state regulations (10 CFR 20.2003 and 17 CCR 30253) limit the radioactivity in industrial wastewater that SLAC releases to the sanitary sewer system. In 2006, SLAC releases totaled less than 0.03 percent of the applicable limits.

Although most of the cooling water or other water present in the accelerator does not contain radioactivity other than what is naturally present, some of the water becomes activated by radiation from the accelerator (see Section 5.2). Routine operations require SLAC to drain accelerator cooling systems from time to time. Cooling water, as well as groundwater and stormwater that enter the accelerator housing are disposed of as part of SLAC's industrial wastewater. Thus a small fraction of SLAC's wastewater volume contains radioactivity. 
Throughout the year, SLAC sampled and analyzed wastewater at about 30 discharge points. Total activity released during CY06 is summarized in Table 5-3.

Table 5-3 Radioactivity in Wastewater Released in 2006

\begin{tabular}{|c|c|c|c|}
\hline Category & Radioactive Element & Activity (Ci) & $\begin{array}{r}\text { Annual } \\
\text { Release Limit } \\
\text { (Ci) }\end{array}$ \\
\hline Tritium & Hydrogen $\left({ }^{3} \mathrm{H}\right)$ & $1.2 \times 10^{-3}$ & 5 \\
\hline \multirow[t]{2}{*}{ Activation products $\left(\mathrm{T}_{1 / 2}>3 \mathrm{hr}\right)$} & Sodium ( ${ }^{22 \mathrm{Na})}$ & 0 & $1^{*}$ \\
\hline & Beryllium ( $\left.{ }^{7} \mathrm{Be}\right)$ & $1.8 \times 10^{-4}$ & \\
\hline Total radioiodine & $\mathrm{n} / \mathrm{a}$ & 0 & \\
\hline Total radiostrontium & $\mathrm{n} / \mathrm{a}$ & 0 & \\
\hline Total uranium & $\mathrm{n} / \mathrm{a}$ & 0 & \\
\hline Plutonium & $\mathrm{n} / \mathrm{a}$ & 0 & \\
\hline Other actinides & $\mathrm{n} / \mathrm{a}$ & 0 & \\
\hline
\end{tabular}

Table 5-4 summarizes the historical results of wastewater monitoring for CY1996 through 2006. The final column of the table compares the radioactivity discharged by SLAC into the sanitary sewer with the annual limit for such discharges set by federal and state regulation.

Each year, the quantities and types of radioactivity in wastewater discharged depend on past accelerator operations and on details of wastewater handling.

Throughout 2006, SLAC reported the results of wastewater monitoring to the SBSA at the end of each calendar quarter. ${ }^{24}$

24 Stanford Linear Accelerator Center, Environment, Safety, and Health Division, Radiation Protection Department, Radioactivity in Industrial Wastewater for the Period 1 January 2006 to 31 March 2006, for the Period 2 April 2006 to 30 June 2006, for the Period 3 July 2006 to 30 September 2006, and for the Period 4 October to 31 December 2006 
Table 5-4 Summary of Radioactivity in SLAC Wastewater, 1996-2006

\begin{tabular}{|c|c|c|c|}
\hline Year & Radioactive Element & Activity (Ci) & $\begin{array}{l}\text { Percentage of } \\
\text { Annual Limit }\end{array}$ \\
\hline 1996 & Hydrogen $\left({ }^{3} \mathrm{H}\right)$ & $3.4 \times 10^{-1}$ & 6.8 \\
\hline 1997 & Hydrogen $\left({ }^{3} \mathrm{H}\right)$ & $2.2 \times 10^{-2}$ & 0.5 \\
\hline 1998 & Hydrogen $\left({ }^{3} \mathrm{H}\right)$ & $7.2 \times 10^{-2}$ & 1.4 \\
\hline 1999 & Hydrogen $\left({ }^{3} \mathrm{H}\right)$ & $7.1 \times 10^{-3}$ & 0.1 \\
\hline 2000 & Hydrogen $\left({ }^{3} \mathrm{H}\right)$ & $2.4 \times 10^{-3}$ & 0.05 \\
\hline 2001 & Hydrogen $\left({ }^{3} \mathrm{H}\right)$ & $2.1 \times 10^{-3}$ & 0.04 \\
\hline \multirow[t]{3}{*}{2002} & Hydrogen $\left({ }^{3} \mathrm{H}\right)$ & $2.4 \times 10^{-2}$ & 0.5 \\
\hline & Sodium ( ${ }^{22 \mathrm{Na})}$ & $5.1 \times 10^{-5}$ & $1.4^{*}$ \\
\hline & Beryllium ( $\left.{ }^{7} \mathrm{Be}\right)$ & $1.4 \times 10^{-2}$ & \\
\hline 2003 & Hydrogen $\left({ }^{3} \mathrm{H}\right)$ & $4.1 \times 10^{-4}$ & 0.008 \\
\hline 2004 & Hydrogen $\left({ }^{3} \mathrm{H}\right)$ & $2.0 \times 10^{-2}$ & 0.4 \\
\hline 2005 & Hydrogen $\left({ }^{3} \mathrm{H}\right)$ & $1.4 \times 10^{-3}$ & 0.03 \\
\hline \multirow[t]{2}{*}{2006} & Hydrogen $\left({ }^{3} \mathrm{H}\right)$ & $1.2 \times 10^{-3}$ & 0.02 \\
\hline & Beryllium ( $\left.{ }^{7} \mathrm{Be}\right)$ & $1.8 \times 10^{-4}$ & $0.02^{*}$ \\
\hline
\end{tabular}

\subsubsection{Stormwater}

The program for monitoring stormwater is described in Section 4.4 of this report. In 2006 (and in all previous years), no radioactivity above background was found in any stormwater sample.

SLAC reported the results of the 2006-2007 stormwater monitoring (including checks for radioactivity) to the RWQCB. ${ }^{25}$

\subsubsection{Groundwater}

Throughout 2006, SLAC performed in-house analysis of water samples from monitoring wells for the presence of radioactivity each time the wells were sampled under the groundwater monitoring plan described in Chapter 6 of this report. As part of the groundwater monitoring program (see Section 6.6), select samples are also sent to an external California-certified laboratory for tritium analysis. The results from the external laboratory are similar to the in-house analysis but not necessarily the same.

With the exception of the four monitoring wells listed in Table 5-5 below (these are in-house results), no radioactivity above natural background was detected in any of the groundwater samples.

25 Stanford Linear Accelerator Center, Environment, Safety, and Health Division, Environmental Protection Department, 2006-2007 Annual Report for Stormwater Discharges Associated with Industrial Activities (June 30, 2007, submitted to Rico Duazo, San Francisco Bay RWQCB) 
The detected concentrations of tritium in the water samples summarized in Table 5-5 were below federal and state limits set for tritium in drinking water (20,000 picoCurie/liter (pCi/L)) under 22 CCR 64443 and 40 CFR 141.66). In addition, groundwater is not used at SLAC for any purposes because of its very low well yields. Even if there was an adequate supply of groundwater available at SLAC, it could not be used as drinking water due to the high content of total dissolved solids (TDS).

Table 5-5 Summary of Tritium Concentrations Measured in Monitoring Wells in 2006 (in-house analysis)

\begin{tabular}{|c|c|c|c|c|}
\hline Period (Month) & Jan to March & April to June & July to Sep & Oct to Dec \\
\hline $\begin{array}{l}\text { Well } \\
\quad \text { Variable }\end{array}$ & & & & \\
\hline $\begin{array}{l}\text { EXW-4 } \\
\text { Avg }{ }^{3 \mathrm{H}}(\mathrm{pCi} / \mathrm{L}) \\
\% \text { of } \mathrm{DWS}^{1} \\
\text { No. of Samples }\end{array}$ & $\begin{array}{r}4141 \\
21 \\
3\end{array}$ & $\begin{array}{r}3359 \\
17 \\
4\end{array}$ & $\begin{array}{r}4215 \\
21 \\
3\end{array}$ & $\begin{array}{r}3665 \\
18 \\
3\end{array}$ \\
\hline 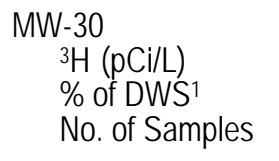 & $\begin{array}{r}<500^{2} \\
\text { n/a } \\
1\end{array}$ & $\begin{array}{r}648 \\
3 \\
1\end{array}$ & $\begin{array}{r}588 \\
3 \\
2\end{array}$ & $\begin{array}{r}<500^{2} \\
\text { n/a } \\
1\end{array}$ \\
\hline $\begin{array}{l}\text { MW-81 } \\
\text { 3H (pCi/L) } \\
\% \text { of DWS } \\
\text { No. of Samples }\end{array}$ & $\begin{array}{r}3555 \\
18 \\
1\end{array}$ & $\begin{array}{r}1504 \\
8 \\
2\end{array}$ & $\begin{array}{r}1589 \\
8 \\
4\end{array}$ & $\begin{array}{r}1043 \\
5 \\
3\end{array}$ \\
\hline $\begin{array}{l}\text { MW-94 } \\
\text { Avg }{ }^{3 \mathrm{H}}(\mathrm{pCi} / \mathrm{L}) \\
\% \text { of DWS } \\
\text { No. of Samples }\end{array}$ & $\begin{array}{r}3286 \\
16 \\
2\end{array}$ & $\begin{array}{r}2154 \\
11 \\
2\end{array}$ & $\begin{array}{r}2769 \\
14 \\
3\end{array}$ & $\begin{array}{r}2695 \\
13 \\
3\end{array}$ \\
\hline
\end{tabular}

\subsection{Assessment of Radioactivity in Soil}

During CY06, SLAC sampled and analyzed soil for on-site projects involving soil excavation that had the potential to be radioactive (such as the decommissioning of the Final Focus Test Beam (FFTB) facility and the construction of the new LCLS facility). Some soil samples near the FFTB dump were found to contain radioactivity in excess of natural background. The excavated soil with radioactive levels above background was disposed of appropriately as radioactive waste at a licensed offsite disposal facility.

\subsection{Release of Property Containing Residual Radioactive Material}

Throughout 2006, all property, real and personal, exposed to any process that could cause it to become radioactive were surveyed for radioactivity before it was permitted to be removed from SLAC. Property that had any detectable radioactivity was identified as radioactive, and was either retained for appropriate reuse on site or was disposed of as radioactive waste. Therefore, property releases do not add to the potential public dose. Material which did not have detectable radioactivity was not considered radioactive and was released from any further controls. There were also controls on movement of property between locations on site, but these are not relevant to this report and are documented elsewhere. 


\subsection{Potential Dose to the Public}

The maximum possible dose to members of the public due to SLAC are very small compared with doses from natural background radiation and are well below all regulatory limits.

Table 5-6 summarizes the dose results for the two modes that were the potential contributors to public radiation dose in 2006: direct radiation and airborne radioactivity. Releases of radioactivity in water and property were too small to result in a radiation dose to a member of the public under any imaginable scenario. The reported maximum dose for the MEI, dominated by direct radiation, is based on a person being present 24 hours per day in 2006 at the location near Sand Hill Road, approximately 650 m (2,133 feet) northeast of the intersection of Sand Hill and Whiskey Hill Road.

Table 5-6 compares the 2006 dose results with regulatory limits and natural background. Like previous calculations, the 2006 calculation of the MEI dose does not include any dose reduction for hills that may lie between the locations of dose measurements and the MEI. However, since 2003, the effects of air attenuation for direct photon radiation calculations (a factor of 40) are taken into account.

Table 5-6 Summary of Potential Annual Doses due to SLAC Operations in 2006

\begin{tabular}{lcccc} 
& $\begin{array}{c}\text { Maximum Dose to } \\
\text { General Public - } \\
\text { Direct Radiation }\end{array}$ & $\begin{array}{c}\text { Maximum Dose to } \\
\text { General Public - } \\
\text { Airborne } \\
\text { Radioactivity }\end{array}$ & $\begin{array}{c}\text { Maximum Dose to } \\
\text { General Public - } \\
\text { Airborne + Direct }\end{array}$ & $\begin{array}{c}\text { Collective Dose } \\
\text { to Population within } \\
80 \text { km of SLAC }\end{array}$ \\
\hline Dose from SLAC in 2006 & 0.4 mrem & $0.1 \mathrm{mrem}$ & $0.5 \mathrm{mrem}$ & $\begin{array}{c}0.7 \text { (direct) + } \\
0.7 \text { (air) }=1.4 \\
\text { person-rem }\end{array}$ \\
$\begin{array}{l}\text { DOE Radiation Protection } \\
\text { Standard }\end{array}$ & $100 \mathrm{mrem}$ & $10 \mathrm{mrem}$ & $100 \mathrm{mrem}$ & $\mathrm{n} / \mathrm{a}$ \\
$\begin{array}{l}\text { SLAC 2006 Max. Dose as } \\
\text { Percentage of DOE Standard }\end{array}$ & $0.4 \%$ & $1.0 \%$ & $0.5 \%$ & $\mathrm{n} / \mathrm{a}$ \\
$\begin{array}{l}\text { Dose from Natural } \\
\text { Background }\end{array}$ & $100 \mathrm{mrem}$ & $200 \mathrm{mrem}$ & $300 \mathrm{mrem}$ & $1,667,000$ person- \\
rem
\end{tabular}

Table 5-7 presents the maximum dose potentially received by a member of the public from direct radiation and airborne radioactivity due to SLAC operations in 1996 through 2006 and compares it with the average dose due to natural background radiation and radioactivity.

\subsection{Biota Dose}

The DOE technical standard, “A Graded Approach for Evaluating Radiation Doses to Aquatic and Terrestrial Biota” (DOE-STD-1153-2002), suggests that DOE facilities protect plants and animals by assuring the following doses' rates due to "exposure to radiation or radioactive material releases" into the applicable environment are not exceeded: 
- Aquatic animals: should not exceed $1 \mathrm{rad} / \mathrm{day}$

- Terrestrial plants: should not exceed $1 \mathrm{rad} /$ day

- Terrestrial animals: should not exceed $0.1 \mathrm{rad} /$ day

The term rad is a unit used to quantify radiation dose.

Table 5-7 Potential Dose (mrem) to Maximally Exposed Individual, 1997-2006

\begin{tabular}{cccc} 
Year & $\begin{array}{c}\text { SLAC Direct } \\
\text { and Airborne } \\
\text { Radiation }\end{array}$ & $\begin{array}{c}\text { Average, Total Natural } \\
\text { Background Radiation }\end{array}$ & $\begin{array}{c}\text { Percentage of } \\
\text { Background }\end{array}$ \\
\hline 1997 & 4.2 & 300 & 1.40 \\
1998 & 4.6 & 300 & 1.53 \\
1999 & 4.5 & 300 & 1.50 \\
2000 & 5.7 & 300 & 1.90 \\
2001 & 5.3 & 300 & 1.77 \\
2002 & 2.1 & 300 & 0.70 \\
$2003^{*}$ & 0.2 & 300 & 0.07 \\
2004 & 0.2 & 300 & 0.07 \\
2005 & 0.3 & 300 & 0.1 \\
2006 & 0.5 & 300 & 0.2
\end{tabular}

* Starting with the 2003 calculations, the effects of air attenuation were taken into account.

\subsubsection{Dose to Biota from Direct Radiation}

In 2006, SLAC monitored dose and dose rate at approximately 250 on-site locations (indoors and out) using passive radiation dosimeters posted for three to six month periods. For each period, the average dose rate among these 250 dosimeters was found to be less than $0.002 \mathrm{rad} /$ day, and the maximum dose rate was less than $0.02 \mathrm{rad} / \mathrm{day}$. Based on the results of this monitoring program and the fact that we know animal populations could not have been present except in locations with these low dose rates, doses to plant and animal populations at SLAC were well within the limits of the DOE standard throughout 2006.

\subsubsection{Dose to Biota from Activation Products}

In 2006, SLAC tested soil and water samples for the presence of radioactivity in excess of natural background, as described in sections 5.5 and 5.6. Tritium was occasionally found in industrial wastewater in 2006, but plant and animal populations have no opportunity for access to industrial wastewater at SLAC. Since the radioactive activation concentrations in these sampled media are much lower than from direct radiation, there is no possibility that plants or animals will receive dose rates that exceed the limits of the standard due to radioactive activation products at SLAC.

In 2006, no groundwater was found with tritium concentrations in excess of the drinking water standards set by state and federal regulations. Section 5.5.3 summarizes the 2006 results of monitoring for radioactivity in groundwater. There is no possibility that plants or animals will receive dose rates that exceed the limits of the standard due to radioactive activation products in groundwater at SLAC. 


\subsection{Low-level Radioactive Waste Management}

Low-level radioactive waste (LLRW) is produced at SLAC sporadically. Prior to 2002, wastes resulting from routine operations had not been tracked as a category separate from other operations such as one-time upgrade, equipment failure replacement, and special projects. A system is now in place to allow tracking of routine operation wastes.

LLRW minimization is accomplished through education and training for the waste generator, careful planning of work operations, thorough survey and characterization of materials, segregation, reuse, and volume reduction when applicable.

SLAC continues to manage its LLRW in compliance with all applicable laws and regulations. During CY06, to support the decommissioning activities of the FFTB facility, SLAC shipped about 19,000 cubic feet of LLRW (mostly from the FFTB project) to appropriate treatment and disposal facilities. 


\section{Groundwater Protection and Environmental Restoration}

\subsection{Introduction}

This chapter describes the groundwater protection and environmental restoration programs at SLAC, including the regulatory framework, site cleanup objectives, an overview of potential chemical impacts, summary of most recent restoration activities, and SLAC’s groundwater monitoring program

\subsection{Background Conditions}

The groundwater regime at SLAC and nearby off-site areas has been comprehensively documented in the SLAC Hydrogeologic Review completed in $1994 .{ }^{26}$ This report compiles data and summarizes results of the numerous geologic, hydrogeologic, and hydrogeochemical investigations that had taken place at or near SLAC for the following reasons:

- Water resources studies

- Research

- Geotechnical studies (used to site structures being built at SLAC)

- Environmental monitoring

The report developed a conceptual model of the groundwater regime at SLAC. Based on many tests in exploratory borings and wells, the hydraulic conductivity of this bedrock is much less than the range of that generally accepted as representing natural aquifer material. The groundwater at SLAC is not used as a drinking water source because of low flow as well as naturally occurring high TDS content.

\subsection{Areas with Potential Impact from Chemicals}

A SLAC 1994 report entitled Summary and Identification of Potentially Contaminated Sites ${ }^{27}$ provided a summary of areas that may have been impacted by chemicals of interest from past SLAC operations. Information for the report was collected from a variety of sources including incident reports, aerial photographs, operations records, reports on previous investigations, and interviews with personnel throughout the facility. Two additional environmental summary documents were completed in 2006. The Environmental Baseline Report ${ }^{28}$ (EBR) provides an updated inventory of facilities and areas at SLAC that were considered to have the potential to have chemical impacts, and summarizes the results of the environmental investigations and remediation activities that have occurred to date. The EBR identifies chemicals of potential concern, defines Investigation Areas and Operable Units, and provides a decision

26 Stanford Linear Accelerator Center, Hydrogeologic Review (SLAC-I-750-2A15H-002, 1994)

27 ESA Consultants, Stanford Linear Accelerator Center, Summary and Identification of Potentially Contaminated Sites (February 1994)

${ }^{28}$ Sapere Consulting, Stanford Linear Accelerator Center Environmental Baseline Report (February 2006) 
process for determining which areas still require additional actions. The Work Plan for the Remedial Investigation and Feasibility Study ${ }^{29}$ provides additional description and current status of investigation areas and describes the framework for completing the environmental investigations and remedial actions at the facility.

\subsection{Strategies for Controlling Potential Sources of Chemicals}

Strategies for chemical source control involve measures to control known soil or groundwater impacts as discussed in the rest of this chapter, and procedures and requirements to avoid practices that could adversely affect soil and groundwater as discussed in Chapter 4. These procedures include the site's SWPPP $^{30}$ and SPCC, ${ }^{31}$ which discuss BMPs for preventing adverse impacts from spills and operations at SLAC.

\subsection{Restoration Activities}

SLAC first began environmental investigation and restoration activities in the mid-1980s and by 1991 had developed a comprehensive environmental restoration program. Program activities range from discovery and characterization to remediation and long-term monitoring or maintenance where required.

The restoration approach at SLAC is to accomplish the following steps:

- Identify sites with actual or potential impacts (involving soil, groundwater, surface water, and/or air)

- Prioritize impacted sites based on site complexity, nature of chemical impact, associated risks, remaining data needs, and projected remedy

- Investigate sites and identify remedies that protect human health and the environment, beginning with the highest-priority sites

- Implement remedies and monitor for effectiveness

As of 2006, SLAC had generally reached the third and fourth steps. Restoration work conducted to date generally consists of two categories, soil excavation to remove localized areas of PCB-impacted soils, and treatment of solvent-impacted groundwater. There are six areas with chemicals of potential concern in groundwater. Each of these is described in Section 6.7 below, along with a description of sites where soil removal has recently been conducted.

\subsubsection{Regulatory Framework}

In May 2005, the RWQCB issued a new Board Order (No. R2-2005-0022) for SLAC for the investigation and remediation of impacted soil and groundwater resulting from historical spills and leaks that occurred

${ }^{29}$ Stanford Linear Accelerator Center, Work Plan for the Remedial Investigation and Feasibility Study (SLAC-I-750-A17M-008, May 2006)

30 Stanford Linear Accelerator Center, Environment, Safety, and Health Division, Environmental Protection and Restoration Department, SLAC Stormwater Pollution Prevention Plan (SLAC-I-7500A16M-002)

31 - Spill Prevention, Control, and Countermeasures Plan (SLAC-I-750-0A16M-001), https://www-internal.slac.stanford.edu/esh/documents_internal/SPCC.pdf 
during the course of operations at SLAC. The Board Order addresses release sites at SLAC and consolidates the investigation and cleanup activities at the facility. It also rescinds an earlier Board Order that addressed contamination at only one of the sites, the FSUST, which is now incorporated into the new Board Order. In January 2006, the RWQCB was designated by the State as the Administering Agency (i.e., lead agency) for the environmental cleanup work at SLAC ${ }^{32}$. As the lead agency, the RWQCB has the responsibility to determine the adequacy and extent of cleanup, issue necessary authorizations and permits, and following the determination that an approved remedy has been accomplished, issues a certificate of completion. The RWQCB has specified site cleanup to residential standards for un-restricted land use ${ }^{33}$, consistent with how the SLAC property is zoned.

SLAC follows the general CERCLA technical guidance in investigating and remediating soil and groundwater. SLAC was not listed in the National Priorities List as a Superfund site because USEPA determined that the conditions at the site did not warrant inclusion.

\subsection{Groundwater Characterization Monitoring Network}

As part of the new Board Order, SLAC has developed a self-monitoring program (SMP) that contains a monitoring schedule for sediment from two drainage channels, surface water, and groundwater. The SMP outlines the frequency at which monitoring samples are to be collected and the chemicals of interest they are analyzed for. Work continued in 2006 on installing additional monitoring wells. Figure 6-1 shows the monitoring network.

SLAC has 128 wells across the site used for groundwater monitoring and extraction. Figure 6-2 and Figure 6-3 identify the specific well locations. The groundwater monitoring wells are used to monitor general groundwater quality in the major areas of the facility that historically or currently store, handle, or use chemicals. Of the 128 wells, 87 wells are used to monitor chemicals of potential concern in six plumes and 28 wells are used as extraction wells for two of the six plumes. The other 13 groundwater monitoring wells are used for general site-wide surveillance. The six locations where plume monitoring occurs include the following:

- $\quad$ Former Hazardous Waste Storage Area (FHWSA)

- Former Solvent Underground Storage Tank (FSUST) Area

- Test Lab and Central Lab Area (TL/CL)

- $\quad$ Plating Shop Area (PSA)

${ }^{32}$ California Environmental Protection Agency, Site Designation Committee Resolution No. 06-01 (January 2006)

${ }^{33}$ Regional Water Quality Control Board, Approval of Stanford Linear Accelerator Center Long Range Redevelopment Plan (November 18, 2005) 


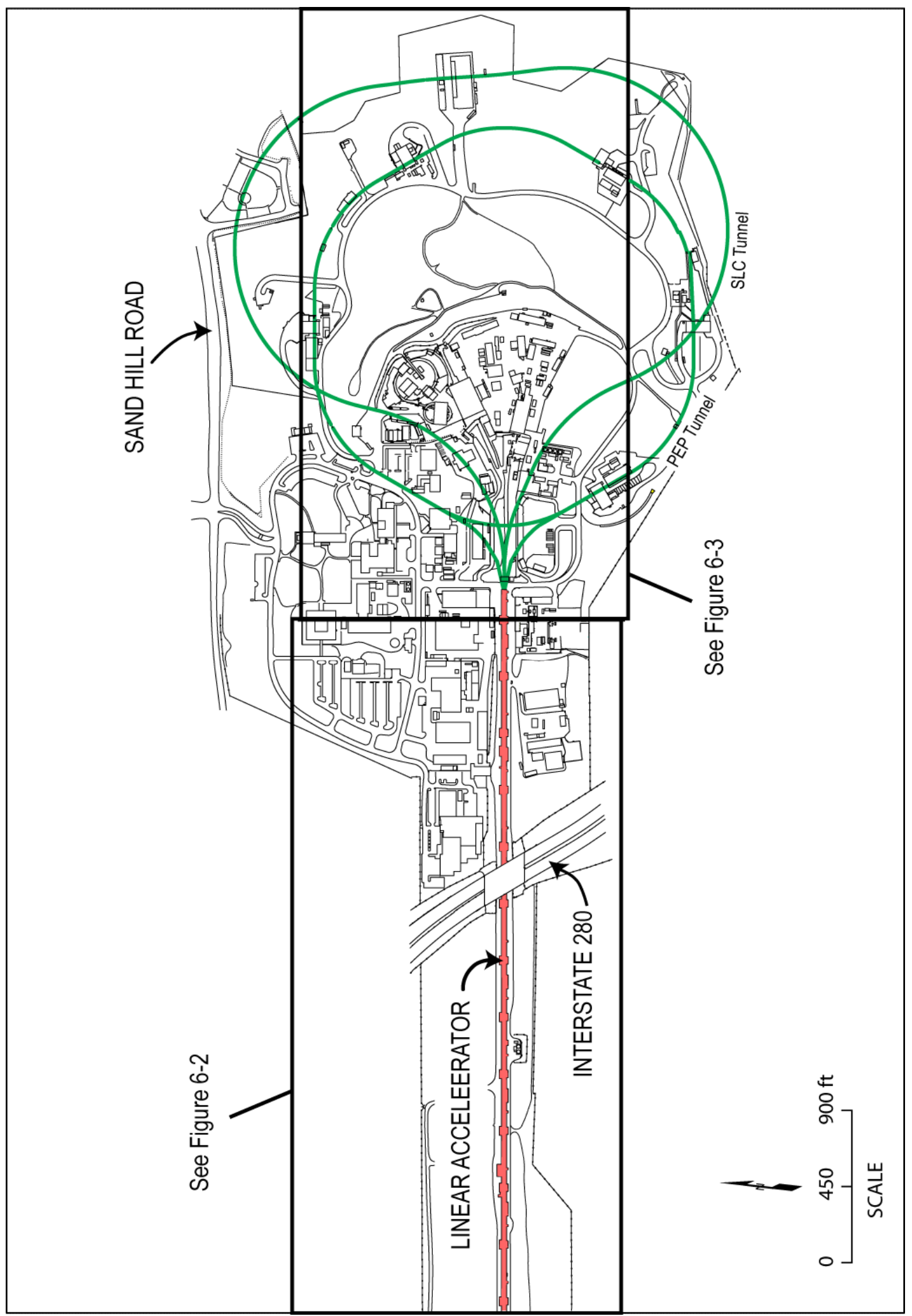

Figure 6-1 Groundwater Characterization Monitoring Network 


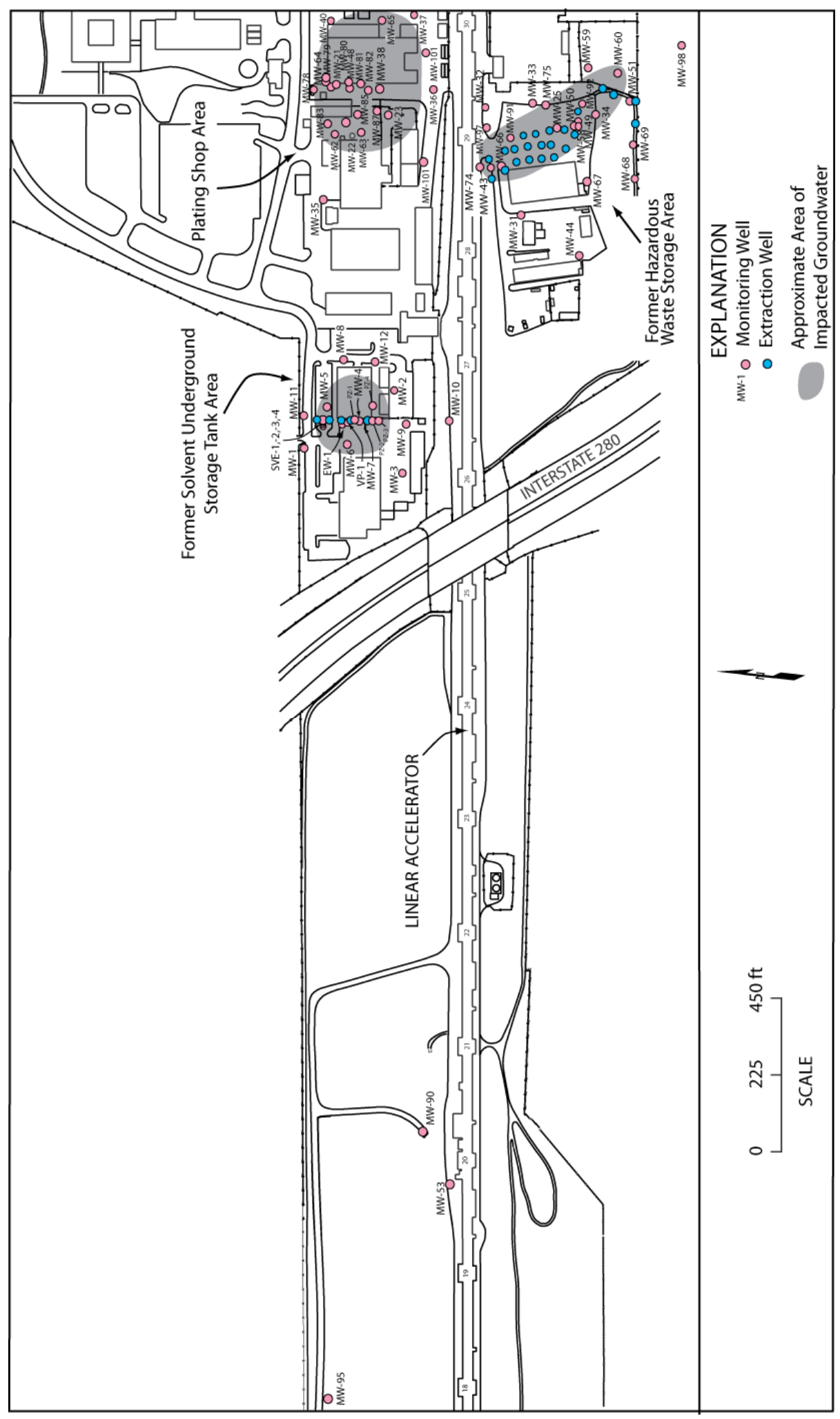

Figure 6-2 Westside Groundwater Network and Impacted Area 


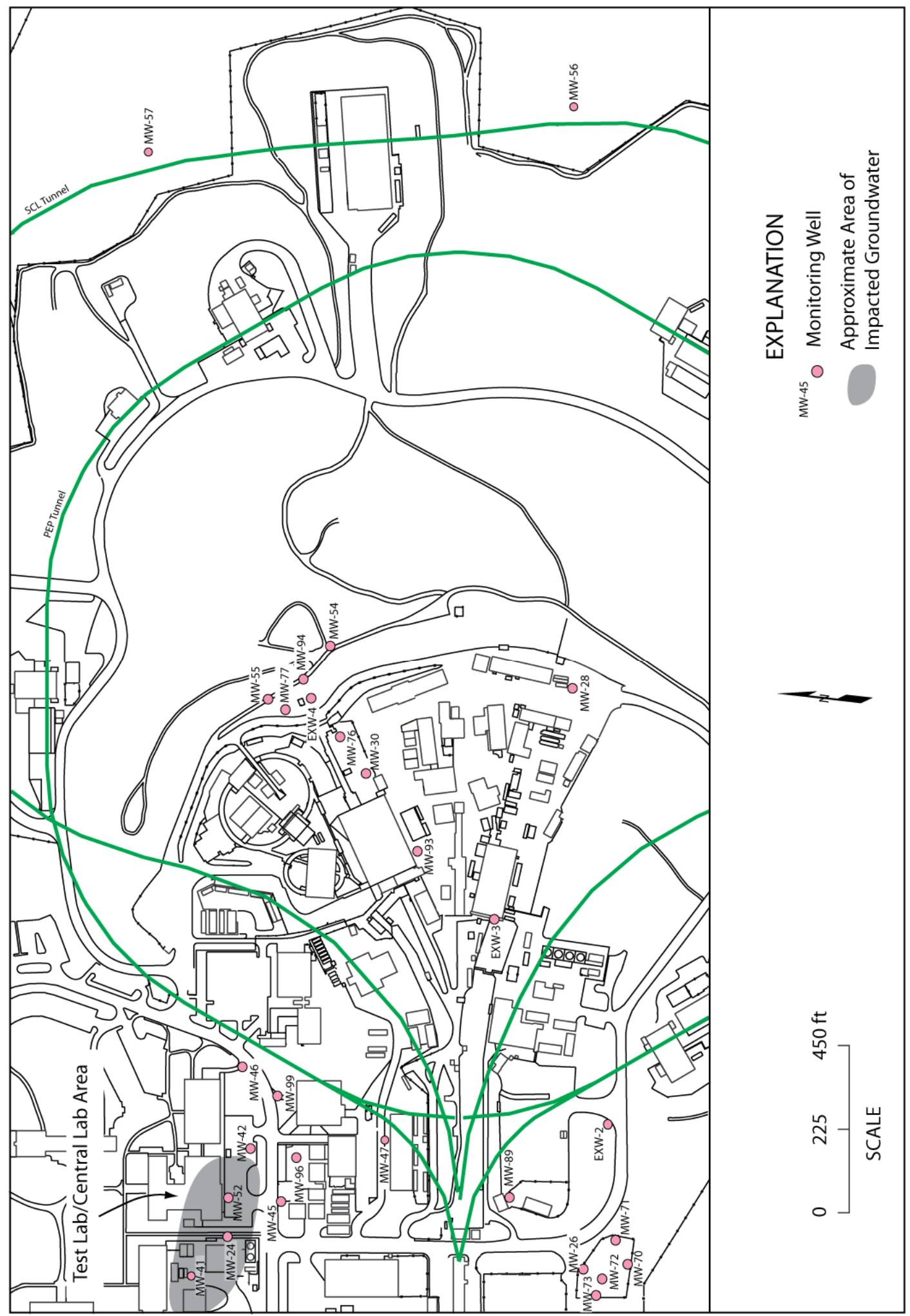

Figure 6-3 Eastside Groundwater Network and Impacted Areas 
- Lower Salvage Yard (LSY)

- $\quad$ Beam Dump East (BDE)

Table 6-1 summarizes the wells at SLAC by location, number, and purpose of the wells.

Table 6-1 Monitoring Locations and Number of Wells

\begin{tabular}{lr} 
Location & Number \\
\hline Plume Monitoring & 6 \\
Beam Dump East & 22 \\
Former Hazardous Waste Storage Area & 22 \\
Former Solvent Underground Storage Tank & 5 \\
Lower Salvage Yard & 23 \\
Plating Shop & 9 \\
Test Lab and Central Lab & 87 \\
Subtotal & \\
Extraction & 5 \\
Former Solvent Underground Storage Tank & 23 \\
Former Hazardous Waste Storage Area & 28 \\
Subtotal & \\
Environmental Surveillance & 1 \\
Centralized Waste Management Area & 1 \\
End Station B & 2 \\
Magnet Yard & 13 \\
Other (remote) & 128 \\
Research Yard & 5 \\
Vacuum Assembly & 3 \\
Subtotal & 1 \\
Total &
\end{tabular}

Groundwater samples were collected at least once from 113 wells in 2006 and analyzed for a variety of constituents. The results of groundwater monitoring of wells were reported to the RWQCB in the semiannual self-monitoring report for the winter of $2006^{34}$ and the summer of 2006. ${ }^{35}$ The groundwater analytical results were generally within each well's historical range of concentrations. Samples were analyzed for one or more of the following:

34 Stanford Linear Accelerator Center, Semi-annual Self-Monitoring Report, Winter 2006 (SLAC-I-7502A15H-016, May 2006)

35 — Semi-annual Self-Monitoring Report, Summer 2006 (SLAC-I-750-2A15H-017 November 2006) 
- Total petroleum hydrocarbons (TPH)

- Metals

- Polychlorinated biphenyls (PCBs)

- Total dissolved solids (TDS)

- General minerals

- Tritium

- VOCs and semi-volatile organic compounds (SVOCs)

\subsection{Site Descriptions and Results}

The six groundwater sites are described below. The sites pose no current risk to human health or the environment. Through the work described below, remediation strategies that protect current and future potential uses of the property are being defined. All samples are submitted to an analytical laboratory certified by the California Department of Health Services.

\subsubsection{Former Solvent Underground Storage Tank Area}

A chemical plume in groundwater associated with the FSUST is located in proximity to the SLAC Plant Maintenance building in the northwestern portion of the main SLAC campus (see Figure 6-2). The FSUST was used to store organic solvents from 1967 to 1978. A pressure test performed on the FSUST in 1983 indicated a leak. The FSUST and accessible chemically impacted soil were removed in December 1983. A network of 22 monitoring wells and five extraction wells were subsequently installed, and groundwater has been monitored for VOCs and SVOCs.

The evaluation of remedial alternatives report for the FSUST established remedial action objectives and then evaluated 42 alternatives to determine which would meet best the objectives. ${ }^{36}$ The selected remedial alternative for the FSUST, a groundwater extraction and treatment system, was constructed at the FSUST area during the summer of 2001 as a pilot system and has been in operation since August 27, 2001.

Since the start up of the groundwater extraction system in August 2001 to December 2006, approximately 469,500 gallons of groundwater have been extracted and treated, resulting in the removal of over $300 \mathrm{lbs}$ of VOCs and SVOCs. Monitoring well data collected thus far indicate a capture zone encompassing the entire plume has been established and chemical data indicate that the plume appears to be shrinking in size. Design plans are underway to upgrade the FSUST treatment system to a dual phase soil vapor/groundwater extraction (DPE) system in 2007. The DPE system would allow for an increase mass removal rate of VOCs and SVOCs.

\subsubsection{Former Hazardous Waste Storage Area}

The FHWSA was in use from approximately 1973 to 1982. During closure of the FHWSA, PCBs were found in shallow soils. As a result, several inches of topsoil were removed. A monitoring well was installed in this area in 1990, and VOCs were detected in the groundwater. Since then, two passive soil gas surveys have been performed; 22 monitoring wells, 23 extraction wells, 15 soil gas probes, and more than 50 soil

36 Stanford Linear Accelerator Center, Evaluation of Interim Remedial Alternatives for the Former Solvent Underground Storage Tank Area (SLAC-I-750-3A-33H-006, 2003) 
borings have been installed at this site. Figure 6-2 shows the limited extent of VOCs in the groundwater. The draft site characterization report for the FHWSA was submitted to the RWQCB in $2004^{37}$ and approved in June 2006.

In 2002, a DPE pilot test proved promising to treat impacted soil, soil vapor, and groundwater, and was recommended as a suitable remediation technology. Two DPE wells were installed at the FHWSA in 2003 as part of an interim dual-phase extraction (IDPE) system. The IDPE system was in operation from December 2003 to March 2006, resulting in the extraction and treatment of a total of 55,000 gallons and the removal of approximately 20 lbs of VOCs.

The design of a full scale DPE system for the FHWSA was finalized in $2004^{38}$ and the construction of the system was completed in March 2006 after six months of construction. The full scale DPE system is designed to reduce the concentration of VOCs in soil, groundwater, and soil vapor at the FHWSA and reduce migration of impacted groundwater. The full scale system utilizes 19 groundwater/soil vapor extraction wells and four vacuum-enhanced groundwater extraction wells. Groundwater extraction and treatment began on March 6, 2006. Soil vapor extraction and treatment began on April 3, 2006. The system extracts and treats approximately 1,000 gallons of groundwater per day using air stripping technology and extracts approximately 88,000 cubic feet of soil vapor per day. At the end of December 2006, the DPE treatment system at the FHWSA removed a total of 435,158 gallons and removed a combined total (groundwater and vapor) of 10.10 lbs of VOCs.

\subsubsection{Plating Shop Area}

In 1990, three monitoring wells were installed down-gradient of the PSA. Chemicals of interest were detected in all three wells; and an investigation began and included installation of additional monitoring wells, a soil gas survey, and remediation beneath a steam cleaning pad.

A total of 23 groundwater monitoring wells, including 2 wells installed in September 2006, are currently located at the PSA (see Figure 6-2). Groundwater sampling results indicate that chemicals are present in groundwater within three co-mingled plumes. The draft site characterization report for the PSA was submitted to the RWQCB in $2003^{39}$ and approved in September 2006. The site characterization report will be submitted to the RWQCB in 2007 as a Remedial Investigation (RI)-equivalent report required under the Board Order. In support of remedial design efforts, a total of 13 soil vapor probes were installed at the PSA in December 2004, and the probes were sampled in 2005 and in June 2006. A draft remedial alternatives evaluation report ${ }^{40}$ has been prepared which recommended soil vapor and groundwater extraction followed by treatment. Design plans are underway for the construction of a full-scale DPE system at the PSA.

37 Stanford Linear Accelerator Center, Draft Site Characterization for the Former Hazardous Waste Storage Area (SLAC-I-750-3A33H-015, September 2004).

38 Erler \& Kalinowski, Technical Specifications and Drawings for the Dual Phase Extraction and Treatment System at the Former Hazardous Waste Storage Area (2004)

39 Stanford Linear Accelerator Center, Environment, Safety, and Health Division, Draft Site Characterization Report for the Plating Shop Area (SLAC-I-750-3A33H-12, December 2003)

40 Erler \& Kalinowski, Inc., Draft Remedial Alternatives Report for the Plating Shop Area, Stanford Linear Accelerator Center, Menlo Park, California (December 2003) 


\subsubsection{Test Lab and Central Lab Area}

A monitoring well was installed between the TL and the CL in 1990 at the site of a former, leaking, diesel pump spigot. Chemically impacted soil was removed and the well was installed to monitor for the possible presence of diesel fuel. Diesel has never been detected in this well, but chlorinated solvents have been.

Data from a soil gas survey, soil borings and additional monitoring wells installed in the TL/CL helped delineate the sources of contamination (see Figure 6-3). Results of the investigation indicated three possible source areas for VOCs, including one adjacent to the TL, and two adjacent to the CL. To further investigate the possible source areas, six soil vapor probe were installed and sampled in November 2006. The results of the effort indicate that a groundwater remediation system may be required to achieve site cleanup goals.

\subsubsection{Beam Dump East}

BDE is used as a subsurface high-energy beam termination point for the End Station A beamline operations and is located in the hillside along the northeastern edge of the research yard. The groundwater is monitored in six wells and sampled at least two times per year. In 2006, as in previous years, the monitoring indicates that the tritium is localized to two wells in the area of the beam dump and present at levels acceptable for drinking water.

\subsubsection{Lower Salvage Yard}

There have been minor detections of petroleum hydrocarbons and VOCs in wells at the LSY. The five monitoring wells at the LSY were sampled in 2006. No chemicals were reported in any of the groundwater samples collected.

\subsubsection{IR-6 and IR-8 Drainage Channels}

In addition to the groundwater sites discussed above, SLAC is also investigating soil sites which have been impacted by chemicals of interest, primarily PCBs, lead and TPH. In one area, the IR-6 and IR-8 drainage channels, sediment in drainage channels have been impacted with chemicals of interest and work continues to investigate these areas.

Much of SLAC's stormwater runoff is conveyed by the IR-6 and IR-8 drainage channels, which ultimately discharge into San Francisquito Creek. Surface water runoff from the Research Yard drains into the manmade IR-6 drainage channel partially located off site. IR-8, also primarily located off site, is a natural ephemeral drainage that was engineered during SLAC construction to accept groundwater from the accelerator and PEP sub-drainage systems and surface water runoff from the campus area at SLAC.

PCBs and lead were first found in the off-site portions of the IR-6 and IR-8 drainages in 1990. An investigation to further characterize the extent of PCBs and lead was performed and included a 2.5-mile segment of San Francisquito Creek. No PCBs were detected in the creek samples. In 1995, the removal and off-site disposal of PCB and lead impacted sediments from the IR-6 drainage channel and its upstream stormwater catch basins were performed.

In 1996, it was found that sediments with PCBs were still entering the IR-6 drainage channel. Since 1996, additional investigations and remedial work have been completed to identify and remove additional potential upstream sources of PCBs and lead. Sediments in the IR-6 and IR-8 drainage channels continue to be monitored annually since 1998 . The annual collection of sediment samples shows that despite 
remediation efforts, PCBs persist in sediments entering the IR-6 and IR-8 channels' drainages, although at levels significantly lower than historic concentrations.

In September and October 2006, an interim maintenance removal action (MRA) at the IR-6 primary drainage channel was performed to remove and dispose of accumulated sediment and soil impacted with PCBs. Prior to initiation of the removal action, an Engineering Evaluation and Cost Analysis and Action Plan for the MRA was prepared by SLAC and submitted to the RWQCB for review, approval, and public comment. In addition, a Joint Aquatic Resource Permit Application was submitted and approved by the RWQCB, the California Department of Fish and Game, and the U.S. Army Corps of Engineers. The removal action consisted of excavation of sediments and soil containing PCBs and metals and offsite disposal. A total of 760 tons (about 507 cubic yards) of sediment and soil was removed in two excavation rounds from the IR-6 Channel and disposed of offsite as Class II waste at the Altamont Landfill \& Resource Recovery Facility located near Livermore, California. Following removal of materials, the excavated channel was restored to its original flow contours by backfilling and compacting with imported clean fill. The project work was completed by installing erosion control measures in the channel, including rip-rap, erosion control matting, topsoil, and hydroseeding.

\subsubsection{Excavation Clearance Program}

During 2006, the excavation clearance program continued to support SLAC-wide projects to ensure proper disposal of excavated soil. An excavation clearance permit must be completed for activities that involve excavation or relocation of soil at SLAC. The permitting process is intended to identify potential hazards associated with excavation work at SLAC and ways to reduce worker exposure to these hazards. These hazards include underground utility lines, chemical contamination, and radiological hazards and ensure proper management and disposal of excavated materials.

More than 135 projects were supported by this program during 2006. A major project supported by the program was the dismantling of the FFTB. This project included the collection of over 200 concrete, asphalt or soil samples. 


\section{A Distribution List}

\begin{tabular}{|c|c|c|c|}
\hline Name & Title & Organization & E-mail \\
\hline Arnold Edelman & Physical Scientist & $\begin{array}{l}\text { DOE, Environment, Safety and } \\
\text { Health Division }\end{array}$ & arnold.edelman@science.doe.gov \\
\hline Raymond Hardwick Jr & $\begin{array}{l}\text { Deputy Assistant } \\
\text { Secretary for } \\
\text { Facility Safety }\end{array}$ & $\begin{array}{l}\text { DOE, Environment, Safety and } \\
\text { Health Division }\end{array}$ & raymond.hardwick@eh.doe.gov \\
\hline Van Nguyen & $\begin{array}{l}\text { Supervisory Safety } \\
\text { and Occupational } \\
\text { Health Specialist }\end{array}$ & $\begin{array}{l}\text { DOE, Environment, Safety and } \\
\text { Health Division }\end{array}$ & van.nguyen@science.doe.gov \\
\hline Rosario Natoli & $\begin{array}{l}\text { Environmental } \\
\text { Protection } \\
\text { Specialist }\end{array}$ & $\begin{array}{l}\text { DOE, Office of Air, Water and } \\
\text { Radiation }\end{array}$ & Ross.Natoli@hq.doe.gov \\
\hline Patricia Dehmer & Associate Director & $\begin{array}{l}\text { DOE, Office of Basic Energy } \\
\text { Sciences }\end{array}$ & patricia.dehmer@science.doe.gov \\
\hline Robin Staffin & Associate Director & $\begin{array}{l}\text { DOE, Office of High Energy } \\
\text { Physics }\end{array}$ & robin.staffin@science.doe.gov \\
\hline Gertrude Dever & $\begin{array}{l}\text { Associate Director, } \\
\text { Laboratory } \\
\text { Operations and } \\
\text { ES\&H }\end{array}$ & $\begin{array}{l}\text { DOE, Office of Laboratory Policy } \\
\text { and Infrastructure }\end{array}$ & leah.dever@science.doe.gov \\
\hline Walter Warnick & Director & $\begin{array}{l}\text { DOE, Office of Scientific and } \\
\text { Technical Information }\end{array}$ & walter.warnick@science.doe.gov \\
\hline Glenn Podonsky & Director & $\begin{array}{l}\text { DOE, Office of Security and } \\
\text { Safety Performance } \\
\text { Assurance }\end{array}$ & Glenn.Podonsky@oa.doe.gov \\
\hline Allan Chiu & Permit Engineer & $\begin{array}{l}\text { Bay Area Air Quality Management } \\
\text { District }\end{array}$ & achiu@baagmd.gov \\
\hline Gary Butner & Acting Director & $\begin{array}{l}\text { California Department of Health } \\
\text { Services, Radiologic Health } \\
\text { Branch }\end{array}$ & gbutner@dhs.ca.gov \\
\hline Erich Simon & & $\begin{array}{l}\text { Regional Water Quality Control } \\
\text { Board, San Francisco Bay Region }\end{array}$ & ersimon@waterboards.ca.gov \\
\hline Dean Peterson & & $\begin{array}{l}\text { San Mateo County Department of } \\
\text { Health Services, Office of } \\
\text { Environmental Health }\end{array}$ & dpeterson@co.sanmateo.ca.us \\
\hline David Boesch & City Manager & City of Menlo Park & dsboesch@menlopark.org \\
\hline $\begin{array}{l}\text { Magaly Bascones } \\
\text { Dominguez }\end{array}$ & & CERN. Library, Periodicals Unit & $\frac{\text { Magaly.bascones.dominguez }}{\underline{\text { @cern.ch }}}$ \\
\hline
\end{tabular}

